\title{
Una nueva concepción del sistema tonal (la concepción global de la música)
}

Pedro Purroy Chicot $^{1}$ Conservatorio Superior de Música de Aragón (ES) pedropurroy@gmail.com 
Decía Einstein en el Prefacio al libro de Planck, Were is Science going? (1932) referido a los hallazgos de Planck y a los suyos propios:

"El descubrimiento de estas leyes elementales...viene ayudado por un sentimiento del orden que se oculta detrás de las apariencias"

Lo que queremos mostrar aquí, es que ese orden que se oculta detrás de las apariencias y esas leyes elementales también existen para la música, pero en un lugar que se encuentra a mayor profundidad del que las teorías conocidas han podido alcanzar hasta ahora, tanto respecto de las obras musicales como del propio Sistema musical.

De hecho, seguramente Schenker ya tuvo un sentimiento semejante. En su caso, el orden y las leyes elementales, tenían que ver con un mundo nuevo de relaciones al que él consiguió acceder- algunas de las cuales, por su capacidad explicativa tomaban la forma de leyes elementales- muy distintas de aquellas que el resto de los teóricos habían observado y registrado en la superficie de las obras musicales. Solo traspasando esa superficie podía llegarse a ellas. Schenker fue el único que consiguió hacerlo. En ese orden hasta él oculto, encontraban su explicación los hechos registrados directamente en la superficie de la música, relativos al comportamiento ahí de los elementos musicales, poniendo en evidencia que el registro de un hecho no podía ser a la vez su explicación, como se había creído hasta entonces. Se necesitaban nuevos conceptos, tan nuevos que solo podían obtenerse en ese nivel de observación más profundo, conceptos que recogían un comportamiento de los elementos tan distinto al observado en la superficie de la música, que este sí podía explicar el correspondiente a los hechos registrados en esa superficie. Por ello y por ocultar los otros, en palabras de Einstein, estos hechos tomaban la forma de apariencias. (Tendremos ocasión aquí de profundizar en todo ello)

Pero si Schenker pudo llevar su mirada más adentro de aquella superficie, podía ser factible la posibilidad de experimentar un nuevo sentimiento, que sería ahora el de la existencia de otro tipo todavía distinto de orden que, de nuevo en palabras de Einstein, siguiera todavía oculto en un lugar aún más profundo, que supusiera el descubrimiento de otras leyes todavía más elementales, de aquellas a las que puede remitirse los hallazgos del propio Schenker. Lo que podemos decir ya desde aquí, es que ese lugar más profundo también existe, pero hay que subrayar enseguida, que el acceso a él hubiera sido imposible sin el paso previo que dio Schenker.

Este texto tiene entonces un doble objetivo: primero, mostrar cómo es ese otro tipo de orden, y cuales son las leyes que teniendo que ver con él pueden calificarse ya como todavía más elementales, y el segundo, reivindicar con ello la teoría de Schenker, mostrando cómo ese paso previo que él había dado al traspasar la superficie que había sido el límite

1 Catedrático de "Análisis musical" en el Conservatorio Superior de Música de Aragón, en el que ha desempeñado el cargo de Director desde el 2001 al 2013. Dedicado plenamente a la enseñanza y a la investigación musical, ha impartido cursos y conferencias en distintas Universidades y en los Conservatorios Superiores de Música más importantes, participando en diferentes Congresos internacionales, no sólo dedicados a la música sino también a la filosofía y a la epistemología, divulgando no sólo sus hallazgos teóricos en el campo de la música, sino en el del pensamiento. Es el traductor al castellano de dos libros de referencia para la teoría schenkeriana: Structural Hearing de Felix Salzer y Introduction to schenkerian Analysis de Allen Forte y Steven Gilbert. Es miembro fundador y presidente de ATAM (Associació de Teoria i Anàlisi Musical) ubicada en Catalunya, y que en la actualidad pertenece a la Red Europea de Sociedades Musicales. 
para el resto de los teóricos, además del extraordinario salto epistémico y epistemológico que supuso para la comprensión de la música, estaba abriendo la puerta para llegar todavía más adentro, y acceder a un lugar donde los elementos llevaban a cabo todavía otro tipo de relaciones, y consecuentemente a una nueva visión teórica.

Porque efectivamente, ese recorrido que lleva desde la superficie a ese lugar más profundo, puede sintetizarse y diferenciarse ya en términos de relaciones, pues si Schenker desde el lugar al que consiguió acceder pudo transcender las relaciones locales que eran las propias de las teorías tradicionales, consecuencia de la supeditación absoluta al tiempo del resto de los teóricos (enlaces de acordes, progresiones tonales, cadencias, modulaciones, bordaduras, suspensiones, apoyaturas, etc...), desvelando la existencia de otro tipo de relación muy distinto, la relación no-local - que ejemplifica directamente su Ursatz (la línea fundamental y la arpegiación del bajo)- en ese lugar todavía más profundo, existe aun otro tipo de relación muy diferente, que llamaremos ya desde aquí relación global, un tipo de relación que transciende no solo el tiempo, lo que ciertamente ya hacía aquellas relaciones no-locales, sino también el espacio en las que estas se representaban, integrándolos a ambos; un tipo de relación, que como podrá comprobarse, es tan perfecta y claramente definible como pudieron ser los otros.

Pero seguramente, lo más sorprendente e inesperado, es que el acceso a ese lugar más profundo de las obras musicales, permitía acceder a su vez a otro espacio que tampoco podía imaginarse que existiera, el propio interior del llamado "Sistema tonal". Un Sistema del que hasta ahora solo hemos conocido su exterior: un conjunto definido de elementos -sonidos- resultado de una modificación tan precisa de la quinta natural (temperamento igual), que le permitía cerrarse sobre sí mismo, y que por ello representábamos en la forma de un círculo, cerramiento del que según se ha dicho, ese conjunto de elementos (Sistema) obtenía su eficacia, tanto para servir de base constructiva como luego explicativa de la música de ese periodo tan específico de la historia identificado a su vez con el nombre general de "Tonalidad".

Pero efectivamente, lo que no sabíamos es que las razones de esa eficacia constructiva y explicativa realmente se encontraban en su interior, pues el Sistema, a la manera ahora de un objeto con sustantividad propia, demostraba ciertamente tener también un interior, y en él una Estructura totalmente desconocida y sorprendente, derivada de propiedades fundamentales (leyes elementales en la cita de Einstein) asimismo insospechadas. ${ }^{2}$

2 No hay que olvidar que el concepto de "Sistema", como una entidad con sustantividad propia, es fundamental en la historia del pensamiento.

Desde la mitad del S. XX representa con su nombre, un nuevo paradigma para el conocimiento y pensamiento científicos, sustituyendo desde entonces al pensamiento analítico que había dominado hasta el primer tercio del Siglo (filosofía analítica: Círculo de Viena, Positivismo, Positivismo lógico, Atomismo lógico), incluso al pensamiento holístico, dando origen entonces al llamado "pensamiento sistémico", pero también al conocido como "pensamiento complejo" ("Teoría General de Sistemas", L. V. Bertalanffy, y "Pensamiento Complejo", Edgar Morin).

EL concepto de "Sistema" aparecerá entonces fundamentalmente ligado al concepto de "Totalidad", y a partir de él a otros también nuevos, como "interrelación", "organización", "complejidad", "globalidad" o "estructura interna". Este va a ser el contexto en el que se definirá también aquí el sentido del concepto de "Sistema", con el que en principio hemos nombrado ese conjunto específico y especial de elementos musicales que se llegó a cerrar sobre sí mismo. Efectivamente, "nombrado" pero no definido, por cuanto en este momento "Sistema", es todavía aquí un concepto en busca de un significado. 
$Y$ es que en ese desconocido e insospechado interior del Sistema, tiene su origen no sólo aquel orden interno que demostraban también poseer las obras musicales en un lugar profundo no alcanzado todavía por ninguna teoría, sino asimismo todos los conceptos fundamentales que constituyen la base de todas las teorías tonales conocidas, las regularidades que de manera general los teóricos habían obtenido directamente de la superficie de la música y que habían convertido en los principios explicativos propios de esas teorías: "quintas", "tritonos", "semitonos diatónicos", "semitonos cromáticos", "tonalidades mayores y menores", "fundamentales", "acordes", etc.... Un origen común para todos ellos, significaba una explicación común también para todos ellos. Siendo así, esos conceptos invertían totalmente su estatus epistemológico, pues de servir de principios explicativos pasaban a ser aquello, que a partir de otros principios que los preexisten, podía ser explicado. Si "Sistema tonal" o "Tonalidad", son también los nombres bajo los que se han aglutinado todos esos conceptos, esa inversión de su estatus conlleva naturalmente una concepción absolutamente nueva de tal Sistema o de la Tonalidad a la que remite, y si ese Sistema ha sido la base para las teorías tonales, ciertamente tiene que suponer también la posibilidad de una nueva visión teórica para la música, seguramente un nuevo paradigma.

Lo que hay que subrayar, es que el único modo de acceder al interior del Sistema era a través del acceso previo a ese interior más profundo de las obras musicales. Desde el exterior del Sistema, desde su forma externa, desde la forma circular en la que lo representábamos, la única que conocíamos, había sido imposible ni siquiera imaginar la existencia de algo así.

Sin embargo, una vez alcanzado el interior del Sistema, se aprende a acceder directamente desde su exterior, y esto es lo que vamos a hacer, sumergirnos primero directamente en él, para desde allí, conectar luego con el interior más profundo de una obra musical, invirtiendo así la dirección que pudo llevarnos allí. Con ello, además de presentar aquí una visión teórica de la música completamente nueva, consecuencia natural de una concepción asimismo totalmente nueva del Sistema, queremos demostrar su capacidad como herramienta analítica. Así, el texto se propone como un doble viaje, primero al interior del Sistema, para descubrir en él, el mundo insospechado de relaciones que lo pueblan, y que lo dotan de esa Estructura interna asimismo insospechada, en la que como hemos dicho, tienen su origen, y así su explicación, no solo todos aquellos conceptos fundamentales que son la base de todas las teorías conocidas, sino también todos los hechos registrados tanto en la superficie de las obras musicales, como en ese lugar más adentro en el que nos situó Schenker. Mostrar esto último, será el objetivo de la segunda parte, lo que haremos a través de un segundo viaje, ahora al interior de una de esas obras musicales. Partiremos también desde su parte más externa, o mejor, desde el lugar ya algo más profundo en el que nos situó Schenker, con lo que demostraremos además que haber llegado allí, era el primer paso para conseguir llegar todavía más adentro.

En lo relativo a nuestra propuesta, debemos señalar que existe ya una diferencia importante, y es que este viaje al interior del Sistema, supone la inversión en la dirección en la que se lleva a cabo nuestra investigación, pues el Sistema y todos esos conceptos fundamentales de los que recibe su nombre específico: "Sistema tonal", que van a cambiar su estatus epistemológico, no van a ser aquí para nosotros el punto de partida para el análisis, como indefectiblemente ha sido hasta ahora, sino al contrario, su objetivo. 


\section{VIAJE AL INTERIOR DEL SISTEMA}

Naturalmente, el viaje deberá ser relativamente corto, considerando no solo el espacio limitado del que disponemos, sino también las importantes dimensiones que realmente tiene ese interior, y que además hay una segunda parte. Pero creemos, que los lugares de ese interior que visitaremos, serán suficientes para hacer una valoración de esta visión teórica que de este modo presentamos aquí y que hemos cualificado como nueva.

Como hemos dicho, una vez alcanzado ese interior a través del interior de las obras musicales se aprende a acceder a él directamente desde su exterior, donde hemos estado situados hasta ahora. Un exterior que efectivamente podemos representar en una de las formas en las que habitualmente lo hacemos, eligiendo 12 de sus elementos relacionados por quintas, y situándolos o bien en la forma de un círculo, o bien en la de una serie de 11 quintas. Elegimos esta última, y por ejemplo estos 12 elementos.

\section{lab mib sib fa do sol re la mi si fa\# do\#}

Mirándolos desde el exterior como hemos hecho hasta ahora, solo vemos ahí quintas desplazándose linealmente en el tiempo una tras otra, pero ni tritonos, ni semitonos diatónicos, ni tonalidades, ni acordes, pero como veremos, todos están ahí en su interior y perfectamente ya formados. Y es que, la puerta de entrada estuvo siempre allí en su superficie, la que presenta esos 12 elementos que por sí mismos podían representarlo. En el caso de su representación como serie, se trataba solo de superar la temporalidad que somete nuestra forma de pensar, y concebirlos no como una pura sucesión temporal, como solo ha podido hacerse hasta ahora, sino como una totalidad.

No así

lab mib sib fa do sol re la mi si fa\# do\#

Sino así

lab mib sib fa do sol re la mi si fa\# do\#

Naturalmente arriba la flecha indica nuestra concepción como serie temporal y local, y el rectángulo abajo que los enmarca quiere representar ya su nueva concepción como totalidad, un concepto que irá aquí adquiriendo también su significado conforme avancemos. En principio, supone concebirlos más como espacio que como tiempo, captarlos entonces simultáneamente todos a la vez, en una única mirada. Si lo hacemos, liberados ya del yugo de la temporalidad, descubriremos un tipo de regularidad distinto, por cuanto los puntos de referencia ya no son ahora el principio y el final de la serie, sino el lugar en el que se neutralizan, el centro. Ese tipo distinto de regularidad que va a tener como referencia el centro, es producto de una ley de composición interna que demuestra tener esa colección de elementos, y que puede enunciarse así: 
"Cualquier elemento, está ahí en la misma relación (medida en intervalos) con los dos que se encuentran en el centro, que la que tiene su opuesto, el que se encuentra al otro lado a la misma distancia de ese centro, y así en general, cada elemento tiene la misma relación con cualquier otro que la que tienen sus opuestos".

Para facilitar la comprobación del cumplimiento de la ley, indicamos ese lugar de referencia que ahora es el centro, con una línea de puntos, y señalamos cada par de opuestos con un color distinto.

$$
\text { lab mib sib fa do sol re la mi si fa\# do\# }
$$

Las parejas de opuestos específicamente relacionados por la ley son entonces de fuera hacia adentro: lab-do\#, mib-fa\#, sib-si, fa-mi, do-la y sol-re

Comprobemos ahora la existencia de ese nuevo tipo de regularidad. Tomemos un elemento cualquiera, por ejemplo el lab. Comprobamos, que efectivamente, tiene las mismas relaciones medidas en intervalos con el sol y el re (la pareja de elementos que se encuentran en el centro), que las que tiene su opuesto, el do\#: un tritono y un semitono diatónico. Así, para el lab: lab-re, un tritono y lab-sol, un semitono diatónico, y para el do\# lo mismo: sol-do\#, un tritono, y re-do\#, un semitono diatónico.

Es fácil de comprobar que se cumple en todos los casos. Y también se cumple, como establece la ley, entre dos elementos cualesquiera; por ejemplo, el fa y el si tienen la misma relación que existe entre sus opuestos el mi y el sib , un tritono. Nada de esto es obvio, no podíamos imaginar que por ejemplo entre los elementos 1, 6, 7, y 12 numerados como sucesión, existiera algún tipo de relación. $Y$ sin embargo existe, como existe entre los elementos 3, 4, 9 y 10, y además es del mismo tipo, y como veremos muy poderoso.

Podemos ver que se trata ciertamente de un tipo realmente distinto de regularidad, en el hecho de que ya no remite únicamente al ámbito de lo no-local- las nuevas relaciones entre los elementos se producen ya en la distancia (en la concepción como sucesión, las quintas que la caracterizan son puramente locales) - sino también y fundamentalmente al ámbito de lo global, porque obliga a que todos los elementos cumplan con la condición que impone esa ley. Significa que si uno no la cumple, no puede cumplirla ninguno de los demás; para ello, cada uno depende del resto pero también de la totalidad que todos constituyen. El orden global, lo demuestra por ejemplo el hecho, de que si eliminamos un elemento, pongamos ahí el de la izquierda, el lab, ninguno de los restantes podría cumplir la condición que impone la ley. El primer efecto sería la desaparición del punto de referencia, el centro, desapareciendo entonces la relación entre los opuestos y así el orden interno que los liga necesariamente a todos como totalidad. Sin embargo, si en el caso de la concepción como serie, ese mismo elemento faltara, no afectaría en absoluto a la relación local que la caracteriza, pues todos los demás seguirían estando localmente en la misma relación de quinta que tenían antes de la desaparición de ese elemento. Por tanto, desde esa concepción como serie, esos 12 elementos, y así el Sistema que representan, no constituyen una totalidad. 
TOTALIDAD, podemos adelantarlo ya, significa dependencia mutua: entre cada elemento y todos los demás, pero también entre cada uno y la totalidad que juntos constituyen, un concepto fuera del alcance de las teorías conocidas, que se irá clarificando conforme avancemos, pero que como vemos exige ya situarnos en un nivel teórico y epistemológico cuya referencia no sea ya la relación local, sino un tipo muy distinto, la relación global. Para el Sistema, supone la existencia de un orden interno que corresponde a un tipo de regularidad muy diferente respecto de cualquiera de los observados directamente desde su exterior, el que en este caso le proporciona esa ley de composición interna.

Dada la naturaleza del orden específico, que esa ley proporciona a los elementos y a las relaciones entre ellos, y así al Sistema que representan, un orden que tiene el centro como referencia, a partir del cual cada elemento está ligado de manera especial con su opuesto, como si fueran uno reflejo del otro, el nombre más adecuado para esa ley es "reflexividad", una ley que el Sistema, al cumplirla, adquiere como una de sus propiedades fundamentales, que como veremos enseguida no va a ser la única.

Porque el hecho de haber descubierto un tipo distinto de regularidad que atañe a esos 12 elementos como colección, no es más que la puerta de entrada al interior del Sistema. Penetremos por ella. Para ello, imaginemos que alguien nos pide por ejemplo ahora, que ordenemos esos 12 elementos, por tritonos, y por semitonos diatónicos, que junto a las quintas, constituyen tres de los considerados conceptos fundamentales que se encuentran en la base sobre las que se sustentan todas las teorías musicales conocidas; por ejemplo, han sido indispensables para identificar y diferenciar las tonalidades, incluso para explicarlas desde esa diferencia. Los ordenamos. Para cada uno de ellos, como para las quintas, solo hay una posibilidad. La siguiente

Por tritonos lab re mib la sib mi fa si do fa\# sol do\#
6 (1) 6 (1) 6 (1) 6 (1) 6 (1) 6

Semitonos diatónicos lab sol mib re sib la fa mi do si sol fa\# re do\#
(4)
(4)
(4) 1
(4)
(4) 1
(4) 1

Para poder relacionarse tanto por tritonos como por semitonos diatónicos, los elementos han cambiado la ubicación que presentaban en su representación por quintas, se han reordenado. Las cifras fuera de los paréntesis, indican el lugar en el que en cada reordenación se encuentra cada uno de los intervalos que representan a esos conceptos fundamentales, y además el número de semitonos diatónicos que hay entre ellos, 6 para los tritonos, y 1 para los semitonos diatónicos. Por otro lado, las cifras entre paréntesis, indican la distancia local a la que se encuentran los tritonos y los semitonos diatónicos en cada reordenación, la misma en cada caso, un semitono diatónico (1) para los tritonos, y una tercera mayor (4) para los semitonos diatónicos, lo que ciertamente lleva a concluir las representaciones como ordenadas. 
Preguntémonos ahora, ¿hay algo que compartan esas 2 representaciones, más allá de los 12 elementos que tienen en común? En efecto, lo hay. Si no lo vemos directamente, es porque nuestra concepción de esas representaciones, vuelve a ser inadecuada como fue la de las quintas. Porque si concebimos cada una de ellas como totalidad, como ya hicimos con la representación por quintas, descubrimos algo totalmente inesperado e insospechado: que también esas otras dos representaciones poseen una ley de composición interna y que esa ley es absolutamente la misma que la que descubrimos en la representación por quintas. Pero hay más, y más inesperado si cabe: la Reflexividad produce en ambas reordenaciones exactamente las mismas relaciones entre los elementos que producía en la representación de quintas, las mismas parejas reflexivas. Para verlo más claramente, ponemos de nuevo las dos reordenaciones, pero ahora del mismo modo que hicimos con las quintas concebidas como totalidad, organizadas desde su centro por la reflexividad, y dando el mismo color a las parejas producidas, y para compararlas a todas incluimos en el gráfico la representación por quintas.

$$
\begin{aligned}
& \text { Por quintas } \\
& \begin{array}{|cccccccccccc|}
\hline \text { lab mib sib } & \text { fa } & \text { do sol } & \text { re la mi si } & \text { fa\# do\# } \\
\hline 7 & 7 & 7 & 7 & 7 & 7 & 7 & 7 & 7 & 7 & 7
\end{array} \\
& \text { Por tritonos }
\end{aligned}
$$

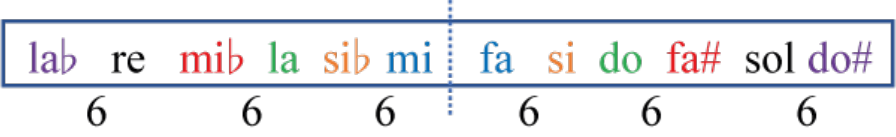

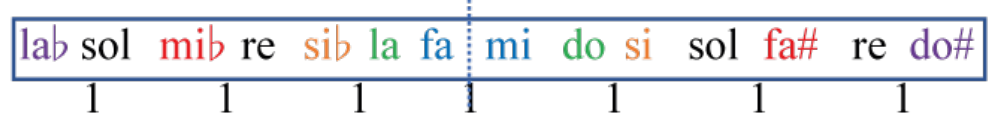

Y efectivamente, podemos ver que si para formar cada uno de esas relaciones, los elementos han tenido que cambiar los lugares que ocupaban en sus respectivas representaciones, lo han hecho con una condición ineludible: que se mantengan siempre las mismas parejas reflexivas, lo que significa que el cambio no es individual sino que tiene que ser global, quiere decir que cada elemento cambia en función del cambio de todos los demás, y eso es lo que permite que en todos los casos se mantenga el orden interno que ha producido la Reflexividad, el que los tres comparten y en el que podemos concluir que todos se originan. La condición de dependencia mutua, no alcanza solo a los 12 elementos, sino también a las tres representaciones. La formación de las quintas, los tritonos o los semitonos, depende de que sea posible la formación de todos juntos, si por ejemplo no pudieran formarse tritonos, no podría formarse ninguno de los otros, pues todos están unidos por la reflexividad, ninguna reordenación puede prescindir de ella. Es más, si no hay reflexividad, no hay intervalos fundamentales. Comprobamos entonces, que el Sistema tiene otra propiedad, y es que puede adoptar diferentes formas externas en las que representarse, la que le proporcionan esos conceptos fundamentales, y a la vez mantener incambiable su forma interna, la que produce la Reflexividad. Realmente, como veremos enseguida, se trata de otra propiedad 
fundamental que junto a la Reflexividad posee el Sistema, y de las que obtiene su eficacia constructiva y explicativa.

Pero si queremos alguna prueba más de la intervención esencial de la reflexividad en la generación de estos conceptos fundamentales la podíamos haber obtenido ya, considerando directamente las relaciones locales que se han producido en cada reordenación, las que indican las cifras. Las indicamos de nuevo

\begin{tabular}{|c|c|}
\hline Por tritonos & \begin{tabular}{|lllllllll} 
lab re & mib la & sib mi fa si do fa\# sol do\# \\
6 & (1) 6 & 6 & (1) 6 & (1) 6 & (1) 6 & (1) 6
\end{tabular} \\
\hline 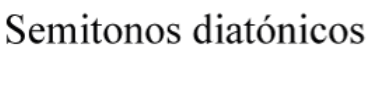 & 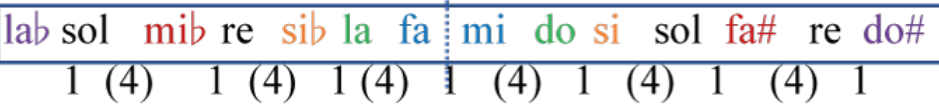 \\
\hline
\end{tabular}

Como podemos ver, en ese orden externo local, que presenta diferenciadamente cada representación, también diferenciadamente, cada 6 , cada 4, y cada 1, tiene su reflejo exacto en el lado opuesto. Pero es que efectivamente, todas esas cifras en sí mismas ya informan de que el modo de concebir el orden que identifica en sí cada reordenación solo puede ser desde el centro. Si no, fijémonos en las que indican las relaciones locales en cualquiera de las reordenaciones, por ejemplo, la de los tritonos, en su caso, los 6 de cada tritono, y el 1, que como hemos señalado es la distancia que en la reordenación hay entre cada dos de ellos. Vemos, que la reordenación pensada como serie temporal, tendría una pauta que se debería repetir en el tiempo, la que forman el 6 y el 1. Partiendo del primer 6-1 a la izquierda que establece la pauta, si nos movemos en el tiempo, es decir hacia la derecha, todo funciona bien hasta llegar al final, porque ahí está el 6 pero no su 1, se rompe la pauta. Es la prueba de que el orden que identifica esta representación no es temporal. Pero en cambio, todo realmente se reordena si concebimos la representación desde el centro, donde hay un 1 , pues a partir de él, como vimos, cada 6 y cualquiera de los otros 1 tiene su réplica exacta en el lado opuesto. Lo mismo ocurre en la representación por semitonos diatónicos, donde la pauta sería 1- 4.

Pero todavía, si en lo referente a la intervención esencial de Reflexividad en la generación de estas relaciones, queremos una prueba más, la tenemos observando por ejemplo la representación por semitonos diatónicos. Vemos, que para formar todos los semitonos diatónicos, son necesarios 14 elementos, lo que requiere que dos elementos de los 12 tienen que duplicarse. Y eso solo es posible si la duplicación no destruye el orden interno producido por la Reflexividad, como hemos visto que sucede, lo que naturalmente obliga a que los dos elementos replicados formen una pareja reflexiva, es decir la duplicación debe corresponder necesariamente a una de las parejas producidas por la reflexividad, como ciertamente ocurre. Observemos la representación

Semitonos diatónicos

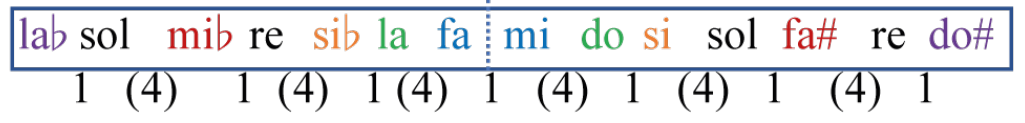


Vemos que efectivamente eso es lo que ha sucedido, los elementos duplicados, son el sol y el re, una de las parejas formadas por la reflexividad (la que había ubicado justo en el centro de la representación por quintas) y la reordenación efectivamente los ha situado de modo que puedan conservar su relación como pareja reflexiva, aunque hayan tenido que duplicarse. Si mantenemos la concepción de la representación como serie temporal, en ningún caso entenderemos porqué el sol y el re están duplicados y ocupan los lugares 2, 4, 11 y 13 que son los que les correspondería concebida la representación como serie. No hay nada que relacione a esos números, pero efectivamente todo cambia, cuando entendemos, que su réplica y su situación responden al orden interno que ha producido la Reflexividad en la reordenación. Orden interno, porque es independiente del orden externo que cada uno de esos conceptos fundamentales presentan en cada reordenación. Mientras el orden externo es distinto en las tres representaciones, y dependiente de la forma que adopta cada uno de esos conceptos fundamentales, el interno, otro tipo de orden, es absolutamente compartido por las tres representaciones, y así independiente de la forma externa que adopta cada una. Además, el privilegio que demuestran justamente esos dos elementos, al ser los únicos que necesariamente deben estar dos veces para conformar todos los semitonos diatónicos, es consistente con otro privilegio que la Reflexividad ha otorgado a esa pareja, que es ser la única quinta cuyos elementos son pareja reflexiva. Todas las demás quintas, necesitan dos parejas reflexivas para formarse, lo que nos permite entender a la vez, que es por ese privilegio, que encontramos a esa pareja, ocupando el lugar asimismo de mayor privilegio en esa representación por quintas, el lugar de referencia, su centro. Por otro lado, ese privilegio que les ha otorgado la reflexividad, lo vuelven a demostrar aquí, porque el resultado de su duplicación, supone ahora, que van a ser también los dos únicos elementos que van a tener un semitono diatónico por ambos lados, el resto solo tiene uno. Así, mientras el sol se relaciona con el lab y el fa\#: lab-sol y sol-fa\#, su pareja, el re, se relacionará con los elementos reflejos del lab y el fa\#, que son el mib y el do\#: mib-re y re-do\#. Mientras el resto de los elementos solo pueden participar en la formación de 1 semitono, estos dos juntos pueden hacerlo en 4 de los 7 que se pueden formar. Todo lo cual, naturalmente deberá tener consecuencias a la hora de utilizar estos elementos y sus relaciones en la construcción de una obra musical. Lo veremos.

Así, esas tres representaciones que corresponden a tres de los conceptos fundamentales que se encuentran en la base de todas las teorías conocidas no solo comparten el mismo número de elementos, que es lo único que podríamos decir hasta ahora, sino algo muy distinto, el mismo orden interno en el que puede decirse que los tres tienen su origen, un origen común que desconocíamos y que ahora puede explicar su presencia en la superficie de la música, decir porqué estaban juntos allí, que es muy distinto de lo que podíamos hacer hasta ahora, que era simplemente constatar que estaban juntos allí, describirlos, darles un nombre. Describir y explicar son acciones de rango epistémico y epistemológico muy diferente. Solo accediendo al origen de algo se accede a su explicación. Lo demás son descripciones de hechos, o apariencias en palabras de Einstein.

Como una prueba más de la acción de la reflexividad podemos visualizar ahora el extraordinario orden en el que se llevan a cabo los reordenamientos en un gráfico, comprobando 
además cómo los cambios se producen de manera global. Por ejemplo, el que transforma las quintas en los tritonos:

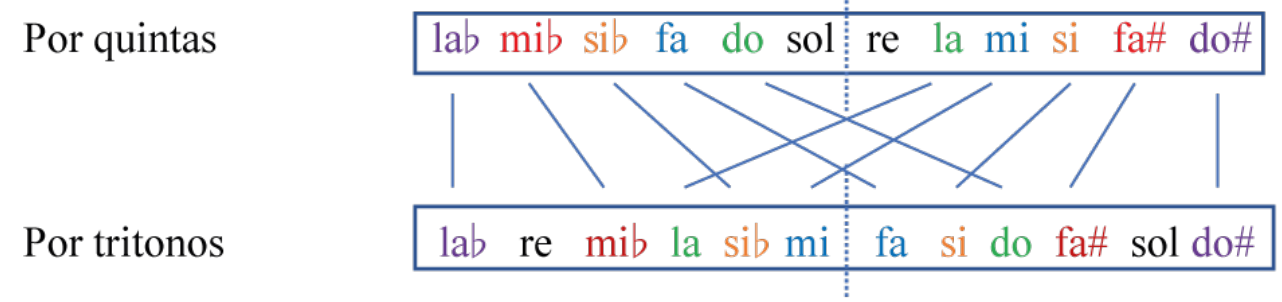

Tenemos ahí ahora la visión directa de la acción de la reflexividad en las líneas que señalan los cambios de lugar de los elementos, y que muestran el orden absoluto en el que se lleva a cabo el proceso de transformación, remitiéndonos entonces de nuevo a un orden que ciertamente debe ser cualificado como global. Significa por ejemplo, que si para formar el primer tritono por la izquierda, el lab debe mantenerse en su mismo lugar, entonces su pareja reflexiva, el do\#, deberá necesariamente hacer lo mismo, mantenerse también en el suyo para formar su propio tritono. Y si entonces para ello, el re debe pasar del lugar 6응 por la derecha en el que se encuentra en las quintas, ahora al lugar $2^{\circ}$ por la izquierda para formar el tritono lab-re, entonces su pareja, el sol, también necesariamente deberá hacer reflexivamente lo mismo, es decir, pasar del 6 lugar por la izquierda al $2^{\circ}$ por la derecha para formar su propio tritono sol-do\#, y así deberá ocurrir con todos, obligando a que lo que haga cada uno dependa globalmente de lo que hagan los demás.

El orden del proceso de transformación es ciertamente extraordinario. Lo impone la reflexividad, y lo posibilita otra propiedad fundamental que trataremos enseguida. Antes de presentarla, debemos darnos cuenta de que podemos ya llevar a cabo conclusiones de ámbito teórico que estaban fuera de nuestro alcance. Por ejemplo, para todas las teorías conocidas, los tritonos fueron y siguen siendo una especie de "quintas extrañas", que de pronto aparecieron en la superficie de la música, desde donde tuvieron que ser necesariamente descritas, pero nunca pudieron ser explicadas. Se trató de explicar las quintas, diferenciadas entonces como "justas", a partir de los armónicos, pero entonces el tritono aparecía realmente como un contraejemplo que cuestionaba tal explicación. La explicación de la quinta, jsólo podía ser válida a costa de asumir que el tritono no la tuviera!, a costa de cerrar los ojos ante el cuestionamiento que en realidad ello suponía para esa explicación. Sin embargo, ahora hemos visto que ambos sí que tienen un origen común y por tanto ahora sí una única explicación común, en definitiva, una explicación, una explicación que no es puramente física sino fundamentalmente organizativa, estructural. Coexisten inseparablemente en el interior del Sistema, participando del mismo orden interno, donde unas, las quintas justas, pueden ser literalmente el origen de los otros, los tritonos, y viceversa, porque el proceso de reordenamiento que transforma unos en otros es totalmente reversible.

Esa reversibilidad que se da entonces entre todos los conceptos fundamentales, demuestra efectivamente su coexistencia en el interior del Sistema. Significa que cualquiera puede ser el origen y el resultado de todos los demás. Origen común y coexistencia, que como anticipábamos, se debe en particular a otra propiedad fundamental que posee el Sistema y que permite algo extraordinario: permite que algo (en nuestro caso el Sistema) pueda cambiar 
su forma externa (en nuestro caso materializándose en cada uno de esos conceptos fundamentales) manteniendo absolutamente invariante su forma interna (la que en nuestro caso ha producido la reflexividad). Esa propiedad fundamental deriva de un principio que el Sistema tuvo que cumplir cuando llevó a cabo su cerramiento, y tiene un nombre y se llama Simetría.

\section{SIMETRÍA}

Y es que la "simetría" ha demostrado y está demostrando ser uno de los principios más esenciales para la ciencia. Ha dado lugar a una de las teorías matemáticas más insospechadas y fructíferas que se conocen: la "Teoría de Grupos". Fundamental en distintos campos del conocimiento, sobretodo en la Física, donde el cumplimiento de ese principio puede llevarse a cabo de diferentes formas. Fue esencial, por ejemplo, para la teoría de la Relatividad, y lo está siendo para el campo de la Física cuántica. Sus dos teorías básicas, la Electrodinámica y la Cromodinámica cuánticas, se fundamentan en ese principio. El autor del hallazgo del principio fue uno de los matemáticos más extraordinarios que han existido, Evariste Galois $(1811-1832)^{3}$

Un matemático o un físico definirían el principio del siguiente modo:

Una simetría, no es un concepto estático sino dinámico, es una acción llevada a cabo sobre un objeto o un sistema, de manera que produce un cambio importante en él, pero a la vez lo mantiene totalmente invariante. Puede decirse entonces que el objeto o el sistema cambia y a la vez no cambia (cómo hemos empezado a ver que sucede con los 12 elementos que representan al Sistema y así con el Sistema). La acción y el resultado de la simetría, se denomina más específicamente "Transformación simétrica" (como la que transforma las quintas en su contrario, los tritonos, y viceversa). La simetría nombra a la vez, el principio a cumplir, la acción que conlleva su cumplimiento (descrita también como como "transformación"), y la propiedad que adquiere aquello que lo cumple. ${ }^{4}$

Aparte del principio en sí, ciertamente lo extraordinario de él, es que puede cumplirse de distintas formas, desvelando la Estructura de muy diversos objetos de diferente grado de complejidad, un grado del que dependerá que la Estructura que nos desvele la simetría sea externa o interna, esté a la vista o fuera de su alcance: una figura geométrica, una ecuación matemática, una ecuación física, una molécula, una partícula cuántica, una fuerza de la naturaleza, el propio Universo, o como empezamos a ver el Sistema tonal, y por derivación la propia música. Su materialización es distinta pero conceptualmente el principio es siempre

\footnotetext{
3 Una importante cantidad de libros han sido escritos para destacar la extraordinaria importancia constructiva y explicativa que tiene en la ciencia este principio. El libro que puede considerarse como referencia es "Symmetry" (1952) cuyo autor es uno de los matemáticos mas reconocidos de la historia, Herman Weyl. Otros ejemplos: "Fearfull Symmetry" (A. Zee, 1986). "Laws And Symmetry" (Bas C. Van Fraassen, 1989). "The Force Of Symmetry" (Vincent Icke, 1995). "Symmetry And The Beautiful Universe" (Leon Lederman and Chistopher T. Hill, 2004). "The Ecuation Than Could'nt Be Solved" (Mario Livio, 2005). "Why Beauty Is Truth. A History of Symmetry" (lan Stewart, 2007).

4 Como vemos "reflexividad" y "simetría" no son conceptos sinónimos, como usualmente se consideran en el lenguaje ordinario, sino que tienen diferentes significados y es desde esa diferencia que como vemos aquí van a poder relacionarse. En el campo de la música, el uso que a veces se ha hecho del concepto de "simetría", ha sido a partir de ese lenguaje ordinario, por ejemplo, cuando es referido a diferentes técnicas contrapuntísticas, como la "inversión" o la "retrogradación", o incluso referida a la repetición de un número de compases, o en algunos análisis que últimamente se han hecho teniendo como referencia su nombre, y así, en todos los casos, efectivamente confundido con el de "reflexividad".
} 
el mismo. Un ejemplo simple de objeto geométrico simétrico, cuya estructura es externa: el triángulo equilátero

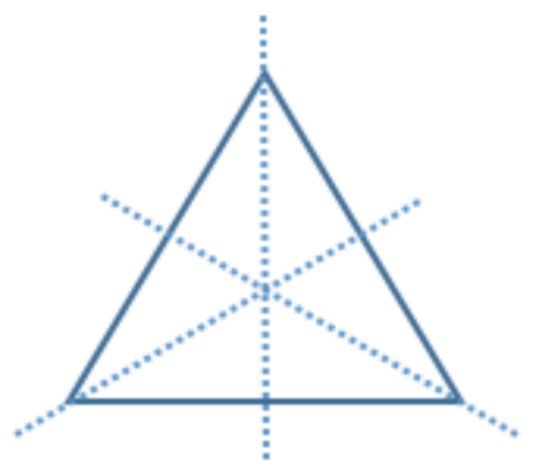

Tiene 6 simetrías (transformaciones simétricas) que dejan totalmente invariante su posición en el espacio: 3 rotaciones, 120, 240, 360 sobre sí mismo, y 3 reflexiones sobre sus mediatrices

Cada transformación, que por ejemplo reordena sus vértices, y todos los puntos que constituyen sus lados, permutándolos en el espacio que ocupa, modifica esa posición, pero A LA VEZ, el triángulo mantiene absolutamente invariante esa posición como tal en ese mismo espacio. Así, la simetría, hace coexistir el cambio y su contrario, la invariancia. De las simetrías específicas que conlleva esa coexistencia, el triángulo obtiene su cualidad como "equilátero". No es simétrico por ser equilátero, como podría pensarse, sino que es equilátero por esas particulares simetrías. Como todo principio, el de simetría, preexiste a la conformación del objeto o el Sistema que lo cumple. Por ello, y esto es importante subrayarlo, la forma particular que adopta un objeto (aquí el triángulo) depende de la forma particular en que cumple con la simetría.

Así, es la forma particular en que el Sistema cumple con la simetría, la que le otorga su propia forma, su Estructura, interna en su caso, que es a la vez de la que en ese interior, obtienen su propia forma particular todos los considerados conceptos fundamentales que se aglutinan y se integran bajo su nombre: "Sistema tonal". Todas las representaciones en las que vemos materializarse esos conceptos, conforman la Estructura interna del Sistema, incluso cada una puede representarla, pero NO SON la Estructura, la Estructura (y así el Sistema) está hecha del entretejimiento conjunto, y por tanto complejo, de todas ellas. Un grado de complejidad, muy distinto entonces del que presenta el triángulo, que supone entre otras cosas que su Estructura, a diferencia de la del triángulo, esté en su interior, por eso no habíamos podido verla desde fuera.

De esa complejidad, el Sistema obtiene su eficacia, y lo demuestra particularmente el hecho, de que también en ella tiene su origen otro de los conceptos fundamentales de los que el Sistema toma su nombre específico: "Sistema tonal", las propias "tonalidades". 


\section{EL ORIGEN ESTRUCTURAL DE LAS TONALIDADES MAYORES Y MENORES}

El Sistema como tal, tiene otra importante propiedad derivada de sus dos fundamentales: puede dividirse en fragmentos con la condición de que estos hereden esas dos propiedades fundamentales, la reflexividad y la simetría. El origen de las tonalidades mayores y menores se encuentra en esta propiedad. Veámoslo. Imaginemos que alguien nos pregunta ahora cuántas tonalidades mayores se pueden formar con esos 12 elementos. Vamos a ver, que no sólo el número, sino su propia constitución, lo establecen la reflexividad y la simetría.

Existe un fragmento de 6 elementos en el interior del Sistema con propiedades realmente especiales. Lo indicamos en la representación por quintas.

lab mib sib fa do sol re la mi si fa\# do\#

Ese fragmento especial, enmarcado con el rectángulo interior- que ya vemos situado en un lugar asimismo especial, el centro de esa totalidad - nos pone ya en contacto directo con las tonalidades tal como han sido descritas por las teorías conocidas, pues esos 6 elementos son los que tienen en común dos tonalidades mayores que se encuentran en relación de quinta, en este caso Fa mayor y Do mayor. Y es especial, no sólo por su ubicación, sino porque efectivamente hereda las dos propiedades fundamentales de la totalidad de la que es fragmento (del Sistema), que como vamos a ver lo dotan de una extraordinaria capacidad generativa y organizativa, por ejemplo, efectivamente para producir las tonalidades que pueden formarse con esos 12 elementos. Por ello le damos un nombre específico: HEXACORDO. Por supuesto, puede entenderse ya que el significado que tiene aquí el término no tiene mucho que ver con el que pudieron darle los teóricos antiguos. La única coincidencia es el nombre que simplemente hace referencia al número de elementos que posee el fragmento.

$Y$ es que como hemos dicho, el fragmento además de reflexivo, lo que ya demuestra el hecho de estar situado en el centro de una totalidad que es reflexiva, también es simétrico. Para verlo, reordenemos por ejemplo esos 6 elementos distribuyéndolos localmente de todas las formas regulares posibles, en términos tonales a partir de todos los intervalos posibles además de las quintas, por $2^{\text {as }}, 3^{\text {as }}, 4^{\text {as }}, 5^{\text {as }}, 6^{\text {as }}$, y $7^{\text {as }}$. Para cada una sólo existe una posibilidad. El resultado es absolutamente insospechado: Sus elementos se reordenan con una condición que conocemos y que impone la simetría: mantener invariante el orden interno que esos 6 elementos demuestran poseer en su representación por quintas, es decir, todas las reordenaciones son transformaciones simétricas de esa representación. Reordenémoslas, pensando todas del mismo modo, en sentido descendente (daría lo mismo en el otro sentido). Por ello podemos pensar también en ese mismo sentido, el hexacordo que hemos obtenido de la representación por quintas, y que tomamos como origen de las transformaciones, es decir por cuartas descendentes 
Hexacordo

Transformaciones simétricas

\section{Por $2^{\text {as }}$}

Por $3^{\text {as }}$

Por $4^{\text {as }}$

Por $5^{\text {as }}$

Por $6^{\text {as }}$

Por $7^{\text {as }}$
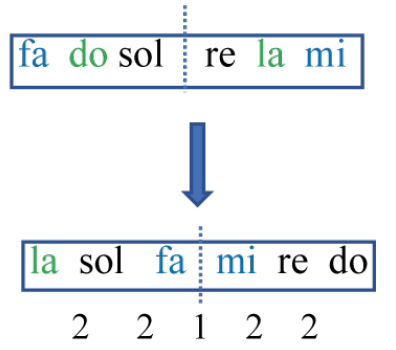

sol mi do la fa re

$\begin{array}{lllll}3 & 4 & 3 & 4 & 3\end{array}$

\begin{tabular}{|cc:c:ccc|}
\hline fa & do & sol & re & la & $\mathrm{mi}$ \\
\hline 5 & 5 & 5 & 5 & 5
\end{tabular}

\begin{tabular}{|c|c:c:c|cc|}
\hline mi & la & re & sol do fa \\
\hdashline 7 & 7 & 7 & 7 & 7
\end{tabular}

$\begin{array}{lllll}7 & 7 & 7 & 7 & 7\end{array}$

\begin{tabular}{|ll:lll|}
\hline re fa la & do & mi & sol \\
\hline
\end{tabular}

$\begin{array}{lllll}9 & 8 & 9 & 8 & 9\end{array}$

\begin{tabular}{|l|l|}
\hline do re mi fa sol la \\
\hline
\end{tabular}

$\begin{array}{lllll}10 & 10 & 11 & 10 & 10\end{array}$

las parejas relacionadas por la reflexividad efectivamente demuestran también aquí ser inseparables (su visualización la siguen facilitando los colores) lo mismo que su constitución reflexiva (lo que indican ya los números que señalan las relaciones locales). Pero los 6 elementos parecen cumplir con otra condición para formar parte del fragmento: que todos ocupen los 6 lugares que el fragmento posee para ser ocupados, pero sólo una vez. Así, cada lugar está ocupado realmente por todos los elementos a la vez. Porque realmente todas las representaciones coexisten en el interior del fragmento, lo que demuestra también aquí el hecho de que no haya ninguna que tenga privilegio sobre las demás, pues también aquí cualquiera puede servir de origen para ser transformada en cualquiera de las otras. Lo que permite la simetría, es sacarlas una a una al exterior para que así podamos verlas separadas. Pero una vez situadas todas ahí y consideradas juntas, que es como están en su interior, se nos permite ser testigos directos del extraordinario orden de ese interior, visualizarlo. Lo podemos ver, a partir de la forma específica que adoptan juntas todas sus representaciones, una forma de unidad que recuerda la que los matemáticos del S. XVIII descubrieron también como propiedad de los números y que llamaron "cuadrado latino". Ponemos juntas las 6 representaciones para verlo 


\begin{tabular}{|llllll|}
\hline la & sol & fa & mi re & do \\
sol & mi & do & la & fa & re \\
fa & do & sol & re la & mi \\
mi & la & re & sol do & fa \\
re & fa & la & do & mi & sol \\
do & re & mi & fa & sol la \\
\hline
\end{tabular}

Cuadrado Hexacordo

\begin{tabular}{|llllll|}
\hline 1 & 2 & 6 & 3 & 5 & 4 \\
2 & 3 & 1 & 4 & 6 & 5 \\
3 & 4 & 2 & 5 & 1 & 6 \\
4 & 5 & 3 & 6 & 2 & 1 \\
5 & 6 & 4 & 1 & 3 & 2 \\
6 & 1 & 5 & 3 & 4 & 3 \\
\hline
\end{tabular}

Cuadrado Latino. Euler

A la izquierda nuestro cuadrado, y a la derecha uno de los construidos por Leonhard Euler (1707-1783), uno de los matemáticos más reconocidos de la historia. Como en el caso de los números, también en nuestro cuadrado, cada elemento está en cada línea y cada columna, y sólo una vez. Pero su orden interno es muy diferente, más extraordinario, lo que ya anuncia que las capacidades generativas y organizativas de este fragmento de 6 elementos también van a serlo. Por ejemplo, podemos ver ahí, que las líneas se reproducen de manera exacta en las columnas: la línea superior, la de las segundas, se reproduce exactamente de arriba a abajo en la columna de la izquierda; la línea siguiente, la de las terceras, del mismo modo en la columna siguiente, y así sucesivamente. Como si el cuadrado pudiera girarse en el espacio sin modificar nunca su forma externa. Podemos fijarnos ahora en el orden preciso y asimismo sorprendente que para situarse siguen las parejas reflexivas. Por ejemplo, podemos seguir la pareja fa-mi desde la representación por segundas. Ahí la simetría la ha situado en su centro; en la siguiente, la de las terceras, se abre para ocupar los lugares contiguos invirtiendo la posición de sus elementos; y en la siguiente, la de las cuartas, se sitúa en los únicos lugares que faltan para ocupar, los extremos, volviendo a invertir la posición, mientras las otras parejas se reordenan perfectamente con ella cada vez. Pero vemos lo que ocurre ahora. Para que los elementos puedan ocupar todos los lugares posibles, las parejas sólo tienen que mantenerse en los mismos lugares que han ocupado en las tres primeras transformaciones, y simplemente intercambiar sus elementos. Así, las quintas son el resultado directo del intercambio de los elementos de cada pareja tal como la simetría las situó en las cuartas, las sextas lo mismo con respecto a las terceras, y las séptimas lo mismo respecto a las segundas. A partir de este orden extraordinario, asistimos entonces al origen de lo que describimos como "inversiones", pues estas no son más que el resultado del cumplimiento de las condiciones que impone la simetría en este objeto simétrico para sus elementos: ocupar todos los lugares posibles, manteniendo su orden interno, el que proporciona la reflexividad, y al que contribuye entonces la propia simetría. El fragmento adquiere por todo ello una coherencia y una consistencia internas extraordinarias, de las que van a derivar de manera lógica su efectividad tanto generativa como organizativa.

Porque el hexacordo tiene otra extraordinaria propiedad derivada de las fundamentales: puede replicarse en el espacio bidimensional, y proporcionar así una nueva forma externa al Sistema. Para comprobarlo elijamos una de sus representaciones, por ejemplo, la representación por segundas, la-sol-fa-mi-re-do, cuya constitución interna en cifras (intervalos) 
es: 2-2-1-2-2. Replicamos el hexacordo reflexivamente en los dos sentidos, desde sus dos mitades, hacia arriba desde su mitad izquierda y hacia abajo desde su mitad derecha, repitiendo el proceso 3 veces. Así:

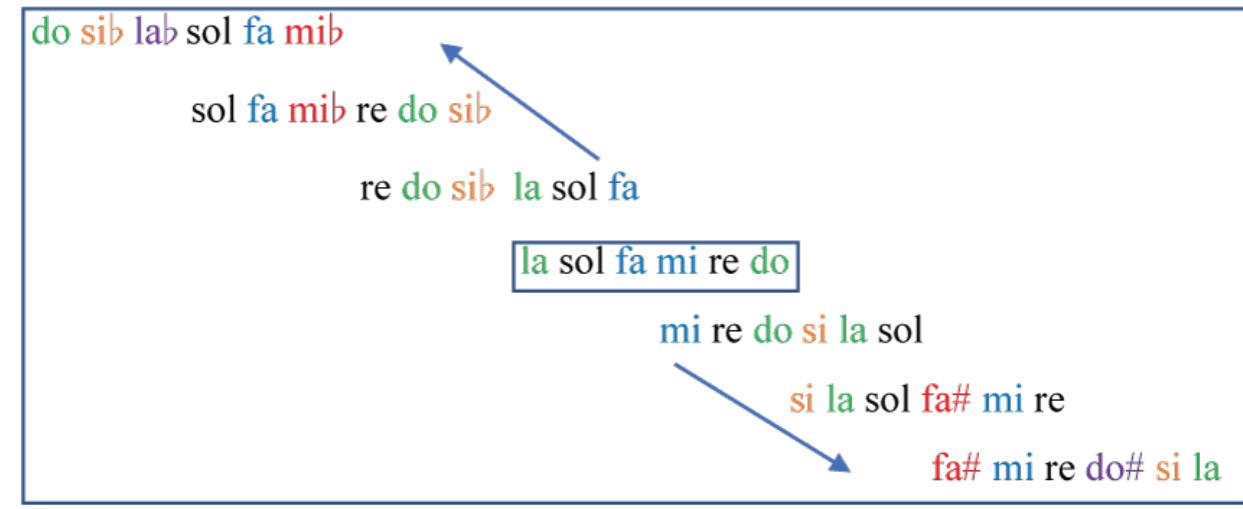

Transformación simétrica

lab mib sib fa do sol re la mi si fa\# do\#

El rectángulo superior del gráfico muestra a través de las flechas cómo el hexacordo se replica produciendo 6 hexacordos más ( 3 por encima y 3 por debajo) desplegando así sus elementos por el espacio bidimensional, y lo hace produciendo a la vez, de forma natural, en cada nueva réplica, y de manera perfectamente ordenada, cada uno de los otros 6 elementos que constituyen con él la totalidad que forman los 12 de la que es fragmento.

Debajo del rectángulo, el gráfico indica que efectivamente ese despliegue es una nueva transformación simétrica de nuestros 12 elementos, llevada a cabo sobre la representación por quintas (podría ser sobre cualquier otra representación), una nueva forma externa que adquiere el Sistema (su Estructura), pues como puede comprobarse, y eso es lo extraordinario, aunque a través de la réplica del hexacordo la transformación ha triplicado sus elementos, ocurre, que donde la simetría ha situado uno de ellos en el despliegue, en el lugar opuesto (reflexivo) indefectiblemente habrá situado su pareja reflexiva, y lo mismo sucede con los otros 6 elementos de los 12 que podemos decir que de manera automática produce la transformación: donde ha producido uno de ellos, en el lugar opuesto indefectiblemente se encuentra su pareja reflexiva. $Y$ respecto a las relaciones, cualquier relación sea local o no-local, medida en intervalos, tendrá su reflejo exacto en el lado opuesto. Es fácil de comprobar. Como vamos a ver, en esas relaciones nuevas y precisas de esta particular forma externa que la simetría permite adoptar al Sistema, tiene su origen las tonalidades mayores.

Porque el hexacordo tiene aún otra capacidad: puede utilizar sus propios elementos ahora para unir ordenadamente de dos en dos los hexacordos que él mismo ha generado. Cada unión corresponderá ya exactamente no solo a los elementos sino también a las relaciones que efectivamente van a caracterizar diferenciadamente cada una de las tonalidades mayores. Lo empezamos a indicar todo en el siguiente gráfico: 


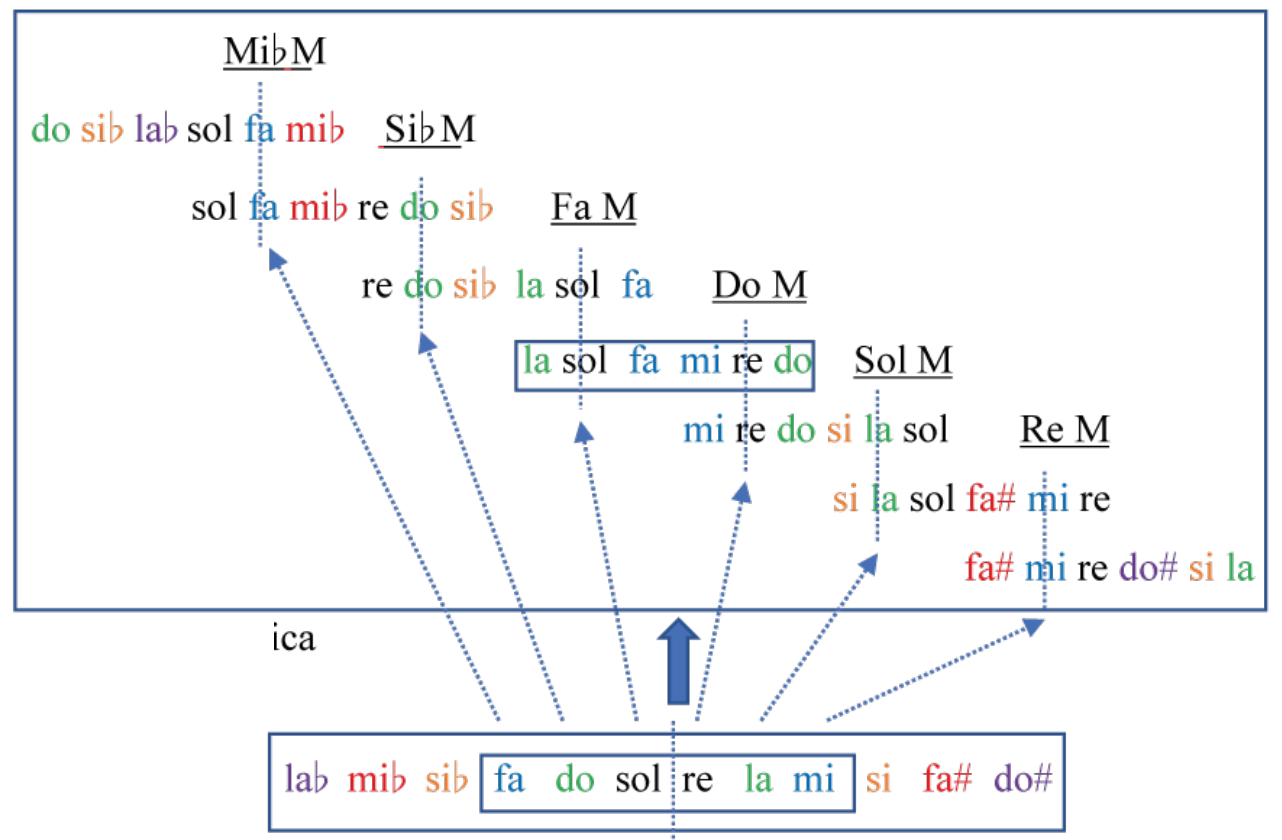

Las flechas punteadas, indican el lugar preciso en el que la transformación ha situado ordenadamente en el despliegue, los 6 elementos del hexacordo que ha generado el resto de los hexacordos. Además de conformar con ellos el hexacordo central, los ha situado justo en el centro de cada dos de los hexacordos que ha producido sus sucesivas réplicas, efectivamente uniéndolos y organizándolos en dos partes iguales que se reflejan la una a la otra (lo que indica en cada caso la línea vertical de puntos).

Sobre cada línea aparece el nombre de la tonalidad mayor que se forma en cada unión. Son 6 tonalidades mayores las que se pueden formar, ni más ni menos. Ni más ni menos, porque entendemos que su número depende totalmente del número de los elementos que constituyen el hexacordo pues en este extraordinario orden son los responsables de producir, no sólo la forma externa que adquiere esta representación (a través de su representación por segundas), sino de las 6 uniones de los hexacordos que la constituyen (a través de su representación simétrica por quintas). Una consecuencia importante de ello, es que, en el interior del Sistema, las tonalidades mayores nacen juntas, literalmente unidas unas a otras, pues cada hexacordo es compartido por dos de ellas, cuando hasta ahora siempre fueron descritas desde su total separación. Ciertamente descritas y no explicadas porque su explicación exigía remitirlas a un origen común, como el que estamos desvelando ahora. Además, el hecho de que se encuentren allí unidas es esencial para la lógica del mecanismo que les va permitir convertirse en música. Y para nosotros entenderlo. Aunque tratarlo en profundidad nos retrasaría demasiado nuestro objetivo, que es el de recorrer lo más ampliamente posible el interior del Sistema al encuentro del origen de los considerados conceptos fundamentales, dada su importancia, veámoslo, aunque sea brevemente.

Tomemos para ello el centro de la representación en el que la simetría ha situado los hexacordos que corresponden a las tonalidades de Fa mayor y Do mayor, que como vemos, efectivamente comparten nuestro hexacordo de referencia (serviría cualquier grupo de tres hexacordos. 
$\mathrm{Fa} \mathrm{M}$

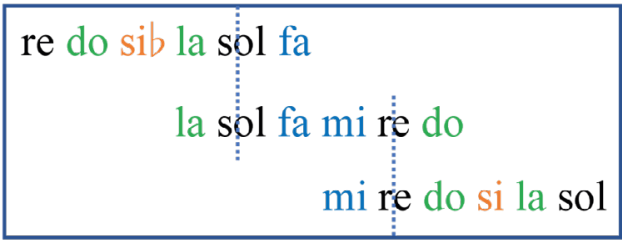

Do $\mathrm{M}$

Vemos primero que la transformación, de manera natural, ha producido ahí dos nuevos elementos en los dos nuevos hexacordos, el siby el si que naturalmente son pareja reflexiva, y que son precisamente aquellos a partir de los cuales se podrán diferenciar las dos tonalidades. Estos dos elementos, situados justo a ambos lados del hexacordo central, van a poder entonces relacionarse con los dos que éste tiene también justo en su centro, fa-mi, a su vez el centro de esos tres hexacordos, ligados también como pareja reflexiva, para formar ordenadamente los dos tritonos que por sí mismos pueden ciertamente representar de manera diferenciada a las dos tonalidades Fa mayor y Do mayor: sib-mi y fa-si. Todo parece seguir un orden absoluto. Porque esa pareja fa-mi, que ocupa un lugar predominante, en el centro de este fragmento de tres hexacordos, y que demuestra aquí ser realmente esencial, a la vez podrá relacionarse con la otra pareja, la formada por el la y el do, situada justamente a ambos lados del hexacordo central, precisamente para formar ahora las terceras mayores, la-fa y mi-do (que vemos reflejándose una a la otra en ese hexacordo) que lo mismo que los anteriores pueden representar diferenciadamente a las dos tonalidades, y en los que como se dirá, resolverán aquellos tritonos. Podemos decir, que de ese modo las 4 relaciones en las que directamente participa la pareja fa-mi, situada en el centro de esta mini-estructura, quedan a su vez totalmente ligadas, relacionadas por ella. Esa relación de relaciones será fundamental para su materialización en música, y ciertamente para la diferenciación de esas tonalidades que en principio coexisten ahí ligadas por el hexacordo que comparten. Pues en un orden absoluto, el tritono sib-mi se unirá efectivamente a la tercera fa-la (relación que efectivamente se describirá como resolución de uno en el otro), y entonces, siguiendo el orden que establece la reflexividad, reflexivamente, el tritono fa-si hará lo mismo con la tercera mi-do, reflejos de las anteriores, un orden absoluto que ciertamente liga asimismo totalmente a todas esas relaciones, para permitirles a la vez que luego puedan diferenciarse y definir así la pertenencia de ese hexacordo central a una o a otra de las dos tonalidades. Y es que como vamos a ver en esa diferenciación también participa la reflexividad.

En efecto, sabemos que si ambas tonalidades comparten ese semitono situado en el centro del hexacordo que tienen en común, aquí fa-mi, es para diferenciarse a partir del sentido que tomará la dirección de esos dos elementos cuando se representen como relación en el tiempo, como música, lo que a su vez, es decir globalmente, estará en función del sentido que tomen sus otros semitonos. Y así, mientras en Fa mayor el mi asciende al fa (en grados tonales como 7-1) y a la vez, su otro semitono, lo hace descendentemente del sib al la (como 4-3), en Do mayor ocurrirá todo lo contrario, el sentido de la relación entre el fa y el mi se invierte reflexivamente, el fa desciende al mi (como 4-3), mientras su otro semitono el formado entre el si y el do, reflejo de aquel semitono sib-la, también invertirá su sentido, 
y el si ascenderá al do ( ahora como 7-1). Indicamos en el gráfico por medio de flechas, este extraordinario orden que impone también la reflexividad a estas relaciones fundamentales para que el hexacordo central pueda definirse en una u otra tonalidad.

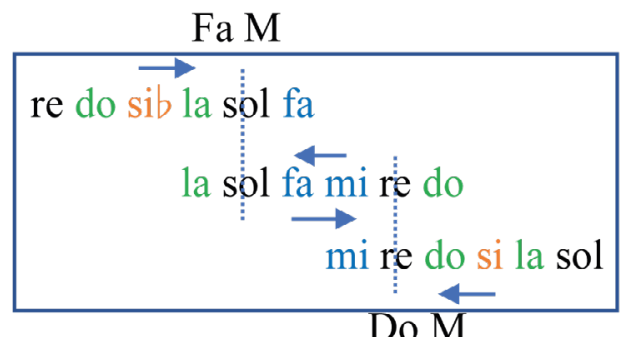

Este orden absoluto en el que se llevan a cabo las relaciones, nos sirve de nuevo ya para comprobar, por ejemplo, que todos esos acontecimientos que fueron registrados en la superficie de la música y que pudieron incluso ofrecerse como reglas de comportamiento, no eran su explicación, sino su descripción, descripciones de hechos (apariencias), porque como estamos viendo, en ese orden interno del Sistema, obtienen realmente la lógica de su comportamiento, y ahora sí su explicación.

Porque ciertamente podemos decir que estamos ante el origen del mecanismo de la tonalidad. Hemos empezado a ver la importancia que tiene para ello el hecho de que las tonalidades estuvieran unidas unas a otras en el interior del Sistema y no separadas como han sido descritas desde las teorías conocidas. Empezamos a entender que la lógica que justifica su separación se encuentra en la lógica de su unión, la explica esta lógica. Pero profundicemos algo más ahora en la lógica de su separación, es decir veamos qué sucede a la constitución de cada tonalidad cuando se apropia del hexacordo que comparte con la otra.

Parece que existe una condición para la separación: que incluso al separarse, la unión de los dos hexacordos que puede constituir una tonalidad mayor siga siendo reflexiva y simétrica, como lo era la unión de las dos tonalidades antes de la separación, y como lo es el propio hexacordo. Dicho de otro modo, asistimos a otra nueva propiedad del hexacordo: su unión con el otro hexacordo con el que forma una tonalidad mayor, sigue siendo reflexiva y simétrica, sigue heredando las propiedades fundamentales de la totalidad de la que esa entidad formada por la unión de dos hexacordos es un fragmento, es decir, del Sistema, constituyendo por tanto y por sí misma una totalidad.

Comprobémoslo. Tomemos por ejemplo los dos hexacordos que corresponden a una de esas dos tonalidades que acabamos de ver ligadas una a la otra, la de Do mayor:

$$
\begin{aligned}
& \text { la sol fa mi ree do } \\
& \text { mi re do si la sol }
\end{aligned}
$$


Si podemos declarar esa unión como reflexiva, es porque comprobamos que esos 7 elementos poseen su propia ley de composición interna, y que ciertamente es la misma que tienen los 12 de la que estos son un fragmento, es decir el Sistema. También en este caso, cada elemento tiene la misma relación con el que la simetría ha situado en el centro, aquí el re, que la que tiene su opuesto, y en general cada uno tiene la misma relación con cualquier otro que la que tienen sus opuestos, y también cada relación sea local o no-local tiene su reflejo exacto en el lado opuesto. Es fácil de comprobar. Así, esta entidad formada por dos hexacordos tiene por tanto una constitución reflexiva que le es propia, y por eso, y por formar parte de una Estructura, podemos darle la categoría de "subestructura". En efecto, la simetría ha producido particularmente en cada subestructura tres parejas reflexivas, que se organizan alrededor del elemento central que sitúa en ellas la transformación, en este caso el re (las hemos indicado con el mismo color): mi-do, fa-si, la-sol. Vemos de nuevo aquí la acción organizativa de la reflexividad, pues es la que produce directamente, las dos relaciones que pueden representar a esta tonalidad, señalándolas expresa y diferenciadamente al ligar reflexivamente sus elementos: el tritono y la tercera mayor (aquí fa-si y mi-do), pero vemos también la acción de la simetría, pues es la que en aquel despliegue bidimensional, los ha ubicado aquí en el lugar preciso para que ahí puedan relacionarse directamente y formar así localmente por puro intercambio de sus elementos los dos semitonos diatónicos que asimismo van a representarla, fa-mi y si-do situándolos justo en el centro de cada uno de los hexacordos, reflejándose uno a otro para que la reflexividad alcance también aquí, ahora de manera particular como ya señalamos antes, al sentido básico de su dirección cuando se representen como música en el tiempo: el fa moviéndose al mi y el si en dirección opuesta (reflexivamente) moviéndose al do. No podemos extendernos más.

Diremos entonces asimismo como una regla, entendida como explicación, que "el tritono resuelve en la tercera mayor". Pero nos damos cuenta que eso sólo era describir un hecho, porque es ahora cuando podemos explicarlo, al poder remitir esas relaciones y su comportamiento a un origen común. Ciertamente, desde este pequeño contexto, podemos decir ya que nos encontramos en el origen mismo de la tonalidad, y ante su propio mecanismo, pues estamos asistiendo al nacimiento común, inseparablemente juntos, de los tres intervalos básicos que por sí mismos la representan, aquí a la tonalidad mayor: los dos semitonos diatónicos, el tritono y la tercera mayor, así como a las relaciones fundamentales que su ubicación precisa permite llevar a cabo entre ellos cuando los veamos representarse como música. Entendemos porqué en el interior de esos fragmentos no pueden existir unos sin los otros. La ausencia en ellos de un orden interno que proporciona globalmente la ubicación precisa de sus elementos, y que obtienen del propio orden interno del Sistema, haría imposible el nacimiento común de esas relaciones, haría imposible la totalidad que juntos conforman, tanto en la forma de la unión de dos tonalidades como en la forma particular de cada una de ellas, y así haría imposible "la tonalidad", su lógica, y entonces también su eficacia, que se encuentra en esa lógica. Si antes vimos, a esos conceptos fundamentales, originándose separadamente aunque coexistiendo en el interior del Sistema, ahora los hemos visto naciendo inseparablemente juntos en el interior de dos de sus fragmentos, que demuestran 
ser especiales al heredar sus propiedades fundamentales, el que forman los tres hexacordos en el que se encuentran unidas las dos tonalidades, y el que forman cada dos de ellos para constituirse ya diferenciadamente en una tonalidad mayor.

Sin embargo, existe ahí una pareja de la que no hemos hablado y que parece quedar fuera de esas relaciones fundamentales básicas- el tritono, la tercera mayor, y los semitonos diatónicos - que conforman esa totalidad de 7 elementos, para constituirse como tonalidad mayor, la formada por el sol y el la. Una pareja que, sin embargo, la simetría ha tratado ahí realmente de un modo especial, la ha duplicado. La vemos enmarcando la subestructura que forman los dos hexacordos, en la que sus dos elementos además de relacionarse en la distancia, como es propio de las parejas, lo hacen también localmente como relación, como segunda mayor, y dos veces, al reflejarse consigo misma. Más abajo, comprobaremos la extraordinaria importancia que tiene también esa relación no sólo en la constitución de lo que hemos llamado "tonalidad mayor", sino también en la "tonalidad menor", pero también entenderemos la lógica de la presencia de ese re que la simetría ha situado justo en el centro de la representación y que la reflexividad también ha tratado de un modo especial, pues es el único que es reflejo de sí mismo.

Pero efectivamente, si la condición para que la unión de dos hexacordos dé cómo resultado la tonalidad mayor, es que herede la reflexividad del Sistema, también lo es que herede su simetría, lo que hace definitiva su categorización como subestructura. Como vamos a ver, de ello depende el origen mismo de los acordes.

Que la unión de esos dos hexacordos es simétrica puede demostrarlo ya directamente el hecho de que puede ser considerada como el resultado de una transformación simétrica llevada a cabo sobre la que también podemos considerar la representación más básica de sus 7 elementos, su representación por quintas. Lo vemos

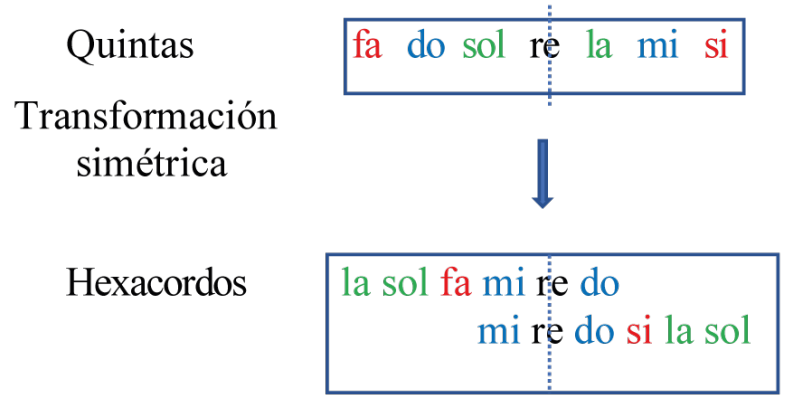

Comprobamos, que la representación por hexacordos, es ciertamente el resultado de una reordenación simétrica de la representación por quintas (o naturalmente ésta de aquella). Sus elementos han cambiado de lugar pero manteniendo su orden interno.

Pero este fragmento especial de elementos que forman parte de la Estructura que hereda sus propiedades fundamentales, y que por ello podemos calificar de Subestructura, tiene ciertamente un número mayor de simetrías. Como hemos anticipado, en una de ellas se originan los acordes. 


\section{EL ORIGEN ESTRUCTURAL DE LOS “ACORDES"}

Demostraremos que ciertamente el origen de los acordes no es puramente físico como se ha tratado sin éxito alguno de explicar, sino fundamentalmente Estructural, como el de las propias tonalidades mayores (Recordamos que la física- los armónicos- que no pueden explicar el tritono, tampoco pudieron explicar el acorde menor. Incluso para superar el problema se pensó en unos "armónicos inferiores" que lo justificaran pero que realmente no existían. Luego simplemente se obvió el problema). De hecho, como vamos a ver los acordes son una de las formas externas que pueden adoptar esos 7 elementos. La extraeremos de su interior paso a paso. Partiremos de su representación por quintas

Quintas

Hexacordos

Unimos los dos hexacordos

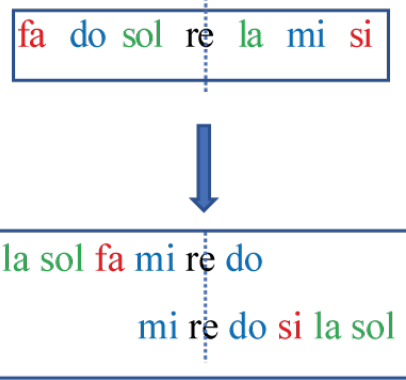

mi re do si la sol

la sol fa mi te do si la sol

Expandimos ahora la representación sacando al exterior la pareja mi-do, intercambiando la disposición de sus elementos:

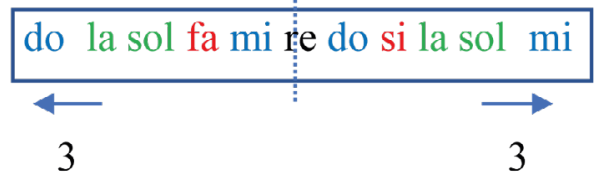

Ninguna de estas acciones afecta al orden interno de esos 7 elementos, ni por supuesto entonces al externo, pues como vemos respecto a este, la expansión ha producido el mismo intervalo en los extremos, una tercera menor (lo indica el 3). Despleguemos ahora por el espacio bidimensional esa representación, pero como siempre de manera que en la transformación siempre se conserve su orden interno. Así: 


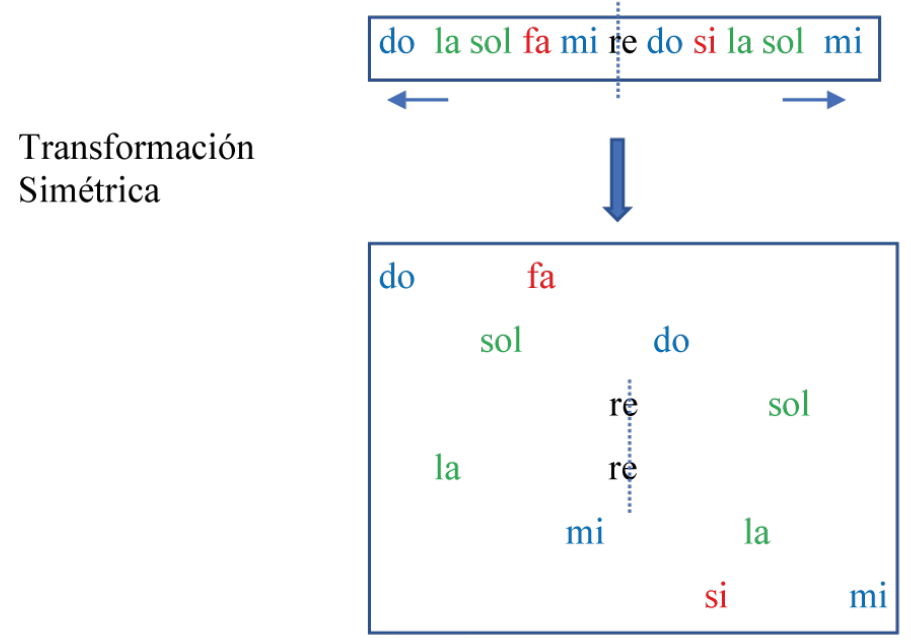

Se trata entonces efectivamente de una nueva transformación simétrica, un nuevo reordenamiento ahora de nuevo en el espacio bidimensional. Se han producido en él 6 líneas con dos elementos en cada una, siempre con la condición de mantener la relación reflexiva de cada pareja, y por tanto su posición, lo que garantiza a su vez la reflexividad de las relaciones producidas, el orden global. Por ejemplo, si la transformación ha situado un do en la línea superior a la izquierda, necesariamente su pareja, el mi, tendrá que estar situado en el lado opuesto (reflexivo), en la línea inferior a la derecha, tal como se encuentran en la representación unidimensional, y así con todos los demás.

Pero incluso podemos descubrir el orden específico y perfecto que la transformación ha seguido para situar los elementos de ese modo particular. Lo indicamos

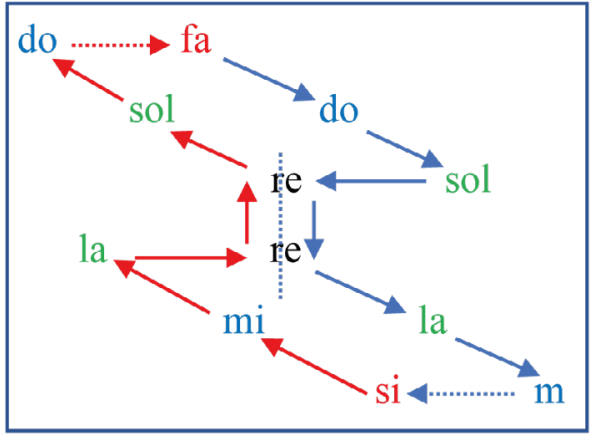

En efecto, podemos decir que esas líneas con sus dos elementos, y la propia distancia que existe entre ellas, se originan a partir de la unión de los dos sentidos opuestos en que podemos leer la representación por quintas de esos 7 elementos, es decir, por quintas y por cuartas (las quintas las indican las flechas azules y las cuartas las rojas). Así

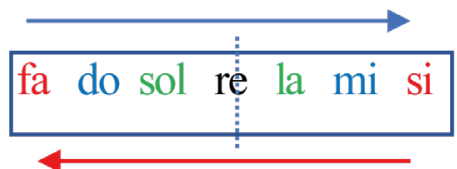


Vemos que, de ese modo, la simetría, de manera natural, no sólo ha situado una quinta en cada línea, sino que también ha situado las líneas en relación de quinta. Esas quintas que la simetría ha formado en cada línea son ya el comienzo del proceso de la formación de los acordes, y las quintas que relacionan localmente las líneas supondrán, como ha sido descrito por las teorías conocidas, la relación más estrecha que puede haber entre esos acordes. Se puede decir que el transcurso por quintas (indicado por las flechas azules) ha originado a la derecha de cada línea lo que describiríamos como las fundamentales de los acordes, y el transcurso por cuartas (indicado por las flechas rojas) a la izquierda de cada línea, lo que van a ser las quintas de esas fundamentales, y así de los acordes que de ese modo están formándose. Por tanto, lo que podemos concluir ya, es que las fundamentales no son el origen de los acordes, como se había dicho ("explicado"), sino que como vemos nacen inseparablemente unidas a las quintas, ambas tienen un origen común, pero también como vamos a ver lo tienen las terceras.

Para comprobarlo, sólo tenemos que dar un paso más en nuestro proceso de transformación simétrica. No olvidemos que todo esto se encuentra en el interior de esos 7 elementos. Lo que hacen las transformaciones simétricas es sacarlo todo al exterior, ponerlo directamente ante nuestra mirada. En efecto, las terceras se forman a partir de la inclusión asimismo totalmente ordenada de esos mismos elementos entre las quintas. Veámoslo

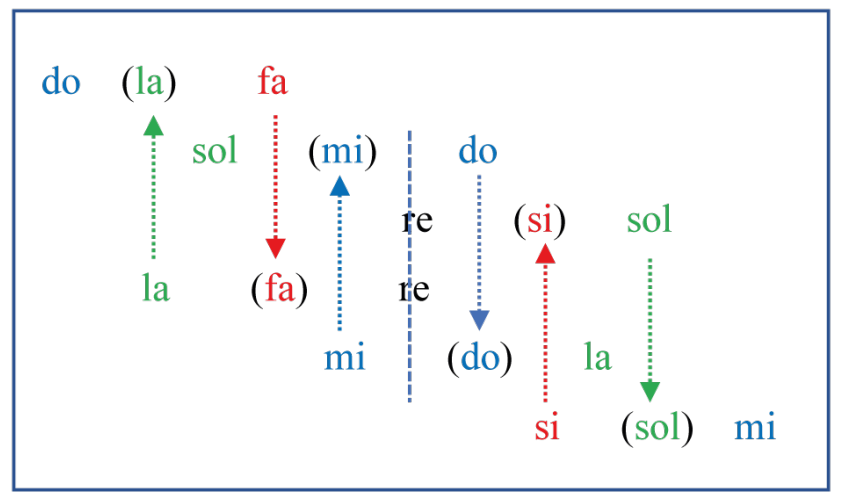

De nuevo, somos testigos del orden absoluto en el que se originan los acordes. Los vemos ya formados en cada línea producto de las inclusiones absolutamente ordenadas de los elementos que ya conformaban las quintas. Las flechas indican la perfecta organización de esas inclusiones (los elementos resultado de la inclusión que forman las terceras, lo ponemos entre paréntesis). En ningún caso, esta nueva transformación destruye el orden interno de esta subestructura, solo cambia su orden externo, su forma externa, una posibilidad que ofrece la simetría, y que en este caso produce los acordes. Ese orden interno, es el mismo que esos 7 elementos demostraban poseer en sus representaciones por quintas y por hexacordos. Podemos decir que en ese proceso esos acordes se constituyen asimismo en una totalidad.

Constituirse en una totalidad, significa como siempre, que el proceso de inclusión en el que se originan es global, cada inclusión depende de todas las demás. Como indican por ejemplo las flechas rojas, significa, que la inclusión del fa-proveniente de la quinta do-faentre la quinta la-re, para formar el acorde la-fa-re, obliga y así posibilita, a que el si, reflejo 
de aquel fa-proveniente de la quinta si-mi (reflejo de do-fa)- se sitúe entre la quinta re-sol (reflejo de la-re), para formar el acorde re-si-sol, reflejo del anterior. Y así todas las demás inclusiones. La visualización del orden en el que todo se lleva a cabo, lo facilita el color de las flechas verde, rojo y azul, que corresponde al color de los elementos de la pareja que se incluye.

Comprobamos efectivamente que el origen de los acordes, como el de las quintas o los tritonos, no es puramente físico, no se encuentra en algo externo a ellos, sino, que una vez que el Sistema llevó a cabo su cerramiento, cumpliendo en ese momento con los principios de los que obtuvo sus propiedades fundamentales, se convierte totalmente en Estructural, entendiendo por ello que su origen se encuentra en el orden interno del Sistema que caracteriza su Estructura. En ese orden, nacen inseparablemente juntas las fundamentales, las quintas y las terceras, todas a la vez, del mismo modo que vimos nacer juntos los semitonos diatónicos, los tritonos y las terceras mayores, para formar la propia tonalidad mayor de cuyo interior vemos ahora emerger a los acordes. Si quitáramos, cambiáramos o añadiéramos un elemento de esa totalidad que forman estos 7 elementos, los elementos que quedaran perderían su cualidad como totalidad, y al desaparecer esa cualidad desaparecerían los acordes, todos a la vez. Por eso entendemos que debía ser 7 el número de elementos que conformaban lo que describimos como tonalidades. Vemos el resultado

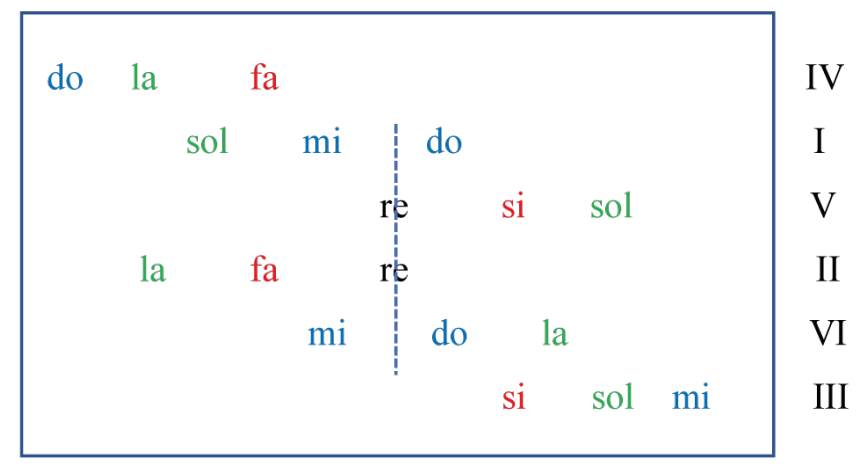

Pero estudiemos algo más lo sucedido, merece la pena, y entre otras cosas veamos de forma más concreta porqué tenían que ser 7 los elementos. Por un lado, vemos que es la simetría la que de foma natural ha producido dos tipos distintos de terceras que ha situado localmente. Por otro, que lo ha hecho, de forma que se conserve absolutamente el orden interno, es decir, que cada una, sea tercera mayor o menor, tenga su reflejo exacto en el lado opuesto, de ahí que se formen acordes que distinguimos como "mayores" $y$ "menores". Por tanto, todo depende de la ubicación en la que la simetría, fiel al orden interno, sitúa a cada tercera. Por ejemplo, la tercera mayor la-fa, que la simetría ha situado a la derecha del acorde do-la-fa, formado ahí en la parte superior, que por la ubicación de esa tercera llamamos Fa mayor, tiene su reflejo exacto en la tercera mayor si-sol formada por los elementos que son pareja reflexiva de los anteriores, y que la simetría ha situado lógicamente ahora en la parte izquierda del acorde si-sol-mi, situado en la parte inferior, reflejo del anterior, que por eso lo calificamos como menor, Mi menor. Y lo mismo con todos los demás. Así, cada acorde 
mayor necesariamente tiene su reflejo en uno menor y viceversa. Esto explica porqué existe el mismo número de acordes mayores y menores. Por tanto su número no es el resultado simple y casual de añadir dos terceras sobre cada uno de esos 7 elementos, que es como ha sido explicada su formación, sino el resultado de una transformación simétrica y por tanto global, de esos 7 elementos, y así de su orden interno; un orden interno que no es simple sino complejo, entendiendo por ello que todos esos acordes están entretejidos conjuntamente en el interior de esta subestructura, lo que es una forma más de decir que esos 7 elementos constituyen una totalidad, o que derivan de un orden en efecto absolutamente global.

Pero cómo vemos, son 6 los acordes formados ahí, falta uno de ellos, el que es distinto a todos, el formado por dos terceras menores, el "acorde del tritono". Saquémoslo a la luz porque también está allí ya formado. Es fácil descubrirlo en el interior de esa totalidad, pues por ser especial se encuentra también en un lugar especial, su centro. Veamos cómo se forma. Lo indicamos en el gráfico

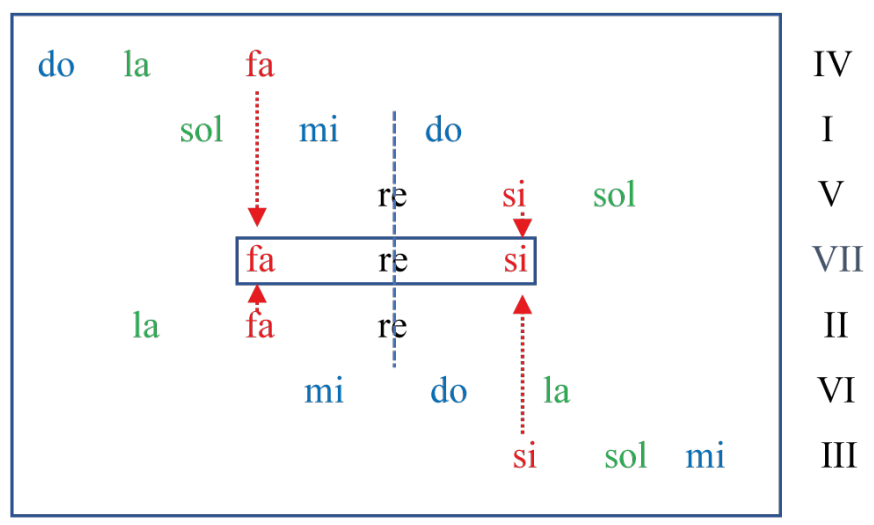

Para ello, la simetría únicamente tiene que situar ahí en el centro los dos elementos que forman el tritono y que para eso la reflexividad los ha hecho pareja reflexiva, el fa y el si. Allí, se podrán relacionar directamente con el re, como si los estuviera ahí esperando para juntos formar efectivamente el acorde fa-re-si. Y efectivamente, entre otras cosas, podemos entender ahora, incluso la necesidad de que el número de elementos que forman esa colección sea impar, 7 elementos, pues sólo eso permite que uno de ellos sea reflejo de sí mismo, como así es, el re. Si no fuera así, particularmente sería imposible formar este acorde, pues dado que dos de los elementos que van a formarlo son ya pareja reflexiva, el fa y el si, tan sólo se necesitaba uno más, uno que no tuviera entonces relación reflexiva con ningún otro, sino consigo mismo. Entendemos también, porqué está formado por dos terceras menores, pues al estar en el centro, ahí una es necesariamente la réplica reflexiva de la otra. Por supuesto, de esos mismos hechos depende la conformación de todos los demás acordes, pues como hemos visto, todos juntos constituyen una totalidad, lo que entraña la dependencia de todo con todo. Como si todo, en efecto, hubiera sido calculado previamente ipero en el propio interior de ese fragmento de 7 elementos que hemos llamado "tonalidad mayor"! que sin duda demuestra por todo ello realmente ser especial. Hasta ahora, podíamos decir que lo era- lo habíamos registrado y por ello visto así en la superficie de la música- pero no sabíamos porqué podía serlo. 
Comprobamos que a partir de ese extraordinario orden en el que se reordenan estos 7 elementos para relacionarse en la forma que hemos descrito como acordes, podemos entender ciertamente muchas situaciones que sólo hemos podido describir pero no explicar, como podemos hacer ahora. Por ejemplo, veamos otra de ellas. ¿Por qué en la superficie de la música hemos visto reunirse esos 7 elementos en la forma que describimos como Do mayor, y no de otro modo?. ¿Por qué si por ejemplo, esos dos elementos que dan origen a ese nombre, el do y el mi, ocupan lugares que realmente no demuestran poseer privilegio alguno en la representación por quintas concebida como serie temporal, la representación que se puede considerar más genuina?.

\section{fa do sol re la mi si}

En efecto, concebida como serie (lo que indica la flecha), el do ocupa el lugar $2 \circ$ y el mi el $6 \circ$. Lugares ciertamente ahí irrelevantes. Sin embargo, otra cosa es, si los concebimos como totalidad. Es decir, como siempre, así:

fa do sol ta mi si

Una vez superada y trascendida la temporalidad, los lugares que ocupan esos elementos ya no son simplemente el $2^{\circ}$ y el $6^{\circ}$, sino dos de los lugares de una totalidad, que la reflexividad relaciona de manera especial, lo que significa que también lo hace con los elementos que los ocupan. Pero ¿por qué esos lugares y por tanto los elementos que los ocupan acaban siendo ahí la referencia para todos los demás?

Ya hemos visto que realmente no existen lugares fijos para los elementos en el interior del Sistema, ni en el Sistema ni en los fragmentos como éste que heredan sus propiedades fundamentales. Los elementos pueden cambiar los lugares que ocupan con tal de que el cambio sea global para todos ellos, y se mantenga entonces el orden interno. Sin embargo, a pesar de que constituir una totalidad significa necesariamente dependencia mutua y así global entre todos los elementos y sus relaciones, vamos a ver que la reflexividad y la simetría ciertamente pueden privilegiar ciertos elementos y ciertas relaciones en las diferentes formas externas que proporcionan a una colección de elementos que como estos 7 se constituyen como totalidad. De esto depende su eficacia. Porque efectivamente, lo que comprobamos en esta última forma externa que ha producido la simetría, es que la pareja formada entre el do y el mi es la única tercera de todas las que se puede formar con esos 7 elementos, cuyos dos elementos son pareja reflexiva, y esta circunstancia que indudablemente privilegia a esa tercera, naturalmente debe ser fundamental en un mundo de terceras como es el de los acordes, es decir, debe tener también ahí su privilegio. Y lo tiene. $Y$ ahora podemos entender porqué lo tiene. $Y$ tiene también que ver directamente con el hecho de que el número de terceras menores sea par (4), e impar el de las mayores (3). Algo que hemos podido describir pero que tampoco hemos podido explicar. Ni nos lo habíamos planteado. Sin embargo, ahora podemos entender cuál es la utilidad real de esa diferencia. Al ser un número par, las 
terceras menores pueden reflejarse por parejas, pero no pueden hacerlo las terceras mayores, al ser su número impar. Y eso hace que haya una tercera mayor que deberá reflejarse a sí misma, lo cual la va a hacer especial. Y esa tercera que es única es también la única cuyos elementos son pareja reflexiva, en efecto de nuevo la formada entre el mi y el do. Pero ¿cuál es realmente la importancia, digamos práctica, de ser reflejo de sí misma?. Para responderlo veamos todo esto de forma mucho más precisa en nuestra representación. Pongámosla de nuevo, ahora con la inclusión del acorde del tritono

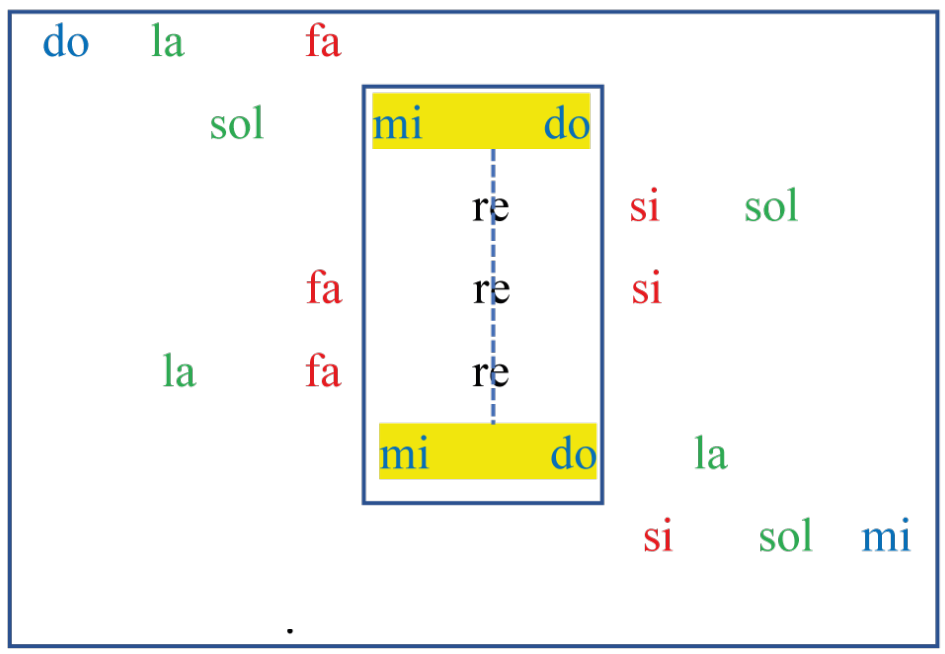

Vemos a esa tercera mi-do (encerrada en el rectángulo, y marcada en amarillo) efectivamente reflejándose a sí misma en el centro de la representación, y ubicada a ambos lados del re, donde justo la ha situado la simetría. Porque la situación para ella es ciertamente muy distinta de la que existe para las otras terceras mayores, si-sol y la-fa, pues si estas que se reflejan la una a la otra ya necesitan dos parejas distintas para formarse si-fa y la-sol, todavía necesitan aún otra pareja más para formar sus acordes, o bien la propia do-mi, o bien la que forma el re consigo mismo. En cambio, la tercera mi-do únicamente necesita otro elemento para formar un acorde, y al reflejarse a sí misma, dos; y como vemos en el gráfico, estos dos elementos se los ofrece específicamente la otra pareja, la formada por el sol y el la. En efecto, ¡como si todo hubiera sido pensado de antemano!. Y esto es extraordinario, porque ese privilegio que demuestra esa tercera, se transmite a los dos acordes que se van a formar en esa unión, los acordes sol-mi-do y su reflejo mi-do-la, es decir los acordes de Do mayor y La menor, el la ofreciéndose como fundamental del acorde de La y reflexivamente el sol como quinta de acorde de Do. Y ese privilegio es importante, porque puede explicar ahora el hecho de que entre los antiguos modos, esos 7 elementos se asociaran asimismo privilegiadamente a dos de ellos, al Jónico y al Eólico, que representados por esos dos acordes iban a acabar representando a la propia Tonalidad, como modo mayor y modo menor respectivamente. Las teorías tonales, ya los habían ubicado juntos, reunidos bajo el 
mismo nombre, "tonalidades relativas". Lo que no sabíamos, es que la razón de poderlos ubicar juntos, es que nacían literalmente juntos, tenían un origen común, y entonces una explicación común, en definitiva una explicación; un origen común que como hemos visto deriva del privilegio que la reflexividad y la simetría otorgan diferenciadamente a algunos de los elementos de la subestructura de la que forman parte. Entendemos que el privilegio que las teorías otorgaron a esos elementos y a esas relaciones, al observar su comportamiento en la superficie de la música, corresponde exactamente al privilegio que esas propiedades fundamentales les otorgan en el interior del Sistema. En el primer caso, somos nosotros los que les otorgamos esos privilegios, en el segundo, es la estructura del Sistema la que lo hace. En el primer caso, estamos ante una descripción de hechos, en el segundo estamos ante la razón por la que entendemos que esos hechos descritos tienen que ser como son y que entonces no podían ser de otro modo, es decir estamos ante su explicación.

El ideal del investigador, es saber no sólo cómo son las cosas, y poder describirlas (que es lo que hemos hecho desde nuestras observaciones sobre la superficie más externa de la música) sino saber porqué son así y no pueden ser de otro modo, es decir poder explicarlas (que es lo que empezamos a poder hacer ahora). ${ }^{5}$

Por supuesto existen muchas otras situaciones descritas por las teorías que podríamos explicar ya solo desde esta representación, pero por limitaciones lógicas de espacio nos encontramos prácticamente al final de nuestro recorrido. Sin embargo, aun para terminar, podemos aproximarnos aunque sea brevemente, desde esa misma representación, incluso a la lógica interna del Sistema por la que el modo Eólico adquiere específicamente su categoría de "tonalidad menor"

Nos va a permitir además ser ahora testigos de otra propiedad más del Sistema: la de permitir en él- y por derivación en estos fragmentos que al heredar sus propiedades fundamentales demuestran ser especiales - la inclusión de nuevos elementos que su cerramiento permitió que también fomaran parte de él, aquellos que aunque habían igualado sus sonidos continuaban siendo distintos, y que por ello se les dio un nombre especial: "enarmónicos", por ejemplo el sol\# y ellab.

En efecto, esa Subestructura, en la que coexisten el Jónico y el Eólico, a partir del privilegio compartido que la reflexividad y la simetría otorgan a sus acordes de tónica, permite la inclusión en ella de esos dos elementos enarmónicos que no solo no afecta al orden interno de esta Subestructura, sino que van a reforzar esa coexistencia, ofreciendo efectivamente el modo específico en que el Sistema permite la representación de esos 7 elementos ya como La menor, y poder seguir representándolos en Do mayor. Vamos a verlo aunque tenga que ser también brevemente. Veamos primero porqué la inclusión de esos elementos es posible. Veámoslo desde su representación por hexacordos

$$
\begin{array}{r}
\text { la sol fa mi re do } \\
\text { mi re do si la sol }
\end{array}
$$

5 Considérese, que el lugar de privilegio en el que la simetría ha situado la relación de esa tercera mi-do con el re, mi-re-do, en el centro de la representación, corresponde al privilegio que Schenker le dio en su Ursatz, como línea fundamental, y así a su origen. No nos podemos extender aquí. 
Lo que se nos permite comprobar de nuevo es la importancia que tiene el hecho de que la reflexividad haya ahí relacionado específicamente el la y el sol (ya anticipamos esta importancia cuando estudiamos esa subestructura). Por ejemplo, ya hemos visto que en el mundo de las terceras (de los acordes) tienen la función esencial de conformar los propios acordes de tónica de La menor y Do mayor. Pero descubrimos ahora algo más de esa pareja de elementos, cuando los vemos ahora en el mundo de las segundas que caracterizan esos dos hexacordos- otra de las formas externas en las que la simetría permite representar estos 7 elementos. Comprobamos, que ciertamente, la reflexividad los ha tratado de una manera especial, pues es ahí la única segunda cuyos elementos son pareja reflexiva, lo que supone que sea también ahí la única pareja que se refleje a sí misma. Por eso la simetría puede situarlos enmarcando esa Subestructura por ambos lados, contribuyendo así a la forma específica de los dos hexacordos. Y es esta circunstancia que privilegia esa segunda, la que permite ahora la inclusión en ella de esos dos elementos enarmónicos, el lab y el sol\#,porque su inclusión no afecta en absoluto el orden interno de la Subestructura. Por ejemplo así:

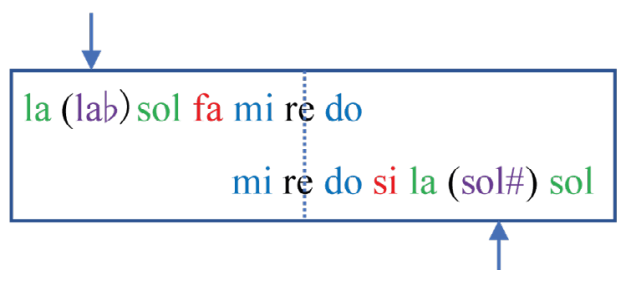

En efecto, en esa doble inclusión, los dos nuevos elementos se comportan como una pareja reflexiva más (de ahí que los hayamos indicado con el mismo color), por ello pueden dividir esas dos segundas mayores reflejo una de la otra, en dos semitonos, uno diatónico y el otro cromático, que seguirán reflejándose mutuamente, el diatónico con el diatónico y el cromático con el cromátivo, lo que ciertamente mantiene el orden interno de la Subestructura. Se trata de una forma de tranformación simétrica más que hace posible la simetría del Sistema.

Pero el orden interno de la Subestructura, no sólo permite incluirlos sino sustituirlos reflexiva y globalmente.

Hagámoslo ya directamente sobre la representación por acordes, y veamos lo que ocurre.

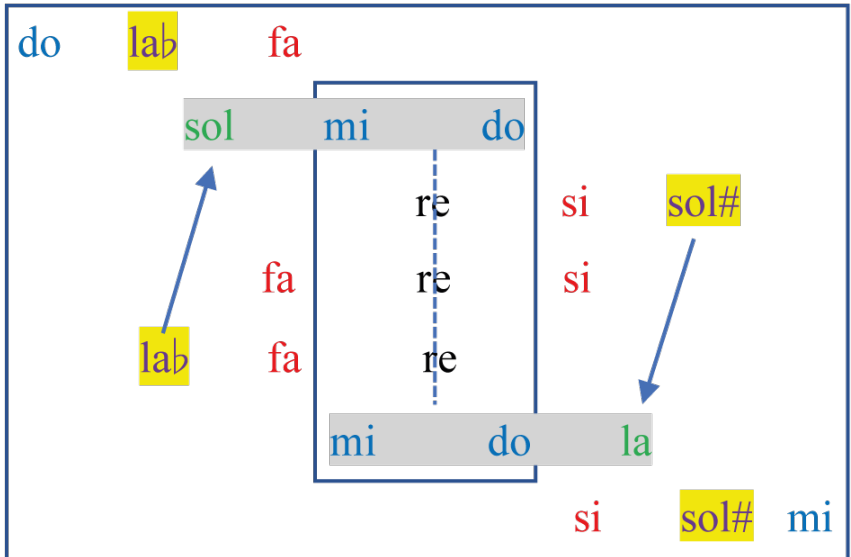


Vemos que la sustitución del la por el lab, en la línea superior y en la tercera línea por abajo, obliga a que en los lugares opuestos, línea inferior y tercera línea por arriba, cambiemos correspondientemente el sol por el sol\# (marcados todos en amarillo). Solo así se mantiene absolutamente el orden interno de la representación. En términos tonales, el cambio de la por lab supone un cambio en el Jónico, que representará Do mayor, y el del sol por el sol\# un cambio en el Eólico, que ahora de manera efectiva se convertirá en La menor. Así mientras el lab, produce en términos tonales la subdominante menor en el Jónico, do-lab-fa, el sol\# en el lugar reflejo convierte el acorde si-sol-mi que la simetría ha situado en la parte inferior, ya en términos tonales, en la dominante mayor del Eólico si-sol\#-mi, convirtiéndolo efectivamente en La menor. Pero se han producido más cambios en el interior de esta subestructura. Por ejemplo, en los tres acordes del centro, los dos situados en la parte superior de esos tres, formarían, leído de izquierda a derecha, el acorde fa-re-si-sol\#, en términos tonales, el acorde de 7’a disminuida de La menor, y los otros dos, que los reflejarían absolutamente, los situados en la parte inferior, formarían el acorde lab-fa-re-si, un acorde de $7^{\mathfrak{a}}$ disminuida, que sería ahora el resultado de la sensibilización del 6 hacia el 5 del Jónico (ahora Do mayor), labsol, correspondiendo entonces a la sensibilización del $7^{\circ}$ al $1^{\circ}$ en el Eólico (ahora La menor), sol\#-la. Una evidencia más del nacimiento común de las "tonalidades relativas" en el interior de una única subestructura. Las flechas en direcciones opuestas, vuelven a mostrarnos que la reflexividad no sólo alcanza a los elementos y a las relaciones sino al modo en que estas se van a representar como movimiento en el tiempo, la de la derecha llevando precisamente el nuevo elemento, el sol\# al viejo elemento la, la llamada fundamental del acorde de La menor mi-do-la (relación \#7-1), y la de la izquierda, reflexivamente, el otro elemento nuevo, el lab, al otro elemento viejo, el sol, la 5a del acorde sol-mi-do de Do mayor (relación b6-5), el reflejo del de La menor. Comprobamos la correspondencia total de dos hechos en los que participa esa pareja que forman el la y el sol. Primero, contribuyen a formar diferenciadamente los acordes de tónica que serán la referencia para las tonalidades que coexisten en la Subestructura de la que forman parte, y al mismo tiempo su relación especial permite la inclusión o sustitución de los elementos que precisamente contribuyen esencialmente a la formación de esas tonalidades que tendrán como referencia esas tónicas.

Por tanto, también es en el orden interno del Sistema en el que tiene su origen la tonalidad menor. Vemos ahí efectivamente cómo las llamadas "tonalidades relativas", nacen inseparablemente juntas compartiendo el mismo origen, el mismo orden interno, complementándose reflexivamente, coexistiendo en principio para ofrecer luego desde esa coexistencia, la posibilidad de decidir por uno u otro cuando vayan a representarse como música.

Respecto al origen común de la tonalidad mayor y la tonalidad menor, y de su coexistencia en el interior del Sistema, debemos decir que existen otras diferentes y extraordinarias simetrías del Sistema que la demuestran de manera particular, y que por razones de espacio no podemos mostrar aquí. Emergen directamente del interior de la Estructura como hemos visto que lo hacen las tonalidades mayores. Realmente en este viaje sólo hemos podido acceder a una parte de su extraordinario orden interno, una parte del interior del Sistema que realmente es mucho más extenso. Ni siquiera hemos podido profundizar en los lugares visitados. Pero aún así creemos que todo lo experimentado aquí, puede ser suficiente para comprender que lo importante de este breve viaje, no sólo es haber visitado el interior del 
Sistema, sino fundamentalmente ya como teóricos y analistas, empezar a comprobar que ese mundo insospechado de relaciones que ya aquí hemos podido ver que lo pueblan, pueden explicar situaciones que han sido observadas y registradas en la superficie de las obras musicales que hasta ahora, desde nuestras perspectivas teóricas tan sólo habian podido ser descritas. En efecto, lo que se ha dado por explicaciones, realmente eran descripciones de hechos. Sin darnos cuenta estábamos confundiendo describir con explicar, sin pensar que son dos acciones que tienen que ver con niveles teóricos y epistemológicos totalmente diferentes, que requieren niveles distintos de observación. Pero esa confusión no atañe únicamente a aquello de carácter más general, que hemos ido encontrando en nuestro viaje, como pueden ser los conceptos fundamentales, entre los que pueden incluirse esas llamadas "tonalidades relativas", incluso algunos de los comportamientos básicos de los elementos que constituyen esos conceptos fundamentales (como el tritono resolviendo en la tercera mayor), sino también a aquellos acontecimientos musicales que desde el análisis precisamente basado en esos conceptos y en esos comportamientos básicos, pueden ser registrados y descritos de manera particular en una obra musical específica.

Y demostrar esto último, va a ser el objetivo de esta segunda parte.

\section{SEGUNDA PARTE}

\section{UN VIAJE AL INTERIOR MÁS PROFUNDO DE UNA OBRA MUSICAL}

Ya dijimos desde el principio, que acceder al interior del Sistema fue solo posible a partir del acceso al interior de las obras musicales. De otro modo, ciertamente hubiera sido imposible. Desde cualquier otro lugar, ni siquiera desde aquel al que Schenker pudo acceder, no hubiéramos podido ni imaginar la posibilidad de su existencia. Alcanzado ese interior más profundo, desde donde somos proyectados al interior del propio Sistema, de lo primero que se es consciente, es de que las situaciones particulares registradas en la superficie de cada obra musical, e incluso las referidas a ese nivel algo más profundo en el que nos situó Schenker, son ciertamente también descripciones de hechos, pero no explicaciones (apariencias como decía Einstein). Comprobamos ahí, que como en el caso del Sistema, también en la música que se había sustentado en él, la explicación se encuentra en un nivel todavía más profundo. A esa profundidad, puede observarse cómo efectivamente la Estructura interna del Sistema se materializa en la forma de la Estructura interna específica y particular de cada obra musical, y esto es fundamentalmente posible debido al gran número de formas externas que aquella puede adoptar, una capacidad extraordinaria que posee, de la que aquí hemos tenido ya suficientes pruebas, y de la que vamos a tener algunas más. De ese modo, el orden interno del Sistema, puede transferirse a la obra musical, para que aparezcan en ella conectados globalmente- y entonces sí explicados- todos esos hechos que han sido registrados y descritos de manera particular desde la superficie de una obra musical concreta. Es obvio 
que la palabra clave es ahí "globalmente". Y eso significa, que si Schenker se dio cuenta de aquella desconexión y ya consiguió de alguna manera conectarlos, como vamos a ver, no lo consiguió del todo, pues esa relación global quedaba allí todavía fuera de su alcance, aunque como volvemos a subrayar, el paso que dio fue decisivo para lograrlo.

Necesitamos entonces una obra analizada por Schenker.

Hemos elegido seguramente una de las que han sido más utilizadas para ejemplificar esa visión absolutamente distinta de Schenker sobre la música, el Primer Preludio del Clave Bien Temperado, una de las grandes obras de Bach. Además, es perfecta para nuestro objetivo, pues Bach elige para construir su Preludio, 12 elementos relacionados por quintas, 12 elementos que por sí mismos pueden representar el Sistema, que son exactamente los mismos que nosotros elegimos para introducirnos en su interior.

$$
\text { lab mib sib fa do sol re la mi si fa\# do\# }
$$

Ya vimos una parte de lo que había en el interior de esos 12 elementos, en su Estructura interna, ahora tenemos que ver que en ese interior, en esa Estructura, también estaba el Preludio. Eso significa, que ciertamente en algún lugar profundo de la obra, su interior está directamente conectado con el del propio Sistema. Tenemos que ver cómo eso es posible, y entonces, cómo el orden interno de la Estructura del Sistema y la propia globalidad que la identifica se transfiere a la obra, a sus relaciones, lo que en términos de explicación, significa poder comprobar efectivamente cómo los propios hechos desvelados por Schenker cambian también ahí su estatus epistemológico, pues de ser considerados explicaciones respecto de los registrados directamente en la superficie de la música, al ser ellos mismos ahora explicados, se convierten también en descripciones, apariencias en palabras de Einstein, aunque naturalmente de una categoría epistemológica muy diferente de la de aquellas que estas últimas habían convertido asimismo en apariencias, y que eran directamente visibles desde la superficie más externa de la música.

Si hemos dicho que el Preludio ya estaba en el interior de esos 12 elementos, solo había que saber extraerlo de ahí, y eso podía hacerse realizando para ello las elecciones apropiadas. Y Bach demuestra saber hacerlo.

Podríamos incluso pensar, que tratándose del Primer Preludio de su gran obra el "Clave Bien Temperado", un homenaje al Sistema mediante el que Bach quería demostrar sus capacidades constructivas, era lógica la elección de justamente 12 elementos que por sí mismos ya desde su primera obra podían representarlo, pues iba a ser perfecto para empezar ya a demostrar desde ese Primer Preludio esas capacidades. Pero lo que no sabíamos, es que, aunque la información sobre cuáles eran esas verdaderas capacidades y de donde las obtenía el Sistema estaba en la superficie de la obra, no podía extraerse directamente de ella, ahí estaba únicamente el resultado, pero no el origen de esas capacidades. Para acceder a él, ciertamente había que llegar incluso a un lugar todavía más profundo del que llegó Schenker.

Por razones de espacio, vamos a fijarnos básicamente en los 19 primeros compases. Hay suficiente información allí, para conseguir llegar más adentro de lo que llegó Schenker, y encontrarnos ya ahí con el interior del Sistema y con el de la propia obra. Ponemos el gráfico del propio Schenker. Cualquiera puede acceder a la partitura de la obra. 

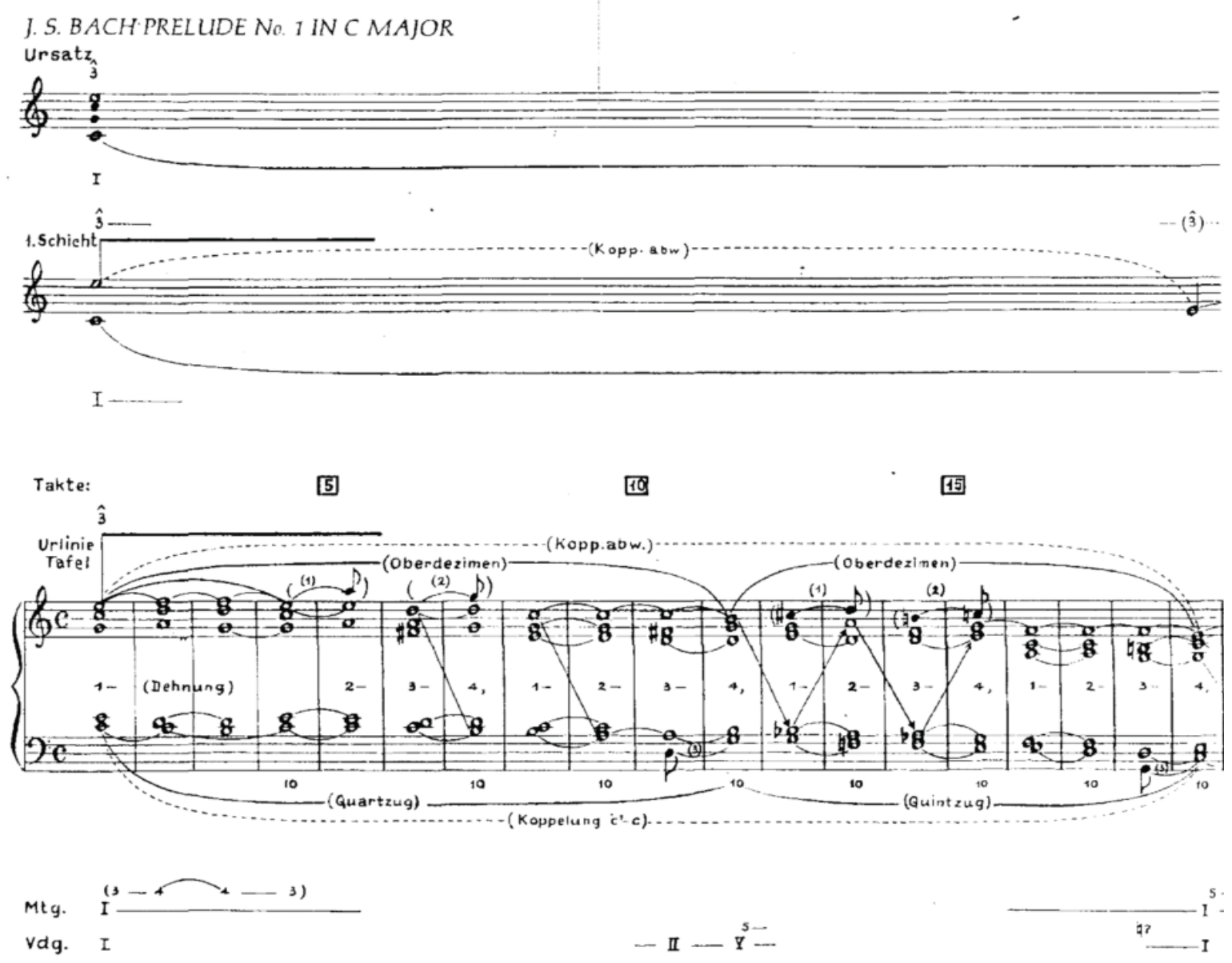

Elegimos esos 19 compases, porque además de haber suficiente información en ellos para acceder más adentro de lo que ya llegó Schenker, desde el lugar en el que él nos sitúa, podemos hacer ya afirmaciones de un calado teórico mucho más profundo que el de cualquiera de las que habían podido hacerse hasta él, incluso después de él; por ejemplo, que juntos, todos esos compases constituyen una unidad. Y la afirmación es más profunda, porque ciertamente se trata de una "unidad" con un significado absolutamente nuevo, pues como él nos desvela, y no sabíamos, hay algo ahí que integra todos los acontecimientos que suceden en esos compases; un hecho que se diferencia claramente del resto, al unir y efectivamente unificar todos los demás: la prolongación de la primera nota de la línea fundamental, el mi- una línea fundamental que como Schenker nos desvelará en su gráfico, la forman el mi, el re y el do- una prolongación descrita como "cambio de registro", que es la que Schenker nos descubre en el nivel medio de su gráfico. Pero lo que nos interesa ahora, es lo que en particular sucede en ese transcurso, que son esos distintos acontecimientos que además del cambio de registro, Schenker pone diferenciadamente ante nuestra mirada en la parte inferior del gráfico, que son los diferenciados por Bach en su Preludio, y que son ya los que fundamentalmente contribuyen a dar su forma a la superficie del Preludio, su forma más externa. Los señalamos: Primero, los cuatro primeros compases, distinguidos claramente del resto, y que Bach sitúa justo antes de que se inicie realmente el movimiento que va a llevar a cabo el cambio de registro, lo que efectivamente va a suceder a partir del 
c.5. Luego, además del cambio de registro, Schenker señala las décimas que justo desde ese momento, lo acompañan nota a nota, pero también los saltos consonantes en los c. 5 y 6 que tienen como referencia el la y el sol, acontecimientos que podemos considerar efectivamente como singulares, puesto que Bach de forma clara y de manera diferenciada sitúa ahí sobre la voz superior que conduce el cambio de registro, rompiendo excepcionalmente la regularidad en la que se han movido y se van a mover luego las voces. ¿Por qué hace eso? ¿por qué dos elementos, y además el la y el sol? ¿una simple ocurrencia? (esta pregunta en sí misma sería impensable, no solo de responder sino incluso de hacer, desde cualquiera de las teorías conocidas, incluida la de Schenker. Intentaremos responderla); luego, más adelante, compases 13 y 15, una nueva irregularidad, situando ahora de nuevo por encima de la voz superior que conduce el cambio de registro, otros dos acontecimientos también claramente diferenciados, que tienen como referencia ahora a los elementos re y do, señalados ahí por sus sensibles respectivas, el do\# y el si, una irregularidad que coincide ahí con otros hechos asimismo claramente diferenciados en su gráfico, y que señalan las flechas: los que ahora conforman el movimiento cromático, si-sib -la-lab-sol, que en ese mismo momento se produce en el interior de la voz que lleva a cabo el cambio de registro, ahora moviéndose por la parte interna de las voces, y que tiene que ver con la intervención ahí, de dos acordes también diferenciados del resto, dos acordes de 7a disminuida, que tonalmente se remitirán a Re menor y a Do mayor, acordes en los que en los mismos términos tonales, se diría que resuelven.

Es evidente, que Schenker se había dado cuenta, de que si lo único que conectaba los acontecimientos musicales registrados en la superficie de la música por los teóricos tradicionales era la temporalidad en la que aparecían, dejando por tanto su conexión en manos de sus relaciones puramente locales, eso era muy poco para que una obra musical adquiriese a partir de ello su categoría como tal. Tenía que haber algo más, algo diferente de la pura temporalidad, otra cosa, y además tenía que ser de naturaleza propiamente musical, algo distinto que vinculara (uniera) todos aquellos acontecimientos en otra dimensión, y lo encontró. Como sabemos, y nos muestra su gráfico, consiguió ver que algunos de los elementos se relacionaban diferenciadamente en la distancia, de manera ya no local sino no-local, más en el espacio que en el tiempo, conformando así un acontecimiento muy diferenciado de los demás que podían integrar a los otros elementos y a los demás acontecimientos en los que ellos participaban, de modo que ciertamente podía conectarlos en otra dimensión que ya no era la pura temporalidad. Por eso, y de manera general, a aquellos elementos y al acontecimiento que conformaban, lo ubicó en el nivel de participación jerárquicamente más elevado, y por ello lo llamó "estructura fundamental", y los otros, conectados a ella, justificados o desde su perspectiva incluso explicados por ella, los situó en diferentes niveles jerárquicamente más bajos que llamó de "prolongación", porque su función era mantener (prolongar) por un tiempo el control organizativo y constructivo de los que pertenecían a los niveles más elevados, aunque estos no estuvieran materialmente presentes, y hasta que ese control pasara a otro elemento perteneciente a ese nivel jerárquico más elevado que constituía la línea fundamental. Pero tenemos que decir ya, que ahí la conexión no era total. Las prolongaciones, realmente quedaban así separadas unas de las otras. En efecto, la descripción 
de cualquier prolongación era totalmente independiente de la de todas las demás. Una vez descrita una prolongación, por ejemplo la de un elemento de la línea fundamental, la forma que adquiriera ya no contaba para la descripción de las otras que se llevaban a cabo sobre los otros elementos, pues para ellas la forma podría ser cualquiera. No importaba cómo fueran las prolongaciones, con tal de que pudieran describirse, darles un nombre dentro de la teoría, algo que ciertamente podía hacerse de manera totalmente independiente unas de otras. Se abría pues, la posibilidad para pensar que pudiera existir algo, totalmente desconocido, que ahora por ejemplo no solo conectase individualmente un elemento cualquiera a uno de los pertenecientes a la línea fundamental, en la forma de una prolongación, sino ahora colectivamente a las propias prolongaciones de todos esos elementos entre sí, incluso ese algo, podría permitir responder a la pregunta sobre la razón por la que la prolongación de cualquier elemento estructural particular (como ese cambio de registro del $\mathrm{mi}$ ), o de alguno perteneciente a un nivel de prolongación elevado, adoptaba su forma concreta (como el movimiento cromático en el interior del cambio de registro). Supondría, entender la razón, por la que una prolongación era como podía describirse que era, es decir, se nos permitiría no solo describirla sino también explicarla, lo que exigía poder hacer lo mismo con todas las demás, tratarla desde su dependencia respecto a ellas, y no solo ya desde su independencia. Significaba, que la posible relación de conocimiento que queríamos establecer con la obra musical, a través de hacerlo con las prolongaciones, no terminaba necesariamente en el momento en que conseguíamos darles individualmente a cada una un nombre, como podría creerse. Había todavía más posibilidades para hacer más profunda esa relación. Pero efectivamente veamos todo eso en el Preludio.

Empecemos preguntándonos ¿Hay algo que no conozcamos todavía, que conecte por ejemplo los 4 primeros compases, diferenciados por Bach y así por el propio Schenker en su gráfico, con el cambio de registro del primer elemento estructural, el mi, cuyo inicio realmente se produce en el c.5, incluso con las décimas que lo acompañan paso a paso, desde ese compás, más allá de la pura temporalidad?. Esos tres acontecimientos: los 4 primeros compases, el cambio de registro y las décimas, pueden ser descritos independientemente unos de otros. Los 4 primeros compases podrían ser distintos, y de serlo no vemos qué vínculo se rompería con respecto al cambio de registro, pues si fueran diferentes, eso no tendría porqué afectar al cambio de registro, pues perfectamente podría ser el mismo, y lo mismo respecto a las décimas, podían estar o no acompañando al cambio de registro, dado que el hecho de que no estuvieran tampoco afectaría necesariamente a la presencia de este último. Entonces ¿hay algo ahí qué liga a todos ellos, es decir globalmente? o por ejemplo, ¿qué vincula efectivamente ese movimiento cromático que se produce en el interior del cambio de registro, señalado específicamente con la flechas en su gráfico, prolongándolo, con el propio cambio de registro, es decir, por qué esa prolongación en el interior del cambio de registro y justamente allí?. Lo hemos dicho ya en distintas ocasiones a lo largo de este texto, una cosa es describir el hecho, decir que está ahí e incluso darle un nombre, y otra explicar las razones del hecho, de su estar ahí. Schenker nos da su descripción, pero no su explicación. Pero es precisamente por eso, por lo que su teoría nos permite dar ese nuevo salto epistémico y epistemológico, pues lo que fue una explicación en su teoría, al ser explicado en otro plano epistémico y epistemológico, se convierte en descripción. Su descripción es ciertamente 
una explicación que convierte en descripciones las explicaciones ofrecidas por la teoría tradicional, pero su teoría no puede responder sobre las preguntas que tienen ahora como objeto sus propias explicaciones, pues las respuestas a las preguntas que pueden realizarse sobre ellas, no pueden responderse en el mismo nivel desde el que se hacen las preguntas, en el nivel de esas explicaciones, pues ciertamente requieren otro nivel de observación en el que puedan ser respondidas, y así ellas mismas explicadas, que es lo que ciertamente ahora las convertirá también a ellas en descripciones (apariencias en palabras de Einstein). Podemos verlo, por ejemplo, respecto de las razones de ese movimiento cromático. A la pregunta sobre su presencia allí justo en ese momento, habría dos respuestas posibles. Una, la que efectivamente podría dar la teoría tradicional. Diría que a ese movimiento lo explica la intervención de dos acordes especiales que ahí utiliza Bach, dos acordes de $7^{\mathfrak{a}}$ disminuida asociados a sus propios acordes de tónica, aquí Re menor y Do mayor, pues según esta teoría ese movimiento sería simplemente la consecuencia del puro enlace de esos acordes. La otra, busca ya la explicación en la conexión de diferentes acontecimientos que naturalmente primero hay que diferenciar, y la da Schenker. Nos diría, que a ese movimiento cromático, lo explica un acontecimiento, desconocido hasta él, que se está llevando a cabo en un nivel de participación jerárquicamente superior, que en este caso es la prolongación de la primera nota estructural, el mi. En concreto, la presencia de ese movimiento cromático lo hace posible el hecho de que justamente allí, la prolongación que paso a paso, nota a nota, lleva al mi al registro inferior, ha llegado a los elementos si, la y sol, y es eso lo que permite justamente allí llevar a cabo una prolongación de esa prolongación, al hacer posible incluir entre ellos el sib y el lab. La primera consecuencia es de orden epistemológico, pues a partir de la presencia de ese acontecimiento de nivel jerárquico superior, que justifica la presencia de esos elementos, se invierte la relación entre lo que explica y lo explicado, pues ahora, no serían los acordes los que explicaran la presencia de esos elementos, como establecería la teoría tradicional, sino estos la de aquellos. Sin la presencia ahí de esos elementos, justificada a su vez por la del cambio de registro, no puede haber ahí ningún acorde del que esos elementos necesariamente formen parte. Pero nada de esto explica la prolongación como tal, como prolongación de otra prolongación, solo dice que está ahí, solo la describe, pues también podría no estar y no afectaría en nada al cambio de registro, dejando por tanto abierta la posibilidad de una nueva pregunta, efectivamente ¿por qué esa prolongación y justamente allí?. Dicho de otro modo ¿existe alguna relación que desconozcamos entre el cambio de registro y la inclusión en él del movimiento cromático, que haga lógico, o incluso necesario, el uso por parte de Bach justamente ahí esos acordes de $7^{a}$ disminuida y sus respectivas resoluciones, más allá de la pura constatación de que se está produciendo ese hecho, de su descripción, la del cromatismo en el interior del cambio de registro, incluso la de los acordes implicados en ese movimiento?. Así, además de ponernos ante otro nivel de explicación, vemos de nuevo, que lo que hace Schenker, es ponernos ante la posibilidad de dar un paso más en nuestro intento de establecer esa relación de conocimiento lo más profunda posible con el Preludio, y con el propio Bach, y efectivamente situarnos así incluso aun en otro nivel de explicación, un nivel en el que poder explicar ahora su propia explicación, lo que a su vez deberá situarnos en un plano epistemológico también totalmente nuevo. Nos permite así, hacernos preguntas sobre acontecimientos que podemos decir ya que contribuyen a la 
unidad del Preludio, y que solo Schenker ha sido capaz de desvelarnos, pero para considerar ahora que esa unidad, que como señalamos, desde su visión teórica, ya era distinta de cualquier otra concebida desde cualquier otra teoría, todavía se produce en un lugar más profundo, o en otra dimensión relacional, aquella que hemos asociado a la globalidad- en la que se integraría el nivel de lo explicado (aquí por ejemplo, el correspondiente al movimiento cromático) con el de su explicación (aquí, el correspondiente a la llegada del cambio de registro a los elementos que lo hacen posible, si, la y sol)- lo que supone que se trata de un tipo de unidad todavía más diferente, la que en la primera parte de nuestro trabajo, hemos diferenciado con un nombre específico, totalidad.

Lo que ya hemos sabido desde allí, es que los elementos como tales, como componentes del Sistema, se relacionan en esa dimensión global, constituyéndose ellos sí como una totalidad. Bach lo "sabe", su mente creativa lo sabe, de ahí la elección de esos 12 elementos para su primera obra. Bach, de alguna manera, por supuesto no-consciente, ha conseguido conectar con el interior del Sistema, le sirve para ello su mente creativa, y entonces, también "sabe" desde ella, que ese interior tiene propiedades realmente especiales que le permiten transferir al Preludio esa cualidad especial que al Sistema lo diferencia como tal, su totalidad (si es así, nosotros estaríamos conectando no solo con el lugar más profundo del Preludio, desde donde su superficie adquiere su forma específica, sino de alguna manera con la propia mente de Bach). Efectivamente solo tenía que elegir un fragmento del Sistema que pudiera representarlo como tal, 12 de sus elementos relacionados por quintas, acceder a su interior y realizar en él las elecciones adecuadas, extraerlas de su Estructura para transferir al Preludio su orden interno.

Así, lo que vamos a hacer, es comprobar cómo efectivamente todos esos acontecimientos destacados por Schenker en su gráfico, primero por Bach en su Preludio, están todos efectivamente conectados en otro ámbito relacional, el propio de la globalidad, que es el propio de la Estructura del Sistema.

Decía Einstein:

"Es un sentimiento maravilloso descubrir las características unificadoras de fenómenos que parecen totalmente desconectados en la experiencia directa de los sentidos"

Algo parecido nos señalaba William Laurence Bragg (premio novel de Física, 1915) "The Atom" en The history of Science" (Londres, 1948):

"La "filosofía natural"... no consiste en el descubrimiento de hechos, sino en descubrir nuevas formas de pensar acerca de ellos. La prueba a la que sometemos estas ideas es esta:¿nos permiten ensamblar unos hechos con otros?"

Conectar fenómenos desconectados, incluso no habiendo sido conscientes durante mucho tiempo de esa desconexión, o ensamblar hechos descubriendo nuevas formas de pensar acerca de ellos, eso es lo que vamos a tratar hacer. Lo hemos hecho con el Sistema, vamos a tratar de hacerlo ahora con una obra musical

Someteremos pues nuestras ideas a la prueba de Bragg, para comprobar si nos permiten 
ensamblar unos hechos con otros. Deberemos ser muy sintéticos. Pongamos la Estructura interna de esos 12 elementos en su forma de hexacordos que ya conocemos.

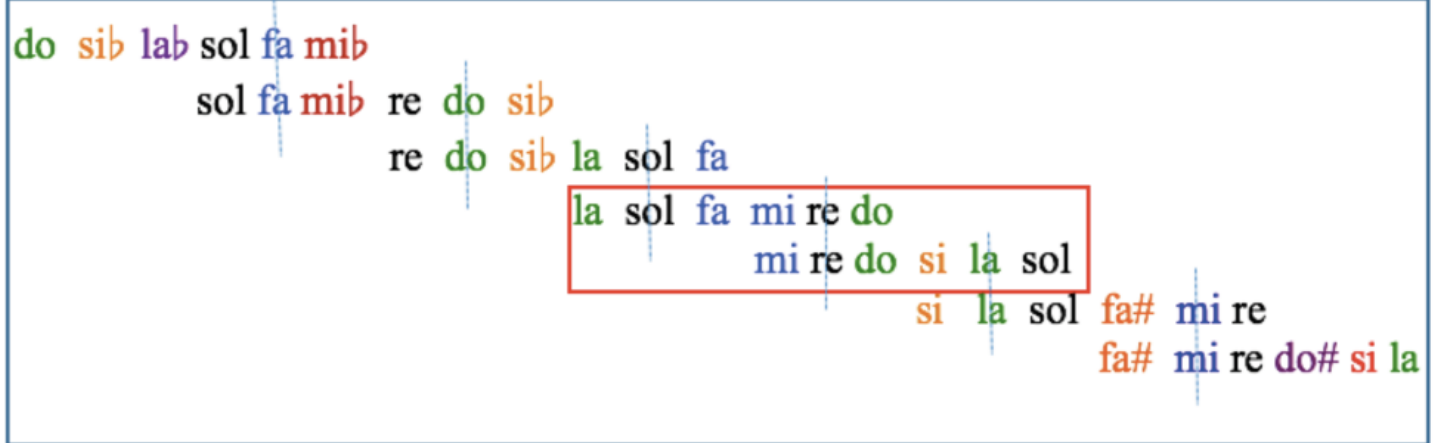

Vamos a ver cómo efectivamente Bach obtiene de ella, de su orden interno, todos esos acontecimientos que Schenker pone directamente ante nuestra mirada. Paso a paso, Bach va a representar en su Preludio esta Estructura, o lo que es lo mismo, como hemos dicho, va a extraerlo de ella. Veamos primero dónde empieza, es decir, de dónde Bach obtiene de ella los 4 primeros compases. Para eso solo tiene que tomar un fragmento particular, el marcado por el triángulo interior. Y es particular, porque es la subestructura que corresponde a lo que llamamos Do mayor, formada por el hexacordo central y el que la simetría ha situado justo por debajo. Una subestructura como sabemos dotada de su propio orden interno. Recordemos, que esa misma subestructura, nos sirvió para descubrir que los acordes se originaban en ese orden interno. Pero ¿qué hay en el Preludio, o en concreto ahora en esos 4 primeros compases que nos lleve a afirmar que también su origen se encuentra en esa subestructura?. Fijémonos en el gráfico de Schenker, en el nivel más cercano a la superficie, donde reduce a su forma vertical, todos los acordes que en el Preludio, según lo que podría ser su propia descripción, realmente se presentan en la forma de una melodía polifónica o melodía compuesta, o arpegiados, en términos puramente tonales. En esa reducción, Schenker diferencia claramente esos 4 primeros compases, indicando en la parte inferior de su gráfico que los 4 acordes que los forman constituyen una progresión armónica cuya función, según su indicación, es la prolongación del l, el acorde de la tónica. Y todo, antes de que se inicie la prolongación de la primera nota estructural, el mi, por cambio de registro, justamente en el c.5. Un teórico tradicional, diría simplemente que la función de esa progresión es la de establecer desde el principio la tonalidad principal, y que esa era la intención de Bach. Pero quizás tenga otras intenciones. Porque hay algo más que en esa reducción Schenker pone ante nuestra mirada, y que puede llamar nuestra atención, algo que él en cambio no considera, ni por supuesto consideraría ningún teórico tradicional ("la información sobre la explicación de los hechos investigados se encuentra siempre en los detalles" le decía Holmes a Watson). Y es que esos 4 compases están formados exactamente por 5 voces, y que además casualmente tienen todas algo en común, la misma forma, la que nosotros describiríamos como "bordadura"; o quizás, en efecto, no sea todo eso tan casual. Ciertamente, es un hecho que podíamos no darle importancia alguna, pero ciertamente puede tenerla. Schenker no se la dio. Para él fue algo que realmente pasó totalmente desapercibido. No hay nada en su gráfico que haga 
pensar otra cosa. Al contrario, la prueba de que no se fijó en ese hecho, es que la única indicación sobre esas voces figura en la parte inferior de su gráfico, donde señala únicamente la relación que se produce en una de ellas, la voz superior, la que se forma entre el 3으 y el 4으, aquí el mi y el fa, y que indica como 3-4-3, pero no hay referencia alguna sobre las otras. De hecho, ni siquiera considera que lo que se ha producido allí, según su propia teoría, es una primera prolongación del $\mathrm{mi}$, a través de ese fa, efectivamente una bordadura, por cuanto en la parte media de su gráfico, expresa claramente que el cambio de registro ya empieza en el primer mi. Sin embargo, el transcurso que lleva el mi al registro inferior en el c.19, realmente empieza en el quinto compás, justo después de esos 4 primeros.

Pero, sin embargo, el efecto que puede tener para nosotros llevar nuestra atención sobre el número de voces, 5 , y el hecho de que todas presenten la misma forma, incluso puede ser doble. Puede primero llevarnos a pensar, que seguramente nada ahí es fruto de la casualidad, y que por alguna razón que en este momento desconocemos, Bach quería vincular las 5 voces. Porque si la única referencia para nuestra atención es la progresión tonal, lo que estamos dando por hecho, aunque no seamos conscientes de ello, es que esa forma especial que adquieren las 5 voces es solo el resultado casual del enlace de esos 4 acordes. Pero efectivamente pensar que no hay nada casual y que por alguna razón Bach quería vincularlas a todas, no es el único efecto, porque incluso podíamos pensar que si existe ese vínculo que las relaciona necesaria y globalmente a las 5, ese vínculo no es la bordadura, sino que la bordadura es únicamente el resultado del vínculo, es decir, que esa bordadura común que las relaciona a todas, tan solo es la información de la existencia de un vínculo que ya no son ellas, sino algo distinto, que no se encuentra ahí directamente a la vista, que de alguna manera está en esas bordaduras pero que efectivamente no son ellas, seguramente una especie de orden que como diría Einstein también aquí estaría oculto detrás de las apariencias que serían aquí las propias bordaduras, una especie de orden que de manera ciertamente global, hace depender cada una de esas voces de todas las demás, una dimensión global que trasciende la propia progresión en las que podríamos justificarlas. Trascenderla, significaría ya que la progresión sería el resultado de esa globalidad y no al contrario (ya vimos que los propios acordes tenían su origen en la globalidad que caracteriza la estructura interna del Sistema y en particular a cada una de las subestructuras, que como la formada por estos 7 elementos, forman parte de ella. Globalidad que entonces pertenece a los elementos, y en todo caso, solo a partir de ellos, indirectamente a los acordes y a la progresión que como este caso algunos constituyen). Por otro lado, ese orden oculto, permitiría, que además de experimentar ese sentimiento de globalidad que para nosotros puede derivar directamente de la apreciación de esa única forma de representarse, pudiéramos explicar de dónde proviene, de dónde esas cinco voces obtienen esa globalidad. Podemos decir, que como vamos a ver, en esa dimensión, la unidad que el propio Schenker percibió en esos 4 compases, no solo se confirma, sino que ciertamente manifiesta ser de un grado muy superior, que es el de aquel que hemos llamado "totalidad".

(Cuando Einstein se refiere a ese sentimiento que tiene que ver con la existencia de un orden que se oculta detrás de las apariencias, lo que le faltó decir, es que la mayor parte de las veces, si no siempre, ese sentimiento es provocado por algo que hasta ese momento había quedado fuera de nuestra atención, pasando totalmente desapercibido, como aquí 
esas 5 bordaduras, los detalles que diría Holmes.)

Vamos a comprobar, que efectivamente esas 5 voces están globalmente relacionadas, y obtienen su globalidad de esa subestructura de 7 elementos que Bach ha seleccionado de la Estructura. Lo único que Bach tiene que hacer, es aprovechar su simetría, transformarla, y darle la forma externa específica que le proporcione esas 5 voces. Eso lo puede hacer su mente creativa, la que ha contactado con la Estructura interna de los 12 elementos elegidos para su Preludio. Imaginemos cómo sería el proceso de transformación, quizás en su propia mente. Podemos partir de la forma clásica en la que representaríamos esos 7 elementos, relacionándolos localmente por quintas y llevar a cabo sucesivas transformaciones.

Quintas

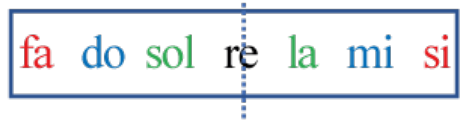

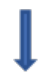

Hexacordos

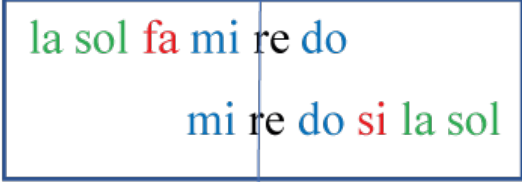

Invertimos la posición

espacial de ambos

mi re do si la sol

la sol fa mi re do

Los unimos

mi re do si la sol fa mi re do

Pasamos la pareja si-fa

al exterior

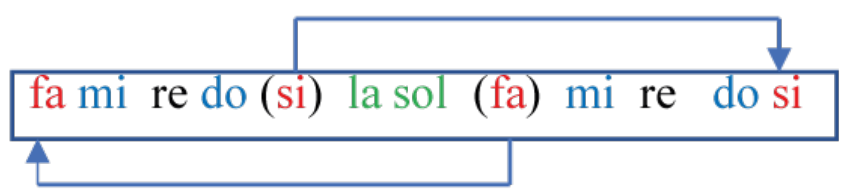

Resultado

\begin{tabular}{|lllllllll|}
\hline fa mi & re do & la sol & mi re & do si \\
\hline 1 & 2 & 2 & 3 & 2 & 3 & 2 & 2 & 1
\end{tabular}


Como vemos, esta representación es ciertamente el resultado de una serie de transformaciones simétricas, pues ninguno de los cambios afecta al orden interno (en cada momento se mantienen las mismas parejas y la misma constitución reflexiva, que podemos ver directamente a partir de las cifras que en la última transformación indican las relaciones locales que ha producido). La transformación final ha producido exactamente 5 relaciones claramente diferenciadas, fa-mi, re-do, la-sol, mi-re y do-si que son justamente las que Bach utiliza para sus 5 voces. Como se ve en el gráfico de Schenker, Bach es absolutamente fiel a su disposición en la representación, situando la de la izquierda la que forman ahí el fa y el mi, como voz superior; naturalmente en la parte musicalmente opuesta, en la más baja, estará su reflejo, el otro semitono, do-si, y las otras siguiendo el orden que establece la transformación: en el centro la voz de las cinco que configura la relación entre el sol y el la, y reflejándose a partir de ella, las otras re-do, la segunda por arriba y mi-re, la segunda por abajo, y así todas materializadas en forma de bordadura: en el centro, sol-la-sol, (la única segunda mayor formada por elementos que son pareja reflexiva) actuando de espejo para las demás, arriba mi-fa-mi, reflejándose abajo do-si-do, luego en las voces intermedias reflejándose también entre ellas, do-re-do y mi-re-mi. Las indicamos de manera diferenciada en un pentagrama.

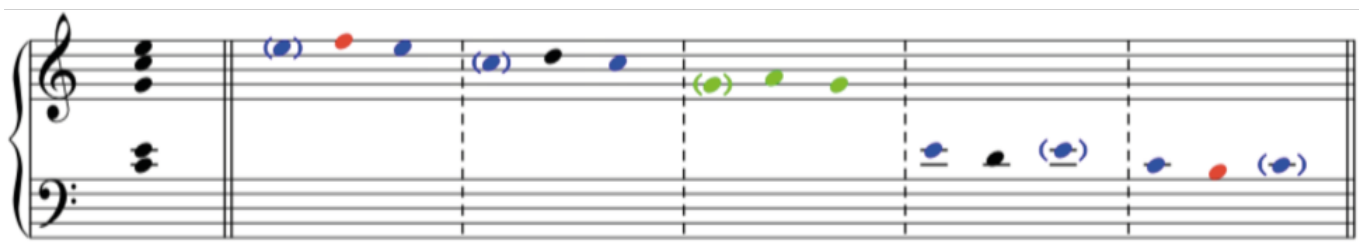

Naturalmente para percibir su orden global debemos concebirlas todas a la vez, captarlas todas en una misma mirada, como hacemos cuando concebimos esos 7 elementos en cualquiera de sus representaciones como subestructura. Pero también podemos fijarnos en los detalles; lo que nos facilita este gráfico. Por ejemplo, vemos de nuevo ahí, el uso privilegiado de esa relación entre el do y el mi, al ser la única que está ahí con sus elementos reflejándose dos veces, un privilegio que, como sabemos, corresponde al que la reflexividad le otorga en esta subestructura, pues ya vimos cuando asistimos al origen de los acordes, que es ahí la única tercera formada por dos elementos que son pareja reflexiva. La primera consecuencia de ello, y de la simetría, es que, como también vimos en aquel otro contexto, ambos elementos pueden relacionarse directamente, por un lado con el re, con el elemento que es reflejo de sí mismo, y por otro diferenciadamente con la pareja que forman el si y el fa, para de manera particular producir aquí todas esas relaciones de segundas mayores y menores, que manifiestan tener así un origen común en un orden común, un orden interno que se materializa aquí de forma particular en el orden externo que presentan ahí esas 5 voces. Si nos fijamos bien, podemos ver dónde han quedado los hexacordos en esta transformación, también absolutamente diferenciados y así ordenados. Vemos, que los elementos y las relaciones entre ellos que conforman las tres voces superiores, pertenecen al hexacordo la-solfa-mi-re-do, y correspondientemente la de las tres inferiores, al hexacordo complementario, mi-re-do-si-la-sol, considerando que ambos están unidos por la relación entre el sol y el la, 
que por eso figura ahora ahí en el centro, sirviendo como referencia organizativa para las demás. Incluso podemos entender la lógica de que sean 5 las voces, un número impar, simplemente porque una de las relaciones en el interior de esta subestructura, la formada por el sol y el la, es reflejo de sí misma, la única segunda que lo es, y que justamente por eso se encuentra en el centro. Las otras, como hemos visto, surgen de las relaciones que la pareja especial formada por la tercera do-mi, tiene, por un lado con el re, y por el otro con la pareja formada por el fa y el si (el tritono). La lógica de ese orden sigue pareciendo extraordinaria.

Así, esas 5 voces no son independientes, no son el resultado casual del enlace de 4 acordes, sino que todas están relacionadas globalmente, como un todo, porque de ese modo están vinculadas a una subestructura que forma parte de una Estructura que conforman los 12 elementos elegidos por Bach, vinculadas así a la propia Estructura. Como hemos dicho, los acordes que se forman ahí son el resultado de este orden, y no al revés, son el resultado de mantenerlo (no podemos detenernos aquí en los detalles de su formación, aunque ya lo vimos de manera general en nuestro viaje al interior del Sistema). Ahora, lo que Bach va a hacer a partir de ahí, es hacer crecer la Estructura, y mostrarnos que ciertamente esa subestructura forma parte de ella, que en ella tiene su origen, como vamos a ver que lo tienen el resto de esos acontecimientos destacados por Bach en el Preludio y por Schenker en su gráfico. Porque Bach, "se da cuenta", su mente se da cuenta, que también el cambio de registro que va a llevarse a cabo sobre el $\mathrm{mi}$, puede obtenerlo de esa misma subestructura. Pero no solo el cambio de registro, sino también, y a la vez, la progresión por décimas que va a acompañarlo paso a paso, pues ambos son el resultado de otra transformación que su simetría le permite a esta subestructura. Para llevarla a cabo y obtenerlos de ella, podemos partir de la representación por hexacordos:

\begin{tabular}{|r|}
\hline mi re do si la sol \\
la sol fa mi re do
\end{tabular}

O incluso, lo podemos hacer de la última transformación de la que obtuvo las 5 voces. Ya sabemos que las transformaciones son reversibles, que cualquiera puede ser el resultado y el origen para las demás

fa mi re do la sol mi re do si

Porque ciertamente, la simetría de la subestructura, permite también representar sus elementos y sus relaciones bidimensionalmente, en la forma de dos líneas paralelas. Se trata de una de las muchas transformaciones que quedaron por mostrar en ese viaje relativamente corto que realizamos al interior del Sistema, y que también forman parte de él. Lo vemos aquí. No podemos entretenernos en el proceso que conduce a ella, ponemos directamente la transformación: 


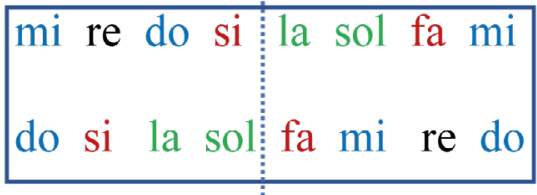

\section{$\begin{array}{llllllll}4 & 3 & 3 & 4 & 4 & 3 & 3 & 4\end{array}$}

Vemos ahí en la línea de arriba el cambio de registro de mi a mi y acompañándola por abajo la otra línea por terceras o décimas, que va de do a do. Es fácil de comprobar, que efectivamente se trata de una transformación simétrica, pues se mantiene absolutamente el orden interno de la subestructura. Cada elemento, conserva su pareja en el lugar opuesto, que aquí se encontrará no solo a la misma distancia del centro sino además en la otra línea, en forma de diagonal. Puede verificarse también directamente, la constitución reflexiva de la transformación, considerando las décimas que localmente se han formado, lo que indican las cifras, que como siempre corresponden al número de semitonos que contienen, aunque las contamos ahí como terceras, mayores y menores. En efecto, cada 4 y cada 3 tiene su reflejo en el lado opuesto. (Considérese algo muy importante: que como en el caso de aquellas 5 voces, esto de nuevo no sería posible, si la tercera mayor formada entre el do y el mi no fuera reflejo de sí misma, no fuera una relación privilegiada en el interior de esa subestructura sería la segunda consecuencia de la que se beneficiaría el Preludio- pues es únicamente por ello que la simetría ha podido situarla enmarcando por ambos lados la representación. Es entonces, cuando además ciertamente demuestra su utilidad, por ejemplo, para servir como punto de partida y de llegada cuando esa subestructura se represente como música, como movimiento en el tiempo, transfiriendo así a la obra musical en la que se materialice su orden interno, al que contribuye de manera especial esa tercera. En este caso, ofreciéndose como origen- y así explicación- de un acontecimiento fundamental que nos desvela Schenker, la prolongación de la primera nota estructural, que él describió como cambio de registro, y que puede además materializarse acompañada paso a paso por sus décimas). Por otro lado, la línea punteada vertical que hemos situado en el centro, además de seguir indicando como siempre la constitución reflexiva de la transformación, nos ayuda a ver dónde han quedado aquí los hexacordos en la transformación, y comprobamos, que lo han hecho también ordenadamente, puesto que las terceras que se encuentran a la izquierda de la línea, corresponden a los elementos de uno de los hexacordos, el formado por mi-re-do-si-la-sol, para lo cual, la simetría lo ha dividido en dos tetracordos, situándolos en la forma de esas dos líneas paralelas, mi-re-do-si arriba y do-si-la-sol abajo, y correspondientemente lo mismo con el hexacordo situado en la derecha, el hexacordo central, la-sol-fa-mi-re-do. Por otro lado, tenemos que subrayar, que esa nueva prueba del privilegio que vemos que tiene esa tercera formada entre el do y el mi, en esta subestructura, permite comprender que de él deriva el que las teorías otorgaron a esa relación, cuando pudieron registrarla en la superficie de la música, y a partir de ella le dieron el nombre a esa colección de 7 elementos, y la llamaron Do mayor. Así, y debemos señalarlo una vez más, una cosa, es decir que esa tercera mayor tiene un privilegio respecto a las demás dentro de esa colección de 7 elementos, que es lo que habíamos hecho hasta ahora dándole a esa colección de elementos el nombre de Do 
mayor, y otra muy diferente, decir de donde lo obtiene. Lo primero es describir un hecho, lo segundo, algo efectivamente muy diferente, explicarlo.

De esta forma, vemos que ya hay tres importantes acontecimientos, que no son independientes uno de otro, sino que aún siendo todos distintos están absolutamente conectados, compartiendo todos algo que es común, que no son los elementos, sino otra cosa que los engloba a todos, y que no conocíamos, el mismo origen, el mismo orden interno, vinculados todos por él. Según palabras de Bragg, ciertamente nuestras ideas nos permiten ensamblar ahora hechos que desde otras ideas realmente no lo estaban, no podían estarlo, y esas ideas tienen que ver ciertamente con otro modo de pensarlos, que, según Bragg, es el objetivo de lo que él llama "filosofía natural", la ciencia. Y esto es trascendente, pues en el fondo y en lo que se refiere a nosotros se trata de un modo distinto de pensar no solo el Preludio y no solo la propia música, sino el propio Pensamiento, porque se trata de otro modo de pensar, incluso el propio significado de "otro modo de pensar".

Pero veamos qué ocurre con los acordes de $7^{\underline{a}}$ disminuida que producen otro acontecimiento destacado, el movimiento cromático en el interior del cambio de registro. ¿Tienen todos también el mismo origen, que es la misma Estructura? ¿Bach los ha obtenido de ella?. En efecto. Para comprobarlo, podemos partir de aquel hexacordo que se encontraba privilegiadamente en el centro de la representación por quintas, y también en el de la representación por hexacordos que obtuvimos desde él, y que allí sirvió para poner ante nuestra mirada directamente todas las tonalidades mayores que podían formarse con esos 12 elementos, un hexacordo que forma parte de la subestructura de Do mayor. Veremos cómo va a demostrar esa capacidad constructiva y organizativa que demostró en el interior del Sistema, pero ahora desde el interior más profundo de una obra musical. Y podemos partir de él porque como vamos a ver todos esos acontecimientos en los que están implicados esos acordes, también puede generarse directamente de él. Lo hacemos desde la representación por quintas:

$$
\text { lab mib sib fa do sol re la mi si fa\# do\# }
$$

Vemos de nuevo el hexacordo en su centro, naturalmente aquí en su forma de quintas. Lo extraemos y lo ponemos en su forma por segundas, que como ya vimos que era una de las representaciones que permite su simetría.

la sol fa mi re do

Su simetría lo dota de otra propiedad más, que también quedó fuera de nuestro recorrido por el interior del Sistema, que es la de unirse a su propia réplica, y conseguir otra transformación simétrica de sí mismo.

\begin{tabular}{|llllllllllllllll}
\multicolumn{4}{c}{ hexacordo } & \multicolumn{8}{c}{ réplica } \\
\begin{tabular}{|llllllllllllllll}
\hline la & sol fa & mi & re & do & la & sol fa mi & re & do \\
2 & 2 & 1 & 2 & 2 & 3 & 2 & 2 & 1 & 2 & 2
\end{tabular}
\end{tabular}


Todo sigue siendo admirable. Vemos ahora, que ciertamente, el resultado es una transformación simétrica del propio hexacordo, pues en ella jse mantienen absolutamente sus parejas reflexivas, así como la constitución reflexiva que podemos ver directamente en las cifras que indican las relaciones locales!. A partir de la tercera menor (3), que en la unión se ha formado en el centro, cada 2 y cada 1 siguen teniendo su réplica en el lado opuesto, como la tenían en el hexacordo. Por supuesto también las relaciones no-locales se reflejan unas a otras: donde hay una tercera menor en el lado opuesto habrá una tercera menor, lo mismo con todas las demás relaciones.

Por otro lado, comprobamos, que el resultado de la transformación hace que esta representación ciertamente esté perfectamente preparada, entre otras cosas, para incluir reflexivamente en ella dos parejas reflexivas tomadas de la Estructura, por un lado la que forman el si y el sib, justamente en el interior de esa tercera menor que se ha formado en el centro, entre el do y el la, y otro, la que forman el lab y el do\# en el interior de las segundas mayores que reflexivamente enmarcan esta representación por ambos lados, la-sol y re-do. Todo parece tan complejamente ordenado, el encaje es tan perfecto, que se tiene la impresión de que alguien hubiera planificado de antemano todo esto. Pero lo extraordinario, es que todo ha surgido de manera natural en el interior del Sistema.

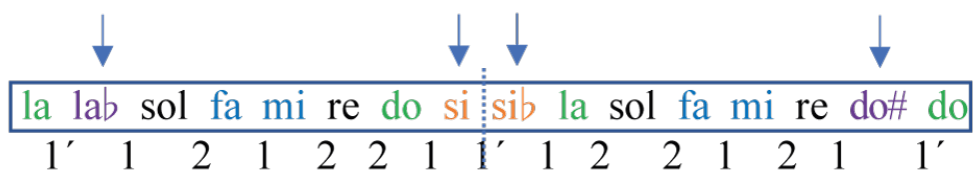

Las inclusiones que señalan las flechas, no modifican en absoluto la constitución reflexiva (se ve en la propia disposición que adquieren las flechas, y lo indican las cifras, con las que hemos distinguido también los semitonos diatónicos de los cromáticos, señalando estos últimos con 1'), y por supuesto se mantienen todas las parejas reflexivas, es decir su orden interno. Como vamos a ver, estas transformaciones, que tienen como origen el hexacordo, producen directamente los dos acordes de 7aㅗ disminuida, además de los acordes de tónica a los que irían referidos, Re menor y Do mayor. No los vemos, pero se encuentran ahí todos unidos, ya preparados para ser extraídos, justo en el fragmento que va del lab al do\#, enmarcado por esta pareja.

Extraigámoslos de ahí. Veremos que están absolutamente ordenados todos con todos. Solo tenemos que descubrirlos,

lab sol fa mi re do si sib la sol fa mi re do\#

para ello solo tenemos que separarlos de forma ordenada. Así: 
Acordes $7^{\mathrm{a}}$ dism.

Acordes Tónica

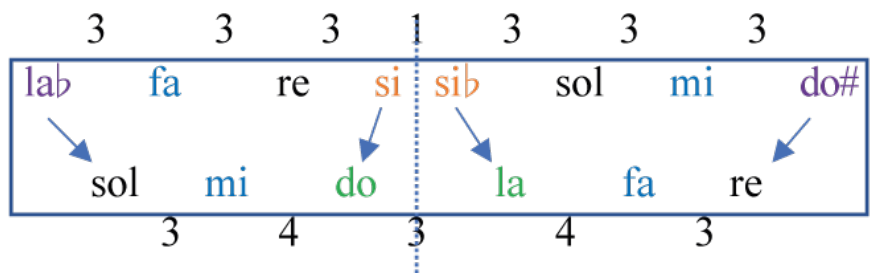

Los vemos diferenciados ahora en dos líneas, arriba los acordes de 7a disminuida situados también diferenciadamente cada uno a ambos lados del centro, y debajo lo mismo respecto a los correspondientes de tónica, y de ese modo, asimismo absolutamente ordenados unos con respecto a los otros, lo que significa que no participan ahí de manera individual, separada e independientemente unos de otros, los asociados a Re menor por un lado y los asociados a Do mayor por otro, que es la forma de entenderlos hasta ahora por todas las teorías conocidas incluida la del propio Schenker, sino globalmente, lo que puede empezar ya a explicar porqué Bach los utiliza aquí a todos ellos juntos (las flechas indican la reflexividad en la que también se llevan a cabo las llamadas resoluciones de las "sensibles" y de las "séptimas"). Por otra parte, descubrimos, que los fragmentos que conforman los acordes de 7’a disminuida por un lado y los de tónica por otro, son también cada uno reflexivo (de nuevo lo indican las cifras) pero también simétrico. Por ejemplo, vemos que los 6 elementos que conforman los acordes de tónica, son una representación del propio hexacordo que nos sirvió para llegar hasta aquí, es decir, una transformación simétrica de ese hexacordo, en este caso se trata de su representación por terceras, sol-mi-do-la-fa-re, formada por la unión de los dos acordes de tónica, o mejor al revés, son los dos acordes de tónica los que se forman complementándose uno a otro, a partir de ese fragmento especial que vuelve a demostrar ser el hexacordo.

Podemos ir ahora a la representación de la Estructura por hexacordos y comprobar de otro modo cómo estos acordes, estaban ya allí ordenando la propia Estructura, abarcando amplios espacios de ella, o incluso podríamos decir que ofreciéndose para proporcionarle su extraordinario consistencia, demostrando que constituyen fragmentos fundamentales en el interior de esta Estructura

lab re fa si

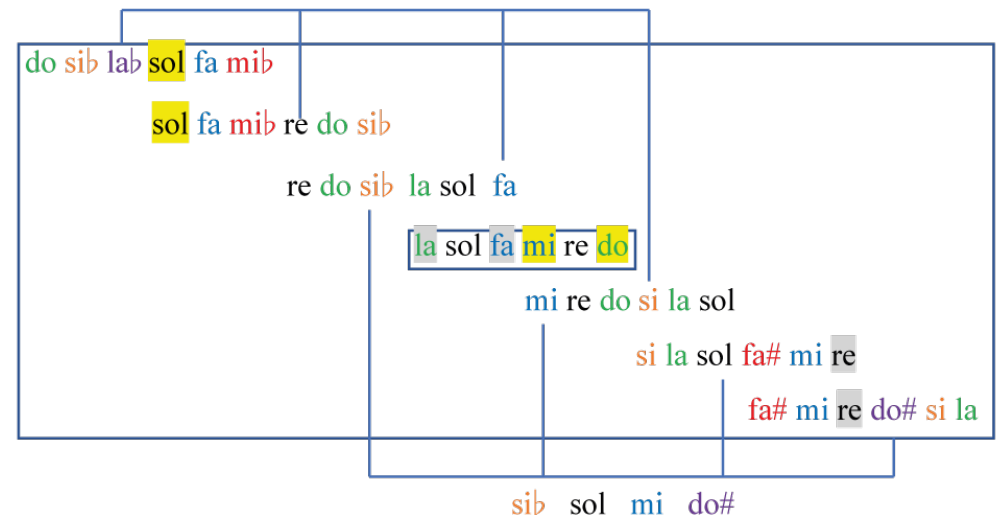


Efectivamente, vemos que los acordes de $7^{a}$ disminuida que aparecen allí señalados por las líneas, y los de tónica, señalados por los colores amarillo y gris respectivamente para diferenciar los elementos que los constituyen, como acabamos de ver, también aquí se completan todos, están todos entretejidos: los acordes de 7ạ disminuida por un lado, y los de tónica por el otro, pues cada acorde de 7a disminuida está formado por los elementos que son la pareja reflexiva de los elementos que constituyen el otro, y lo mismo los de tónica, pero complementándose también entre todos ellos de esa manera en la que ciertamente aparecen ahí entretejidos unos con otros. Vemos que además de poder asociarlos a una subestructura (tonalidad) en particular, también los podemos encontrar integrando en ellos prácticamente toda la Estructura, lo que vuelve a atestiguar su extraordinaria y compleja constitución, y así del Sistema que representa. De esa complejidad, entendida como la propiedad de aquello cuyos componentes están entretejidos conjuntamente, como estos acordes, la Estructura y así el Sistema, como vemos obtiene su eficacia para ser convertido en música. Eficacia significa aquí la capacidad que demuestra para proporcionarle, aquí al Preludio, su orden interno.

Pero podemos ser todavía más precisos en cuanto al uso que va a hacer Bach de esos acordes en su Preludio, por ejemplo, podíamos preguntarnos ¿por qué se sirve de ellos justo en ese momento del Preludio? Y la respuesta, nos conecta de nuevo con el cambio de registro y la progresión por décimas que lo acompaña, conectando de nuevo de ese modo diferentes hechos en ese nivel relacional desconocido hasta ahora por nosotros, el global. Y la razón, es que justo en el c.11, una vez que el cambio de registro ha llegado a la décima que forman el sol y el si, acabando así de materializar uno de los hexacordos de la subestructura de Do mayor, el cambio de registro se adentra en el otro hexacordo, el hexacordo central, para materializarlo. Lo señalamos en la representación

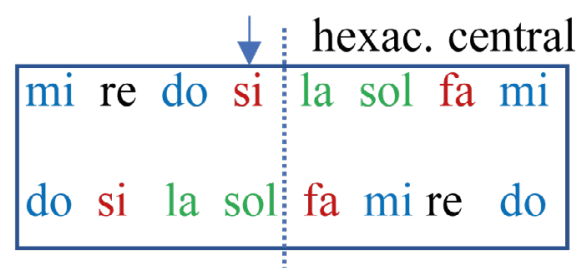

Entendemos la extraordinaria importancia que tiene el hecho de que la simetría haya situado ahí los hexacordos de forma claramente ordenada. Ahora en efecto, llegado a la décima sol-si (c.11), que indica la flecha, el cambio de registro va a introducirse en esa parte derecha, claramente diferenciada por la simetría, la que corresponde al hexacordo de la subestructura de Do que es a la vez al hexacordo central de la Estructura.

Y es ahí justamente, cuando Bach, antes del paso del si al la, de la voz que conduce el cambio de registro, va a hacer algo distinto: incluir el primer elemento que empieza así a conformar el movimiento cromático, el sib (c.12, voz interior). Y esto es únicamente posible, porque como vamos a comprobar, ese hexacordo, al estar en el centro de la Estructura está preparado para albergar directamente en él todos esos acontecimientos, sin necesidad de replicarse. 
Podemos decir que es otra propiedad de la Estructura que nos desvela el propio Preludio, y es que como vamos a comprobar, la Estructura del Sistema, puede incluir el todo (aquí esos 4 acontecimientos, acordes de $7^{a}$ disminuida y de tónica, que hemos visto pueden abarcarla) en la parte (el hexacordo central). Vemos las múltiples posibilidades constructivas que proporciona ese hexacordo. Ya lo vimos con la propia Estructura, ahora lo vemos con el Preludio.

Desde la Estructura por hexacordos podemos ver cómo la simetría permite la inclusión de elementos que figuran en una parte de una de sus representaciones, en otra parte de ella, para producir ahí nuevas relaciones, por ejemplo la pareja que forman el lab y el do\#, entre el la y el sol, y el re y el do, que precisamente se encuentran a ambos lados de ese hexacordo realmente especial que la simetría ha situado en el centro, y del que por ello Bach se va a servir asimismo de manera especial

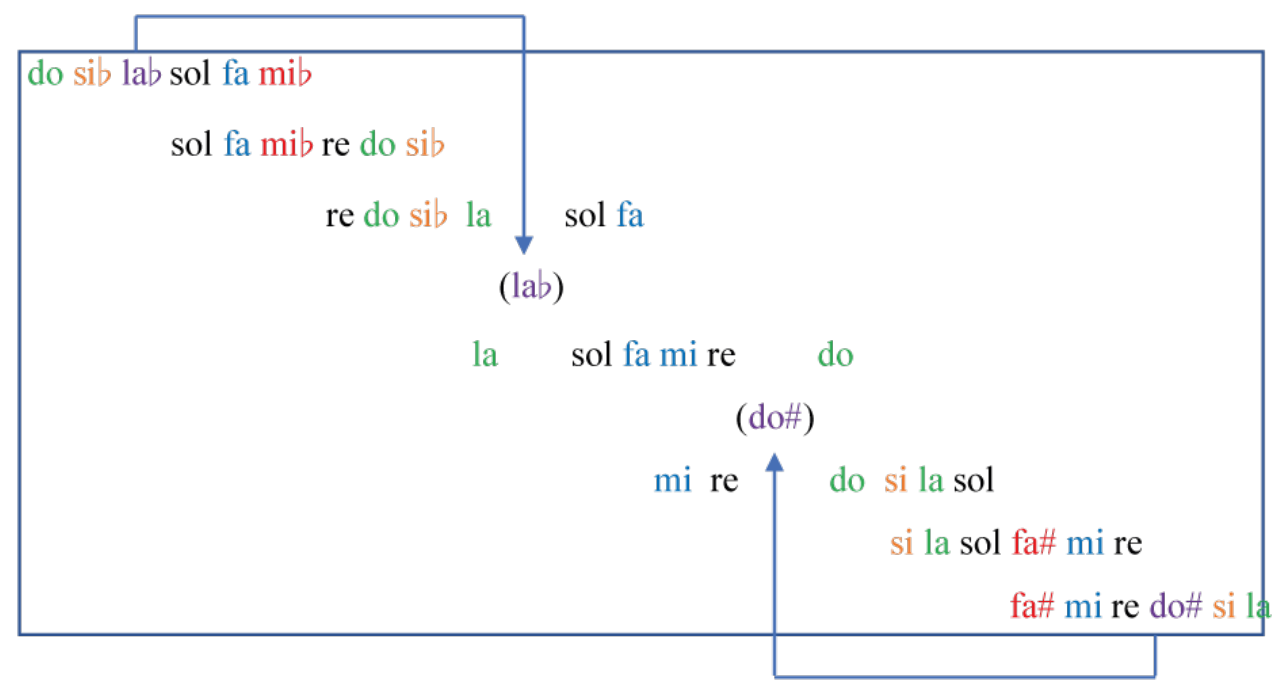

Antes, realizamos esas inclusiones directamente sobre la unión del hexacordo con su propia réplica, para extraer los acordes de $7^{a}$ disminuida y los correspondientes de tónica, ahora vemos la lógica de esas inclusiones desde la propia Estructura. Comprobamos, que efectivamente, como señalan las flechas, la simetría de la Estructura permite llevar a cabo inclusiones de elementos, en el interior de relaciones que se encuentran en otro lugar de la Estructura, sin que ello modifique en absoluto el orden interno, lo que hace posible que los elementos puedan participar en diferentes relaciones, como aquí demuestran esos dos, el lab y el do\#, que en principio tenían otra función en la Estructura, que era la de participar en la formación de dos de las subestructuras en las que puede dividirse y que corresponden a las tonalidades mayores que se pueden formar con esos 12 elementos. (Vemos algo importante: Respecto a las relaciones en las que participan esos elementos, Bach puede elegir cualquiera de las opciones que le ofrece la complejidad de la Estructura, por supuesto, siempre en función de la opción que elegirá para el resto de los elementos y de las relaciones posibles que puedan llevar a cabo entre ellos y que asimismo les ofrezca la Estructura). Evidentemente, el hexacordo central estaba especialmente preparado para ello, pudiendo entonces albergar en él globalmente esas otras relaciones en las que van a participar esos 2 elementos, relaciones que, en este caso, tienen que ver con esos acordes en los que esos elementos participan, y 
que ahora entendemos que es por esa capacidad del hexacordo, que Bach los va a utilizar justamente cuando el cambio de registro junto a sus décimas, van a materializarlo en el Preludio. Pero lo podemos ver todo mejor si sacamos fuera de la Estructura los tres hexacordos que se encuentran en el centro.

lab fa re si

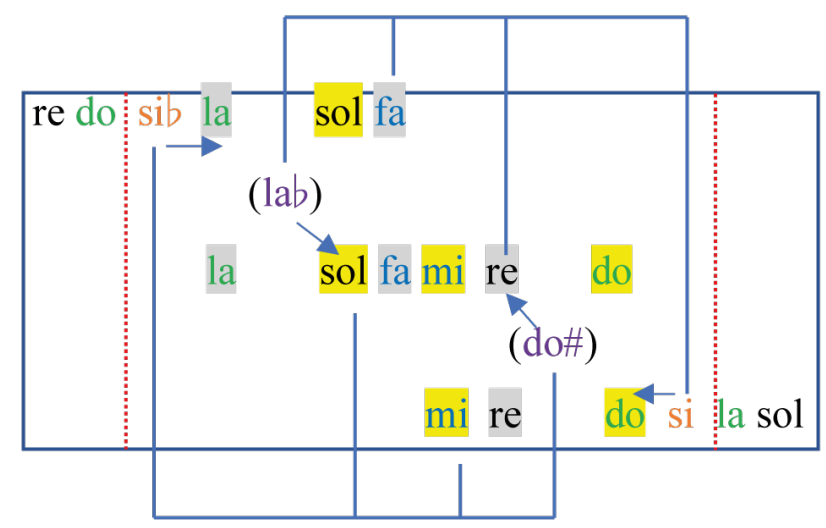

sib sol mi do\#

Las líneas, los colores y las flechas, permiten visualizar el extraordinario orden en el que todo está ocurriendo. Las líneas azules indican de nuevo el lugar en el que las inclusiones han formado ahora justamente ahí los dos acordes de 7a disminuida, y de nuevo, diferenciados ahora ahí por los colores amarillo y gris los acordes de tónica correspondientes, complementándose también reflexivamente, el acorde de Re menor en gris y el de Do mayor en amarillo, y todos con todos, y como vemos ahí integrados también todos con todos, y así entretejidos también aquí unos con otros. Lo que ahora cambia, respecto a la forma que adquiere el hexacordo cuando se une a su propia réplica, de la que extrajimos directamente los acordes, es que la pareja que forman el si y el sib que allí estaba en el centro, aquí la vemos situada justo a ambos lados del hexacordo, o lo que es lo mismo en el centro de los hexacordos que están por encima y por debajo, donde esos dos elementos ya presentan ahí una relación de semitono, el sibcon el la, arriba, y el si con el do, abajo, reflejándose mutuamente, y así unidos ya al la y el do que enmarcan el propio hexacordo, y entonces unidos ya así al propio hexacordo. Es decir, lo que nos permite ver directamente esta representación, es el extraordinario orden del que emergen todas las relaciones que potencialmente estaban en el interior de esos acordes, y que no veíamos cuando los extrajimos directamente de esa particular transformación del hexacordo que es el resultado de la unión con su propia réplica, relaciones que son expresamente las que Bach va utilizar. Las vemos ahí diferenciadas. Como indican las flechas, arriba el movimiento cromático que producen el siby el lab, sib-la-lab-sol, y debajo, reflexivamente el que corresponde a las relaciones de semitono que señalan la relación entre el re y el do, si-do y do\#-re, y todo dentro del espacio que enmarcan ahora esa pareja especial que son el si y el sib, que hemos indicado con la líneas rojas de puntos. Es como si Bach, una vez que el cambio de registro con sus décimas ha materializado el otro hexacordo de Do, el inferior tal como aparecen los hexacordos en la Estructura, y la línea que conduce al cambio de registro ha llegado al si, después de haber materializado el tetracordo mi-re-do-si - que como hemos visto, y vemos ahí, corresponde al que ofrece 
ese primer hexacordo para el cambio de registro- "saltase" directamente al sib a su pareja reflexiva, donde está la otra línea roja para unirse localmente con él, tal como aparecen el Preludio. Y esto es posible, porque si la relación entre el si y el sib, tratada especialmente por la reflexividad, al ser el único semitono cromático cuyos elementos son pareja reflexiva, tiene por ello la capacidad de materializarse localmente juntos en el centro de una representación, como hemos visto antes sobre la unión del hexacordo con su propia réplica, esos elementos al poderse reflejar también en la distancia, como demuestran aquí, también pueden "abrir" su relación, para albergar así en su interior otros acontecimientos que de ese modo puedan así relacionarse todos de manera global, y así con ellos mismos.

Ese último gráfico permite obtener mucha más información que de otro modo no disponíamos. No podemos entretenernos aquí, pero por ejemplo, podemos ver cómo los 4 elementos que conforman la parte interna del hexacordo central, sol-fa-mi-re, formada por dos parejas reflexivas que demuestran de nuevo ser muy especiales, aportan sus elementos tanto para formar los acordes de 7a disminuida como los de tónica, mientras la simetría permite que los otros dos la y do, que forman la otra pareja, cambian ahora a la que forman el lab y do\#, uniéndose incluso a ellos, participando ahí en el centro de todas estas relaciones especiales con las que Bach está construyendo su Preludio, dotándolo así del orden global en el que todas ellas se originan, como lo hacen los elementos que participan en ellas.

Vemos que cada transformación simétrica, que proporciona a la Estructura una forma externa diferente, ofrece distintas posibilidades para obtener de ella diferenciadamente esas relaciones que pueden proporcionar a la obra su orden interno, su globalidad. Como acabamos de ver, en el caso de esos acordes, una de esas formas permitía extraerlos directamente, mientras la otra proporcionaba ya las relaciones precisas con la que de manera particular los elementos que conformaban esos acordes, podían contribuir a la transferencia al Preludio de su orden interno. Pero vamos a ver ahora, que una forma externa, como la que resulta por ejemplo de la unión de hexacordo con su propia réplica, ofrece la posibilidad de obtener de ella un número mayor de relaciones, mayor del que en este caso ha supuesto por ejemplo la extracción de ella directamente de esos acordes. Estas diferentes relaciones, obtenidas no solo de las diferentes formas externas que puede adoptar la Estructura, sino de una misma forma externa, seguirán haciendo posible que su orden interno, se distribuya por el Preludio, de manera que todas estén globalmente conectadas. Comprobémoslo.

Pero antes debemos señalar algo muy importante. Estamos en el interior del Preludio, y estamos no solo ratificando la existencia de la Estructura interna del Sistema, sino que estamos sabiendo mucho más de ella de lo que supimos en el viaje que realizamos a su interior, entonces directamente desde la superficie del Sistema. Ya dijimos entonces, que el viaje debía ser corto, había sido corto, y que la extensión de su interior, era mucho mayor de la visitada en nuestro viaje. Aquí tenemos la prueba, estamos descubriendo en él, en su Estructura, ese mundo mucho mayor de relaciones que la pueblan, y realmente la constituyen como tal Estructura, lo que por otro lado demuestra a la vez, lo que advertimos ya desde el principio, que al interior del Sistema, solo podía accederse desde el interior de las obras musicales, como realmente estamos haciendo aquí. Y eso es lo que vamos a seguir haciendo ahora

Pongamos de nuevo esa transformación del hexacordo resultado de la unión con su pro- 
pia réplica y veamos qué más le puede estar ofreciendo a Bach, y entonces lo que Bach nos ofrece a nosotros respecto a la información sobre el Sistema, sobre su interior, y así sobre sus capacidades constructivas.

\begin{tabular}{|lllllllllllll}
\hline la sol fa & mi re do & la sol fa $\mathrm{mi}$ re do \\
\hline 2 & 2 & 1 & 2 & 2 & 3 & 2 & 2 & 1 & 2 & 2
\end{tabular}

Ya vimos que esa tercera menor que se forma en el centro, permite incluir aquellos dos elementos en su interior, el si y el sib, que como dijimos ahí aparecerán juntos, relacionados así localmente, y de ese modo, manteniendo las relaciones locales de segunda propias de esta representación del hexacordo. Y ahora nos damos cuenta, de que incluso podemos entender porqué necesariamente tienen que ser dos los elementos incluidos en esa tercera menor, en este caso el si y el sib; con uno solo, se mantendría la regularidad de las segundas, pero lo que no se mantendría sería la constitución reflexiva que posee la unión del hexacordo con su propia réplica, pues la inclusión de uno solo de ellos en el interior de esa tercera menor, la destruiría, pues si bien, en efecto, mantendría la regularidad de las segundas, en cambio produciría dos segundas diferentes en el centro, lo que no haría posible esta nueva transformación, no sería posible mantener su orden interno. Entendemos que ambos elementos, se necesitan mutuamente. Y con ello, no sólo entendemos a la vez la lógica por la que la reflexividad particularmente los ha ligado necesariamente uno a otro, sino que empezamos entender su utilidad práctica. Ya hemos visto, que situados localmente o de manera no-local, hacen posible que el resto de los elementos con los que participan en cualquiera de las representaciones en las que figuran, puedan relacionarse de manera particular y hacerlo además globalmente. La ausencia de solo uno de los elementos, efectivamente destruiría el orden global que presentan esos acontecimientos en los que todos de ese modo participan, que es el orden global del Preludio. Pero veamos cuáles son las otras posibilidades que estaba ofreciendo esta representación, en la que ambos figuran juntos.

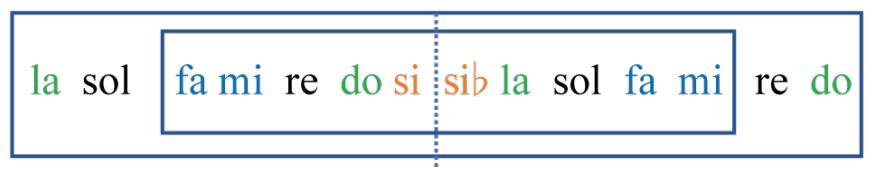

Y lo que descubrimos, es algo que no habíamos visto antes, y es que de este fragmento centrado en esa relación entre el si y el sib, que se originó a partir del hexacordo central, ciertamente Bach puede obtener otras relaciones. Por ejemplo, ahí hemos diferenciado por medio del rectángulo interior, un fragmento de esta transformación, el que se encuentra entre las dos relaciones fa-mi, una relación que sabemos que en la Estructura ocupa un lugar privilegiado, su centro (al ser a la vez el centro del hexacordo que la simetría ha situado allí). Y es que se trata del otro semitono, en este caso diatónico, que es el único cuyos elementos son pareja reflexiva y por tanto el único, que como vemos aquí, puede ser reflejo de sí mismo, y como ocurría con los elementos que constituyen el semitono cromático formando entre 
el si y el sib, puede "abrirse" como aquí, incluso como relación, para albergar también otras relaciones, lo que permite a ambos semitonos, intercambiar entre ellos su acción. Porque como vemos, si en aquella representación que extrajimos del centro de la Estructura, el centro de ella lo ocupaba la relación entre el fa y el mi, y el espacio en el que se llevaban a cabo las relaciones que Bach iba a trasladar a su Preludio, estaba limitado por la relación entre el si y el sib, ahora reflexivamente ocurre lo contrario, esta relación está en el centro del espacio enmarcado ahora por la propia pareja que forman el fa y el mi, un espacio en él que ciertamente pueden llevarse a cabo otros acontecimientos, acontecimientos que por ello estarán absolutamente conectados a los anteriores. Indiquemos ya alguno en el gráfico de esta representación

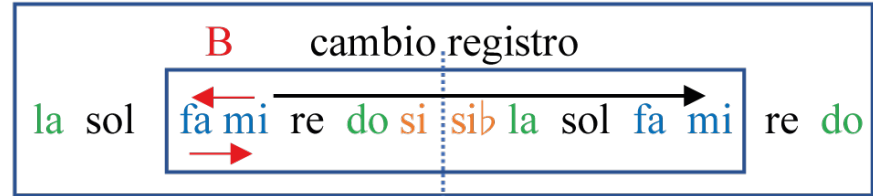

Como indican las flechas, Bach puede obtener de ese espacio, no solo la prolongación por cambio de registro de la primera nota estructural, el mi (indicada por la flecha negra que va de mi a mi), sino también la primera prolongación que recibe ese mi del fa, en los 4 primeros compases, una bordadura (indicada ahí por las flechas rojas), una prolongación, que como ya señalamos, Schenker realmente no la indica en su gráfico, no la considera como tal. Como ya vimos, esa relación en su gráfico solo aparece indicada debajo de esos 4 primeros compases como 3-4-3, pero como ya señalamos, si nos fijamos en la parte media, donde nos descubre el cambio de registro, ahí la incluye en él, cuando realmente el cambio de registro se inicia justamente después en el c.5, lo que hace que esa relación entre el fa y el mi, sea, en términos schenkerianos, realmente una prolongación distinta. Y lo que nos desvela esta representación, es la razón por la que efectivamente hay dos prolongaciones, es decir nos permite no solo referirnos a esa primera prolongación del mi como bordadura, constatarla como tal, sino además explicarla, explicando a la vez la razón por las que ambas prolongaciones aparecen localmente juntas. Nos tenemos que remitir de nuevo al orden interno de la Estructura y a la globalidad que conecta los acontecimientos. Entendemos que esa primera prolongación del mi, ciertamente estaba obligada por la Estructura, en concreto por esa relación entre el fa y el mi, que al ser especial en ella, ser reflejo de sí misma, cuando se situase en la distancia, y se ofreciera así para transferir el orden de la Estructura al Preludio, no solo tenía que estar al final de uno de los acontecimientos fundamentales de los que el Preludio iba a obtener ese orden, el cambio de registro, ahí para concluirlo, sino necesariamente también al principio. Y eso solo podía ser justamente allí en la forma de una bordadura. Recordemos por otro lado, que la forma específica como bordadura que tiene esa relación entre el fa y el mi, mi-fa-mi, la obtiene específicamente del orden interno de la subestructura que utiliza Bach para los 4 primeros compases, que establece, primero, que ciertamente esa sea su forma, la que globalmente comparte con todas las demás voces, y segundo, que su ubicación sea la voz superior. Pero si entendemos la necesidad de esa bordadura inicial, a la que obliga el orden interno que se está así representando, lo mismo 
ocurre, por ejemplo con el hecho de que una vez el cambio de registro ha cubierto su primera parte llegando al si, el elemento siguiente sea el sib, pues, como hemos visto, también Bach se ve obligado a ello por ese orden interno de la Estructura, solo así puede transferirlo al Preludio; decir entonces, que entre la tercera menor que se ha producido en la réplica del hexacordo en su centro, tiene que haber necesariamente dos elementos, efectivamente el si y el sib, es lo mismo que decir, que después del si que conduce el cambio de registro, Bach también necesariamente tenía que incluir un sil, solo así podía ser fiel al orden interno de la Estructura, y transferirlo al Preludio. Nos damos cuenta, que estamos en otro nivel de observación, y por tanto seguramente también en otro plano epistémico y epistemológico, pues por ejemplo ahora, se nos estaría permitiendo responder a una pregunta que ni siquiera podíamos imaginar la posibilidad de hacernos antes ¿por qué Bach introduce el sib en el c.12, justo después de que el cambio de registro ha llegado al si? incluso ¿por qué necesita hacerlo, si podría no haberlo hecho sin que el cambio de registro se viera afectado?. Y las preguntas tienen sentido porque ahora es posible la respuesta. Ya lo hemos dicho, simplemente porque Bach lo necesita para transferir a su Preludio el orden interno de una Estructura, en la que ese sib está ligado completamente al resto de los elementos de la Estructura y a las relaciones que de manera particular conforman el resto de los acontecimientos del Preludio, y para ello particularmente está ligado a ese si. Es la razón por la que ambos aparecen allí localmente relacionados, es decir, es la explicación del hecho no solo su descripción.

Pero fijémonos ahora de nuevo en nuestro último gráfico. Específicamente en lo que queda fuera de ese fragmento que se encuentra entre la réplica de la pareja fa-mi. Se trata "curiosamente" de dos relaciones que Bach también trata de manera especial: a la izquierda, la formada por el la y el sol que es la voz que excepcionalmente Bach, en los cs. 5 y 7, sitúa de forma destacada por encima de la voz superior que conduce el cambio de registro, según el gráfico, formando parte de dos prolongaciones, dos saltos consonantes, justo cuando va a empezar el cambio de registro, en el momento en el que el mi va a pasar al re (efectivamente esos 2 elementos, la y sol están relacionados, constituyen una voz, aunque al remitir cada uno de sus elementos a dos prolongaciones diferentes, dos saltos consonantes, aparecen realmente aislados; ya lo dijimos, las prolongaciones tienen el peligro de separar relaciones, aislando como aquí sus elementos. Porque ciertamente, esos dos elementos constituyen una voz importante, la que diferenciadamente ha estado en el centro de las 5 que conformaron los 4 primeros compases, y que aunque sigue ahí, por alguna razón que ahora entenderemos, Bach la subraya sacándola al exterior, justamente después, en el c.5); y es que a la derecha del fragmento, en el lugar reflejo, los elementos reflejo del la y el sol, el re y el do, son también justamente los que diferenciadamente sitúa por encima del cambio de registro en los cs.13 y 15 , y que como aquellos constituyen también una voz. Lo que podemos indicar de este modo.

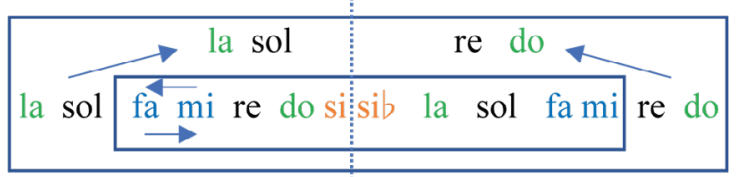

Existía pues algo más allá de la temporalidad en la que materializa el Preludio que conecta 
absolutamente esos dos acontecimientos que fuera de esa temporalidad parecían totalmente desconectados, uno en los cs. 4 y 5 y el otro en los cs. 13 y 14. Pero es que además, los conecta al resto de los acontecimientos que hemos ido viendo. Si nos fijamos bien, y pensamos juntos los saltos consonantes, que sitúan el la y el sol por encima del cambio de registro cuando este está llevando a cabo el movimiento mi-re-do

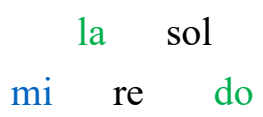

producen localmente un movimiento de quintas mi-la-re-sol-do, y por otro lado hacemos lo mismo con los elementos señalados por encima de la voz que lleva el cambio de registro, en esos c. 13 y 14, el re y el do, junto con los elementos a los que en ese momento ha llegado el cambio de registro, el la, sol y fa.

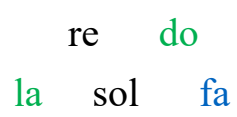

Veremos que también producen un movimiento local de quintas, la-re-sol-do-fa, que complementa absolutamente el anterior. Las ponemos juntas

$$
\begin{aligned}
& \text { mi la re sol do } \\
& \text { la re sol do fa }
\end{aligned}
$$

Y decimos que lo complementa porque si ahora las unimos

$$
\text { mi la re sol do fa }
$$

Descubrimos de nuevo la capacidad organizativa del hexacordo, por cuanto como vemos, esa representación de quintas corresponde de nuevo (como aquellos acordes de tónica de Re menor y Do mayor) exactamente a la del hexacordo, es el propio hexacordo. De modo, que esos dos acontecimientos diferenciados por Bach, y luego por Schenker en su gráfico, ciertamente aparecen conectados por algo muy distinto de la pura temporalidad en la que se materializa el Preludio, pero también muy distinto de las prolongaciones que se les pueden atribuir en ese nivel de observación en el que nos sitúa Schenker. Él las registra, las describe, pero no puede explicarlas, no puede decir qué liga necesariamente a esas prolongaciones, qué es lo que las conectaba en la distancia, para que Bach las pusiera ahí. Para ello se requería el acceso a otro nivel de observación más profundo, en el que su conexión estaba asimismo conectada con otros acontecimientos que como ellos habían sido registrados y descritos desde otro nivel de observación, que es en el que nos situó Schenker.

Pero de nuevo, podemos ser más precisos con respecto a lo que está aconteciendo. Para 
ello, incluyamos de nuevo en nuestra última representación, esa pareja que va a contribuir a que se formen ahí los acordes de $7^{a}$ disminuida, el lab y el do\#, que como sabemos caben precisamente en el interior de esas dos segundas, la-sol y re-do. Porque como podemos ver, además de estar en los extremos de la representación, las dos se encuentran en el interior del fragmento formado dentro del reflejo de la pareja fa-mi consigo misma, pues participan ahí también en el cambio de registro, y además invertidas, quiere decir, que mientras la relación entre el re y el do, que participa en la primera parte del cambio de registro, Bach la va a situar por encima de la materialización de su segunda parte, con la otra que forman el la y el sol, ocurre reflexivamente lo contrario, participa en la segunda parte del cambio de registro, y Bach la ha situado antes por encima de la materialización de la primera parte. Así, hagamos la inclusión de esos dos elementos el lab y el do\# sobre esas relaciones en el interior del cambio de registro.

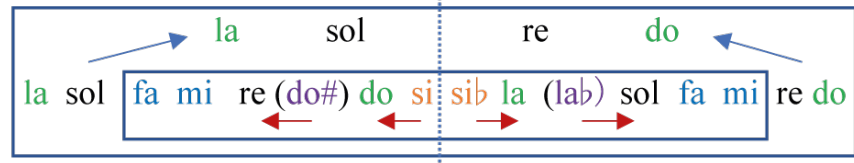

Esos dos elementos incluidos, indicados entre paréntesis, junto a los que forman la pareja formada por el si y el sib ya sabemos que producen todos esos semitonos, lo hemos visto en otro contexto, sobre otra representación. Los volvemos a ver ahí diferenciadamente como una síntesis perfecta de lo que está aconteciendo. Los indican aquí las flechas rojas. Con ellos, como sabemos, por un lado Bach va a señalar los elementos re y do, do\#-re y si-do, y por otro, va a conformar el movimiento cromático en la segunda parte del descenso cuando llegue al la y el sol, reflejo de los anteriores, sib-la y lab-sol, como vemos allí. Lo que nos desvela esta representación, es que lo que hace Bach es situar los movimientos que señalan el re y el do, no en el interior del la primera parte del descenso, es decir, no en el interior del descenso que allí está materializando el otro hexacordo de la subestructura de Do mayor, que no es el central de la Estructura, sino sobre la segunda parte del cambio de registro en la que ahí sí se materializa ese hexacordo central, y donde como hemos visto también puede situar la relación entre el re y el do, y ahí ya con sus propias sensibles, lo que produce los acordes de 7a disminuida, acciones que como hemos visto no solo permite sino que establece la simetría. Lo podemos señalar en nuestro gráfico

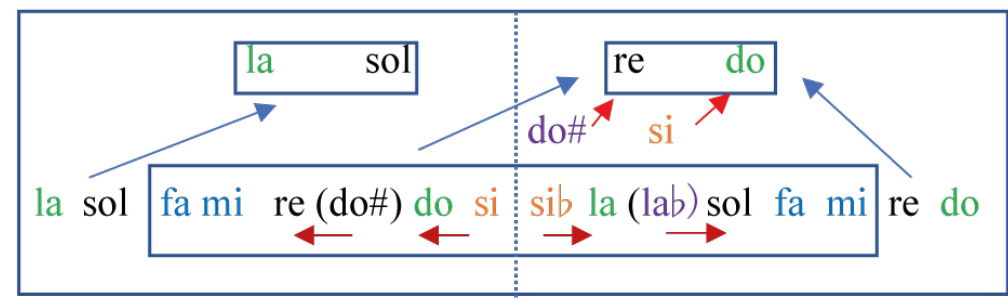

Si nos fijamos bien, esa relación entre el re y el do, que Bach nos ha ofrecido diferencia- 
damente en la segunda parte del cambio de registro, y que en esta representación figura además enmarcándola por su parte derecha y justo fuera del fragmento del que Bach toma las dos prolongaciones de la primera nota estructural, el mi, corresponde precisamente a los otros dos elementos, el re y el do, que según nos desvela Schenker, son a los que ahora se va a dirigir el Preludio, es decir, los que junto al mi constituyen la línea fundamental, que como vemos en esta representación le ofrece directamente la Estructura, aparecen allí al final en su derecha justo después del mi, señalándole el camino. (Ya vimos que en esa subestructura, la tercera formada entre el mi y el do, es una relación privilegiada por la reflexividad y luego por la simetría, un privilegio que se traslada a la relación especial que ambos pueden establecer con el re, mi-re-do, el único elemento que en esa subestructura es reflejo de sí mismo, lo que ciertamente, como ya sugerimos antes, explicaría el privilegio que demuestran tener esos tres elementos como constituyentes de la línea fundamental, y así el que Schenker tuvo que otorgarle al descubrirla en el nivel de observación al que consiguió acceder. No tenemos espacio aquí para ahondar en ello. Pero ya hemos visto por ejemplo, como uno de sus elementos, el mi, que se encuentra ligado directamente al fa en la Estructura, al ser una pareja que puede reflejarse a sí misma, puede "abrir" su relación para albergar incluso la propia Estructura)

No nos podemos extender mucho más, no podemos exceder mucho los límites de este texto. Pero, aunque dijimos que nuestro objetivo eran esos 19 compases, no podemos resistirnos a ir un poco más allá. Llegados al c.19, el Preludio se dirige efectivamente hacia el siguiente elemento estructural, el re, un acontecimiento que Bach va a señalar también en su Preludio a través de otro acontecimiento diferenciado ahí por él, el que en términos tonales se describe como "pedal de dominante" (c. 24), y que forman ese re con su pareja reflexiva, el sol. Lo señalamos con una flecha roja en su gráfico

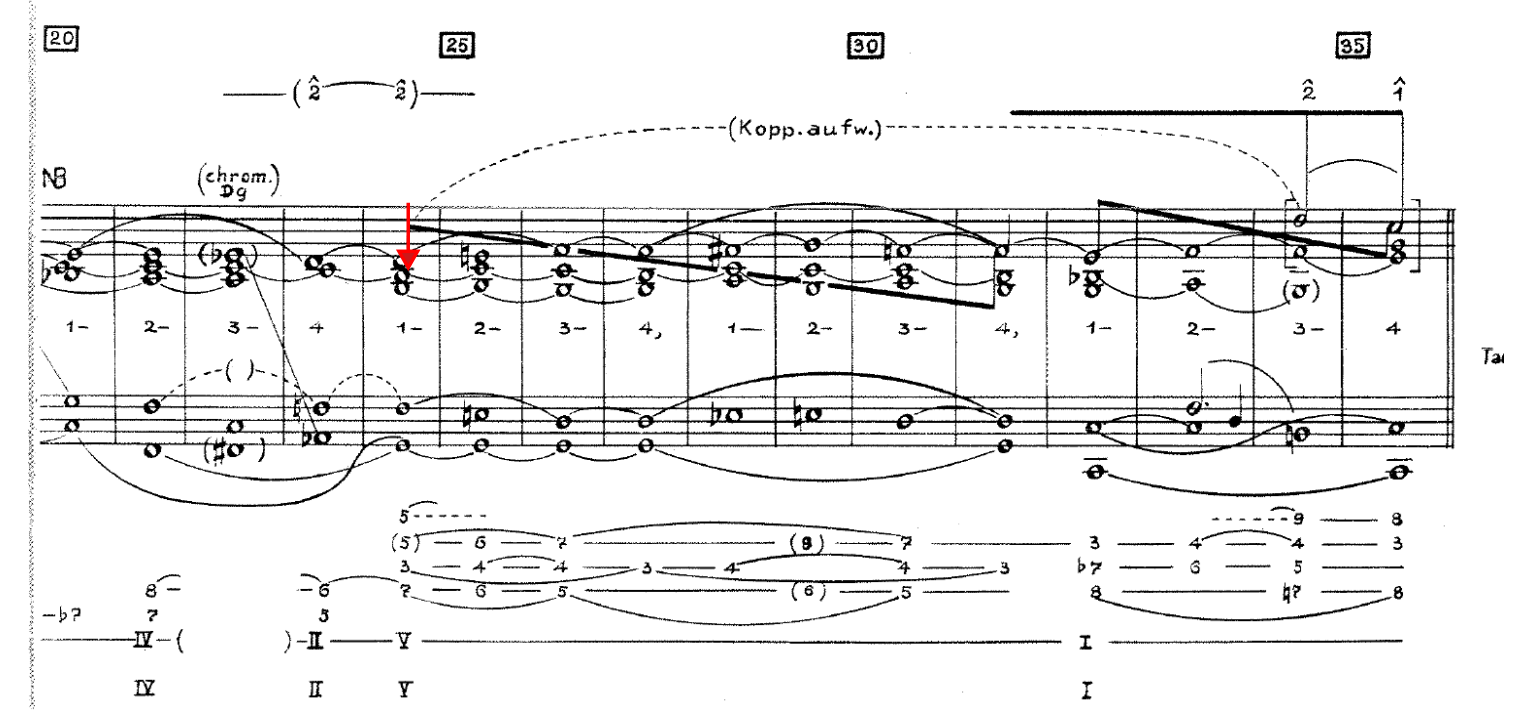

Pero fijémonos cómo lo hace. No llega al re directamente desde el mi, sino que una vez que éste ha llevado a cabo su cambio de registro, lo hace, diríamos que cromáticamente, a través del mib (c.22, señalado como "nota cromática" en su gráfico), el único elemento de la 
Estructura que faltaba por intervenir en el Preludio, el que la completa, y que es un elemento también realmente especial en ella, porque la reflexividad lo ha ligado directamente al fa\# como pareja reflexiva, una relación que Bach materializa allí (los vemos a ambos indicados entre paréntesis por Schenker en su gráfico y así juntamente diferenciados). Y es especial su relación, porque ambos forman una 7aㅗ disminuida, siendo en la Estructura la única cuyos elementos son pareja reflexiva, o dicho en la otra dirección, es la única pareja reflexiva cuyos elementos están en esa relación especial que es la 7a disminuida, constituyendo además de ese modo, juntos, una de las dobles sensibles de la pareja que forman el re y el sol. Ya vimos en la primera parte de nuestro trabajo, que una de las circunstancias por las que esa pareja que forman el re y el sol demostraba asimismo ser especial, es que está formada por los dos únicos elementos de la Estructura que tienen un semitono diatónico por ambos lados, en términos tonales, una doble sensible, producto de su relación con dos parejas, las que forman por un lado el lab y el do\#, y por otro la que forman el fa\# y el mib. Ya dijimos allí, que esto debía tener consecuencias, en cuanto al uso que podía hacerse de ellos cuando alguien quisiera transformar esas relaciones especiales en una obra musical. Lo estamos viendo aquí. Ya vimos a aquella pareja formada por el lab y el do\#, participar de manera especial en aquellos acontecimientos de los compases del 12 al 15, en relación con la pareja que forman el re y el sol, pero, aunque esos acontecimientos como vimos estaban allí totalmente conectados, en el Preludio aparecían separados, pues la relación entre el do\# y el re, era una de las que Bach situó por encima del cambio de registro y la que tenía el lab con el sol, actuaba en el interior del cambio de registro concluyendo el "movimiento cromático". Entonces, es ahora cuando comprendemos la utilidad práctica que tiene el hecho de que esa pareja que forman el re y el sol, ostenten ese privilegio, pues en la Estructura existía una pareja, la que forman el fa\# y el mib, que podía remitir directamente a esa quinta, demostrando de nuevo por ello ser especial, porque "remitir directamente", quiere decir que a partir de ella, esos dos elementos, el sol y el re, pueden ahora sí materializarse realmente juntos sobre un mismo acontecimiento, un acontecimiento especial, en términos tonales, el "pedal de dominante". Un acontecimiento, que desde Schenker podemos entender ya de otro modo, pues si en él de manera particular participa el sol, la llamada dominante que en términos tonales por sí mismo da el nombre al pedal, al acontecimiento, vemos que lo hace inseparablemente del re, incluso supeditado a él, pues, lo que nos desvela Schenker, es que ese re es el elemento que a partir de ahí va ejercer el control organizativo del Preludio como segundo elemento de la línea fundamental. La función del sol, es entonces convertirse en su representante, garantizando con esa presencia continua que va a tener en esta parte, ese control organizativo del re, aunque sobre ese sol, ocurran otros acontecimientos en el que participen otros elementos distintos del re, en términos schenkerianos prolongándolo. Y es que respecto a los tres acordes de $7^{\text {a }}$ disminuida que se pueden formar con estos 12 elementos, también uno de ellos es diferente, y por tanto especial, pues mientras en la Estructura, dos de ellos, como vimos, tienen que complementarse mutuamente, dado que cada uno está formado por los elementos que tienen su pareja reflexiva en el otro, sib-sol-mi-do\#, y lab-fa-re-si, en cambio el otro, en el que participa directamente esa pareja especial que forman el fa\# y el mib, solo necesita una pareja, y la tiene, es la que forman el do y el la, mib-do-la-fa\#, lo que significa que puede extraerse directamente de la Estructura, del mismo modo que puede extraerse la 
quinta que forman el re y el sol que es donde ahora se ha dirigido el Preludio. Por eso Bach lo guardaba para este momento (c. 22), un momento en el que ambos, el re y el sol, debían actuar juntos, como hemos dicho, uno para constituir el $2^{\circ}$ elemento estructural, y el otro, el pedal que ocupando prácticamente toda esta segunda parte, va a mantener en esencia la presencia del re, hasta su contacto definitivo con el do, aunque sobre el sol ocurran otras cosas. Podemos remitirnos de nuevo al hexacordo para comprobar incluso desde él cómo todo estaba ahí perfectamente ordenado para obtener de él estas relaciones

la sol fa mi re do

Vemos en efecto, cómo está también perfectamente preparado para incluir además de la pareja lab y do\#, lo que ya sabíamos, la que forman ahora la séptima disminuida entre el fa\# y el mib.

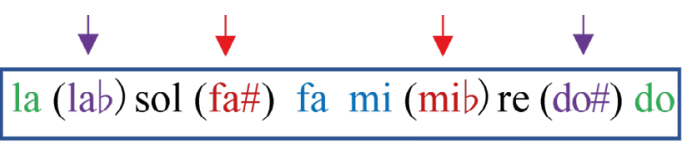

Vemos de nuevo la capacidad del hexacordo. Sus 4 segundas mayores, estaban ciertamente preparadas para albergar al resto de elementos, no solamente el lab y el do\# en el interior de las parejas que están en el exterior, la-sol y su reflejo re-do, como ya vimos antes, sino también las otras dos, que se encontraban en el interior sol-fa y su reflejo mi-re, para incluir en su caso la pareja fa\# y mib. La diferencia, es precisamente la situación de las segundas en las que se incluyen, y el resultado por ello de la inclusión, que como hemos dicho, es que esos dos elementos, no solo sean pareja reflexiva sino que la reflexividad ha hecho que tengan una relación muy especial, una $7^{\mathfrak{a}}$ disminuida. Significa que como hemos dicho, a diferencia de los otros elementos incluidos, el lab y el do\#, solo necesitan una pareja más para formar esa entidad especial que llamamos acorde de 7a disminuida, mientras aquellos necesitaban dos, en este caso, efectivamente la pareja formada por el la y el do, que enmarca el hexacordo. Lo que efectivamente permite extraerlos directamente de la Estructura, sintetizada ahora en ese hexacordo central.

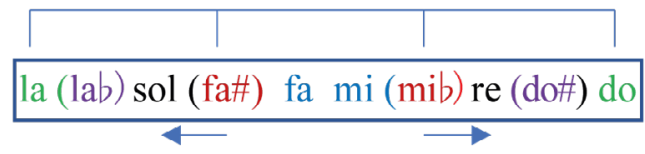

Ahí lo vemos. Hemos señalado con las flechas el orden reflexivo en la que directamente se llevan a cabo las relaciones de esa 7 a con la pareja que forman el sol y el re. Y decimos ahora directamente, porque ciertamente fue diferente lo que ocurrió en los compases 12-15, con sus otras sensibles que claramente vemos allí relacionadas con ellos también localmente, el lab y el do\#. Pues como ya señalamos ahí, por un lado el lab se relacionó con el sol, en el interior del cambio de registro (participando en el movimiento cromático), y el do\# con el re, por encima del cambio de registro. Pero es importante subrayarlo, porque desde esta representación, vemos claramente que el uso que hace Bach de esas relaciones, depende de la ubicación de 
esos elementos en la Estructura, en este caso en el interior del propio hexacordo en el que se incluyen. O dicho de otro modo, es todo tan sutil, que esa diferencia de ubicación es la que le ofrece a Bach utilizarlos de un modo u otro en su Preludio. Desde lo que sabíamos hasta ahora de ellos, parecía que los tres acordes de $7^{\underline{a}}$ disminuida que pueden formarse con estos 12 elementos, tuvieran el mismo grado de privilegio, pero como podemos ver ahora no era así, lo que suponía que, como vemos que hace Bach aquí, ofrecían la posibilidad de un uso completamente diferente cuando con ellos debía conformarse una obra musical.

Sin embargo, volviendo al Preludio, vemos que Bach hace algo más. Retarda la coincidencia del sol con el re al c.24, incluyendo entre el fa\# y el sol su otra sensible, que ya conocemos, el lab, que escuchamos ahí en el bajo (c.23), que junto con el fa, el si y el re (la nota estructural) conforman el acorde de $7^{\mathfrak{a}}$ disminuida lab-fa-re-si, del que Bach ya nos informó en aquellos c.14 y15, elementos que corresponden al recorrido ahí de cada una de las voces, que como siempre se interfieren ahí unas a otras. Si podemos decir, que de ese modo retarda la llegada del sol, también podemos ver que lo que hace es anticipar la llegada del re, y esto es importante como vamos a ver, porque lo que esto le ofrece a Bach, es la posibilidad de ofrecernos más información. En primer lugar, lo que sabemos de ese acorde, es que cada uno de sus elementos, que pertenecen a distintas voces, se relacionan en la Estructura, directamente con los que conforman el acorde de Do, con lo que está anticipándonos aquí lo que va a ocurrir, o lo que tiene que ocurrir, y es que al igual que en aquellos compases ahora el objetivo de ese re, es el do (una relación que en aquellos compases 14 y 15 se llevaba a cabo en una voz interior, directamente, aunque de manera no-local por efecto de la melodía compuesta. No podemos tratar aquí lo que ocurre con todas las voces, pero puede entenderse ya que tiene que ver con todo lo que estamos viendo). Lo diferente, es que aquí ese contacto, que va a ser el contacto final entre ambos, el re y el do, va a ser pospuesto hasta el final del Preludio, lo que va a ocupar toda esta parte del Preludio, que queda integrada así en el interior de esa relación. En términos schenkerianos, todo lo que ocurra en ese transcurso que va a llevar el re al do, se describiría como la prolongación del re. Pero además de anticipar todo esto, hay algo más allí que efectivamente nos permite entender porqué Bach hace esto. Y de nuevo, habría que recordar a Holmes, diciendo que "la información está fundamentalmente en los detalles" y añadiendo "que es aquello que se destaca del resto". En efecto, al anticipar el re, sobre ese lab, ocurre algo diferente, algo que aprovecha Bach, y es que la llegada ahí al re coincide con un hecho de nuevo absolutamente singular, que ciertamente no había sucedido en el Preludio, y que efectivamente se destaca del resto, pues por primera vez escuchamos ahí en el c. 23, tres elementos, el si el do y el re, relacionados localmente por segundas, y además cuatro veces, mientras hasta ese momento todas las relaciones de segundas que caracterizan todas las voces habían sido siempre no-locales, producto natural de la forma externa que le da Bach al Preludio, la forma que describimos como "melodía compuesta". Vemos este acontecimiento destacado en el c.23, en el que efectivamente por primera vez dos voces, representadas por el si y el re, aparecen localmente unidas, naturalmente por el do. 


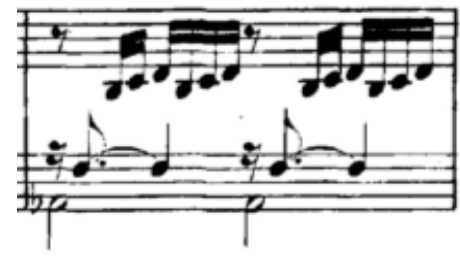

Así es, si las relaciones de segunda (grados conjuntos) es la manera en que musicalmente se relacionan los elementos en cada una de las voces (lo vimos ya en los cuatro primeros compases), y por otro lado seguimos asociando la continuidad al paso del tiempo, a la sucesión uno tras otro de los instantes, hay un conflicto allí. Pues todo ocurre ahí en el Preludio como no esperaríamos que sucediera: hay continuidad en la distancia, en lo no-local (representada por los grados conjuntos de las voces), en cambio, al contrario, hay distancia en la continuidad de los instantes, es decir, en el ámbito local los elementos se relacionan por salto, pues ese es el resultado de la forma específica que Bach elige aquí para representar sus voces, que es la de interferirse unas a otras, que es esa forma que describimos como "melodía compuesta" o "polifónica". Así, nunca dos elementos de dos voces distintas podrán aparecer conectados localmente por un elemento distinto a ambos, como sucede ahora. De ese modo, esa regularidad creada por Bach para la superficie de su Preludio, obligada por esa forma específica en que se relacionan las voces, ciertamente por primera vez se rompe totalmente ahora en ese compás 23 , un acontecimiento que ciertamente se destaca claramente del resto, una nueva irregularidad dentro de la regularidad con la que Bach ha conformado la superficie de su Preludio, entre otras cosas seguramente para esto.

Bach lo deja ahí muy claro, porque si por un lado, escuchamos esos tres elementos si, do y re localmente relacionados de forma continua, por otro nos aclara enseguida que ciertamente dos de ellos, el si y el re, son elementos que pertenecen a dos voces distintas, pues inmediatamente, por el propio efecto de repetir esa irregularidad tres veces más, escuchamos a ambos, como lo habíamos hecho con todos hasta ahora, sin ningún contacto local (continuo) entre ellos. Específicamente, como vemos en ese compás, lo escuchamos en la forma del diseño re-si-do-re (primero localmente separados y enseguida localmente unidos), un diseño que además diferenciadamente conforman las 4 semicorcheas de la $2^{a}$ y 4a parte del compás. Dado que en su gráfico, Schenker reduce todas las relaciones no-locales a relaciones locales, y así los saltos locales a la continuidad, que es por otro lado la que caracteriza el movimiento de las voces, este momento en el que realmente por primera vez en el Preludio aparece la continuidad en el ámbito de lo local en la forma de dos voces directamente conectadas, analíticamente pasa totalmente desapercibido, y sin embargo, se trata de un hecho excepcional, que por eso mismo puede llevar información crucial sobre la estructura interna del Preludio, incluso primero sobre la existencia de esa estructura, como diría Einstein, provocando el sentimiento de un orden que se oculta detrás de las apariencias.

Pero ¿porqué es tan importante ese momento? ¿de qué nos informa?. Las respuestas las obtenemos, solo llevando nuestra mirada atenta (o escucha atenta) sobre la superficie del Preludio, pues comprobaremos que existe otra situación en él en la que va a suceder lo mismo, pero solo una vez más, y en la distancia, y también en un lugar relevante, justamente 
antes del final (el último grupo de semicorcheas del penúltimo compás, c. 34), en el que escuchamos ahora algo exactamente igual, de nuevo tres elementos relacionados localmente por segundas, ahora fa-mi-re,

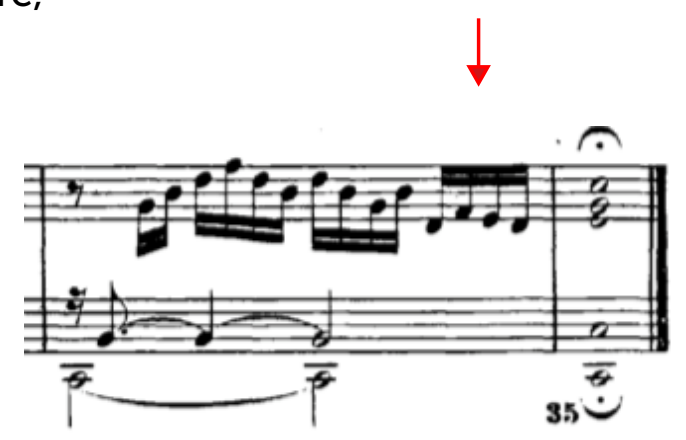

De nuevo se trata aquí de dos elementos de dos voces distintas, el re y el fa conectadas aquí directamente (localmente) por el mi. Como antes, escuchamos el re y el fa primero localmente por salto, y enseguida, unidas localmente en forma continua, y también reunidos en un grupo de semicorcheas, y como vemos justo antes del momento en que aquel re cuya relación con el do, quedó pospuesta en aquel c.23, va a conectar por fin con su do en la parte superior, de nuevo ahí de manera no-local.

Pero todavía más importante, es que a ambos acontecimientos, no solo los liga el hecho de ser distintos y de destacarse por ello del resto, ni tampoco el que además sean totalmente iguales en su forma, sino algo más que tiene ya que ver con los elementos y las relaciones particulares que participan en ambos acontecimientos. Porque los dos, ubicados en la distancia y en lugares ciertamente relevantes en el Preludio, ahora juntos, conectados por su misma singularidad, remiten a un orden diferente, informando así de la existencia de ese orden, que no es ya ni local, ni no-local, sino global. Lo vemos en un esquema:

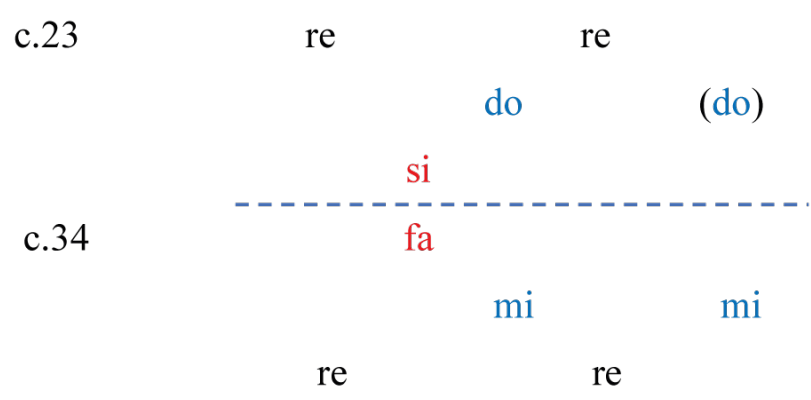

Y ese orden tiene que ver con la Estructura interna de los 12 elementos que Bach eligió para su Preludio, y más concretamente con una de sus subestructuras de las que ya nos informó desde el principio, la de Do mayor. Vemos, que ambos diseños, remiten complementariamente a las parejas que informan de nuevo así del orden interno particular de esa subestructura, en la que la reflexividad ha reunido de nuevo el si y el fa, y el do y el mi, y el re consigo mismo (ahora la línea horizontal hace de espejo), y decimos "de nuevo", porque esa información sobre la relación global en esa subestructura, que llamamos Do mayor, efectivamente la 
recibimos ya en los primeros 4 compases, a partir de aquellas 5 bordaduras, a partir de otra forma externa que la simetría permitía a esa subestructura. Aunque de una manera distinta, evidentemente es la misma información. Es la ratificación de que el origen de esa subestructura, que Bach ha tomado como referencia para la construcción de su Preludio, estaba en una Estructura, de la que, como el resto de los acontecimientos formaba parte, y que paso a paso desde aquella primera información sobre ella, ha ido construyendo Bach a la vez que construía su Preludio, o viceversa, construyendo esa Estructura a la vez que lo hacía con su Preludio, y dándonos así información sobre ellas, sobre la Estructura y la subestructura que por su situación especial en ella ha tomado como referencia (no olvidemos que uno de sus hexacordos es el centro de la Estructura). Ahora, y así, lo ratifica.

Pero es que además todo es muy sutil, y tenemos que señalarlo todavía, porque hay una pequeña aunque importante diferencia entre los dos diseños, y es que mientras el último elemento del primero, el re, re-si-do-re (c.23), se va a mantener, no solo materialmente en el siguiente compás ya sobre el pedal (c.24), sino estructuralmente hasta el final, en cambio en el segundo diseño, ese mismo re situado también en su final, se mueve directa y localmente al mi del último compás, re-fa-mi-re-mi. Y decimos que todo es muy sutil, porque esa última relación local entre los elementos fa, mi y re, con su llegada al mi, retroactivamente confirma de manera clara, que aquella del c.23, entre el si, el do y el re, debía tener su final en el do (de ahí que lo pusiéramos entre paréntesis en nuestro esquema). Lo único que iba a ocurrir, es que ese final debía retardarse (prolongarse) a través de detener el movimiento último del re, justo hasta que esa relación reflejo entre el fa, el mi y el re, se materializase llegando ahí sí directa y localmente a su final, el mi, que es lo mismo que en aquel compás 23 debía haber ocurrido con aquella relación entre el re el do y el si, que llegara también al do, algo que efectivamente quedó pospuesto ahí, hasta que al final, y ahora lo entendemos mejor, la relación pudiera completarse, complementándose así con la otra.

No podemos extendernos más. Para ir concluyendo, creemos que todo lo narrado hasta aquí, nos permite decir que hemos visto cómo para nosotros los elementos cobran vida en el Preludio, o mejor, cómo el Sistema, desde su Estructura interna, cobra vida en el Preludio, en una obra musical. Y no solo eso, sino que además de ratificar con ello la existencia de esa Estructura interna del Sistema, lo hace, como ya señalamos, ofreciéndonos mucha mas información sobre ella, y sobre el mundo interno del Sistema, de la que habíamos obtenido en aquel viaje a su interior que realizamos en la primera parte, partiendo allí directamente desde su superficie. En el caso de los elementos, también ciertamente lo hemos visto cobrar vida, por ejemplo, hemos comprobado que aun siendo siempre los mismos, los hemos visto cumplir diferentes funciones pero todas absolutamente vinculadas, porque entendemos que todas derivan de los lugares que ocupan en la Estructura, o en alguna de sus subestructuras o fragmentos particulares de ella, de las diferentes formas que en ellos pueden adoptar, y de las diferentes relaciones que pueden llevar a cabo en esos lugares, lugares y relaciones entonces que obtienen de la reflexividad y la simetría. Por ejemplo, hemos visto a dos elementos el la y do, ligados específicamente por la reflexividad en la Estructura, dos elementos que por un lado van a actuar conformando ese acorde de 7aㅡ disminuida especial, junto a otra pareja asimismo especial la que forman el fa\# y el mib, una pareja relacionada directamente con otra pareja asimismo especial la que forman el re y el sol, justo los dos elementos con los que 
por otro lado, aquellos mismos la y do, se unirán para conformar ahora las relaciones la-sol y re-do, que también de manera destacada Bach situará por encima del cambio de registro, relaciones que luego Schenker por eso mismo destacará en su gráfico. Por otra parte, esas relaciones en las que esas dos parejas participan, la-sol y re-do se ofrecerán también por ejemplo para permitir incluir en ellas, otra pareja, ahora la formada entre el lab y del do\#, y producir, junto a esas dos segundas la-sol y re-do, todos aquellos acontecimientos relacionados con aquellos 4 acordes especiales que eran los otros dos acordes de $7^{\text {a }}$ disminuida, y sus correspondientes de tónica. Aún por otro lado, esas dos segundas participan también en el propio cambio de registro (la segunda re-do, como hemos visto al final, ofreciendo además sus elementos para completar con el mi la línea fundamental). Y todo por el lugar privilegiado que esos dos elementos, el la y el do, ocupan por ejemplo en el hexacordo central, limitándolo por ambos lados: la-sol-fa-mi-re-do. Incluso, a partir de ese hexacordo, veremos otra vez a esa pareja la y do, relacionándose ahora con la que forman el fa y el mi, que figuran en el centro del hexacordo, precisamente para poder constituir con ella las terceras la-fa y mi-do, que de nuevo junto al sol y al re, conformarán ahora los acordes de Re menor, la-fare, y de Do mayor, sol-mi-do. Incluso, respecto a esa pareja fa y mi, pudimos entender que su privilegio en la Estructura, era la razón por la que Bach la utilizaba asimismo de manera privilegiada como la primera relación destacada del Preludio, constituyendo la voz superior de los primeros compases, y conformando así la primera prolongación del mi, la bordadura, antes de que esa misma relación entre el fa y el mi, en su capacidad de reflejarse en la distancia, propiciase seguidamente también la segunda prolongación, el cambio de registro. Respecto de otros elementos, y a partir de su vinculación absoluta con todos estos, pudimos entender por ejemplo la razón de la participación especial del sib en el c.12, justo después del si, dos elementos que figuraran por ejemplo a ambos lados de ese hexacordo, reflejándose así: sib-la-sol-fa-mi-re-do-si. Sabemos ahora que todas esas relaciones, la que forman el la y el do, o el re y el sol, o el fa y el mi, o el si y el sib, que participan en todos esos diferentes acontecimientos, completamente vinculadas las unas a las otras, son todas especiales. Lo son en el Preludio, y entendemos que la razón es porque también lo son en el interior de la Estructura que ellas mismas contribuyen a formar.

Naturalmente, todo ello hace que cambie absolutamente nuestra percepción del Preludio, pero también nuestra concepción del análisis, porque cambia totalmente el modo de concebir la manera en la que realmente se vinculan en una obra musical los elementos y las relaciones específicas que entre ellos van a llevar a cabo para conformar la obra, lo que naturalmente deberá cambiar la propia concepción de la teoría en la que ese análisis deberá sustentarse. A esto debía referirse Bragg cuando decía que "La "filosofía natural" no consiste en el descubrimiento de hechos, sino en descubrir nuevas formas de pensar acerca de ellos". Lo que vemos que implica a la vez y necesariamente, el descubrimiento de nuevos hechos que ya serán pensados también de esa nueva forma. Y añadía "La prueba a la que sometemos estas ideas es esta:¿nos permiten ensamblar unos hechos con otros?. A este respecto y en nuestro caso, desde ese cambio de concepción, desde esa nuevas ideas que suponen un cambio radical en la forma de pensar, ya podemos responder que los elementos y las relaciones que conforman los acontecimientos en las que participan de manera particular en la constitución del Preludio, realmente ya no aparecen desconectados, o lo que es lo mismo, 
únicamente conectados o ensamblados, por la pura temporalidad del Preludio, y ni siquiera por los distintos niveles jerárquicos en los que puede diferenciarse la participación de los elementos y los propios acontecimientos desde ese nivel de observación en el que Schenker consiguió ya situarnos, sino por algo muy diferente, algo que ciertamente los ensambla a todos, como pedía Bragg, solo accesible desde un lugar más profundo, y es su pertenencia a un mismo orden, un orden común que los integra allí globalmente a todos, elementos y acontecimientos, y del que todos participan en su creación, un orden global que trasciende el tiempo y el espacio, las dimensiones local, y no-local, en las que esos elementos y sus relaciones se representan, y que es el orden del que precisamente depende su ubicación precisa en ese tiempo y en ese espacio. En efecto, su ubicación en la temporalidad o en el espacio, depende de que, desde ella, cada relación informe de su origen común, lo que exige que cada lugar que ocupa cada una, esté en función del lugar que ocupan las demás, lo mismo en el Sistema que en una obra musical. De ese modo, la información de ese orden común al que pertenecen todas las relaciones, está distribuida por todas ellas. Solo desde esa diferente perspectiva epistémica que nos sitúa a su vez en otro plano epistemológico, donde la dependencia mutua es la exigencia para los elementos y las relaciones, ya sean locales o no-locales, estamos justificados a decir que todas los elementos y las relaciones particulares que llevan a cabo en el Preludio actúan como un todo, que es de ese modo cómo el Preludio adquiere la cualificación que puede diferenciarlo de cualquier otra distribución de elementos por el tiempo y el espacio que no cumplan con esa condición, y es la de haberse constituido como totalidad. Un concepto que se convierte en fundamental para la cualificación de una obra, y que quedaba totalmente fuera del alcance de cualquiera de las teorías conocidas.

Por supuesto, se entiende que el Preludio no agota las posibilidades constructivas de esta Estructura, aquí tan solo hemos visto una de ellas. Las elecciones de Bach tomadas de esa Estructura podían haber sido otras, y hubiera sido otra la obra. Y eso lo hace posible la simetría del Sistema, su capacidad de representarse en diferentes formas externas. Aquí en el Preludio, hemos visto algunas de las que conocimos en nuestro viaje al interior del Sistema, pero también, como hemos señalado, otras nuevas que no pudimos ver en aquel viaje, existiendo aún un número importante de ellas que pueden dar origen a otras obras musicales, y dotarlas así de su propio orden interno. Lo que prueba ya el Preludio, desde el acceso a su interior, es por un lado, que el interior del propio Sistema es efectivamente, como ya habíamos advertido, mucho más extenso que lo que vimos en aquel viaje que ya calificamos como relativamente breve, pero también, y es algo asimismo importante, que el modo de acceder a ese interior era como dijimos únicamente posible a través del acceso al interior de las obras musicales. Por supuesto, una vez conocida la existencia de esa Estructura interna del Sistema y de sus extraordinarias propiedades, se nos facilita el acceso a la de las propias obras musicales.

Y se entenderá mejor que el Preludio no agote las posibilidades constructivas del Sistema, si ahora tenemos en cuenta precisamente una de esas extraordinarias propiedades que de él hemos conocido, y es la de que algunos de sus fragmentos, formados por un número distinto de elementos de los 12 que pueden directamente representarlo, pueden heredar su reflexividad y su simetría, porque eso significa, que el número de elementos que junto a sus 
relaciones, pueden conformar una obra musical, no necesariamente tienen que ser 12, ni que sean expresamente los que eligió Bach para su Preludio, sino que pueden ser otros y en un número mayor o menor, porque esa propiedad extraordinaria que tiene el Sistema, permitirá que los elementos elegidos, puedan conformar en su caso, una Estructura particular de la que una obra podrá obtener su propio orden interno.

Creo que con lo visto hasta aquí, respecto al Preludio, ciertamente podemos atrevernos a decir también junto con Einstein que "Es un sentimiento maravilloso descubrir las características unificadoras de fenómenos que parecen totalmente desconectados en la experiencia directa de los sentidos", y entender qué significa esas afirmación, es decir, su extraordinario alcance epistémico y epistemológico. Y eso, en nuestro caso, no solo referido a una obra musical, el Preludio, sino al propio Sistema en el que todas las líneas teóricas de investigación conocidas han basado su estudio, obteniendo algunas la categorización como teorías.

Porque el problema es ciertamente de orden epistemológico, pues ocurre, que desde el nivel de observación propio de una teoría, es imposible ser consciente de la existencia de desconexión alguna entre los hechos registrados por esa teoría, pues la toma de conciencia de su desconexión, será siempre el indicio de la posibilidad, o mejor de la necesidad de otra teoría diferente, de otro nivel de teoría que tenga que ver con el acceso a otro nivel de observación donde podrán registrarse otros hechos que puedan conectar aquellos que alguien pudiera haber percibido como inconexos desde el nivel de observación inmediatamente más bajo. Este sería el caso de Schenker. Evidentemente, como ya hemos señalado, él se dio cuenta por ejemplo, de que, en el nivel de observación propio del resto de las teorías, fijado total e irremediablemente a la superficie de las obras musicales, la única conexión entre los acontecimientos registrados era la temporalidad, lo que los condenaba a un único tipo de relación, la relación local. Sin embargo, ya hemos visto que aunque pudo acceder a otro tipo de relación, la no-local, en ese nivel de observación todavía había desconexión. Hemos visto, que el vínculo que los conectaba era mucho más profundo, que esas prolongaciones que en ese nivel podían describirse independientemente unas de otras, realmente formaban parte de una Estructura global, a la que pertenecían no solo ellas, y no sólo algunos elementos que conformaban la obra como ocurría en la estructura schenkeriana, sino todos los que participaban en su conformación, así como todas las relaciones que les permitía esa Estructura global que todos compartían, su orden interno, un orden interno que de ese modo se transfería de la Estructura al Preludio, transfiriéndose con él las cualidades que la definían y diferenciaban, que eran las del propio Sistema poseedor de esa Estructura: su globalidad y su constitución como totalidad. Dos conceptos fundamentales referidos a la comprensión de la música, que como ya hemos señalado, quedaban fuera del alcance de cualquiera de las teorías conocidas, incluida la propia teoría de Schenker, aunque debemos subrayarlo de nuevo, era la única que podía ponernos ante su alcance, y por tanto ante el logro de un nueva teoría epistémica y epistemológicamente diferente.

Respecto de esa diferencia, y para terminar, solo señalar que una de las evidencias de haberse producido quizás un salto a otro plano epistémico y epistemológico, es el cambio de significado que experimentan los conceptos propios del nivel desde el que se lleva a cabo ese salto, como por ejemplo aquí el propio de "Estructura"

Como hemos visto, el significado que ha adquirido aquí el concepto de "Estructura", 
indisociablemente ligado a los de "globalidad" y "totalidad", es muy distinto del que ese concepto tiene en la teoría de Schenker, siendo fundamental en ella, y siendo este ya distinto de cualquiera que pudiera haber tenido en otro teoría. Solo hay que pensar, que si en la estructura entendida en términos schenkerianos, solo algunos de los elementos están directamente vinculados, en nuestro caso, lo están todos, incluso sus relaciones, y de manera fundamental y necesaria. Pero ocurre algo todavía más especial ahí, y es que como hemos visto, en esta Estructura ligada totalmente a la globalidad, además de estar fijados en ella de manera ciertamente global y así absoluta e inamovible sus elementos y sus relaciones, haciéndolos depender totalmente unos de otros, se les permite representarse de distintas formas, es decir, a esta Estructura la define algo que la diferencia inmediatamente de cualquier otra concebida hasta ahora, es el hecho de ser a la vez invariable y variable, inmóvil y móvil, o lo que es lo mismo, tener una única forma interna, la derivada de su orden interno producto de la reflexividad, pero al mismo tiempo múltiples formas externas, derivadas de su simetría, lo que dota a su orden interno de esa complejidad que la permite representarse de diferentes formas, tanto en una obra musical particular, dando lugar a los distintos y específicos acontecimientos que la constituyen (como hemos visto en el Preludio), como también en la forma de múltiples obras musicales. Por supuesto, otro de los cambios absolutos de significado que tiene que ver con esta diferente concepción de la música, de la teoría y del propio análisis, que hemos expuesto aquí, y como hemos demostrado, atañe al concepto que es con seguridad el más fundamental para la teoría de la música, el de "Sistema", también ligado indisociablemente ahora a conceptos totalmente nuevos como el de "globalidad" y el de "totalidad", y al propio concepto nuevo de "estructura", conceptos cuya novedad también ciertamente puede atestiguar que se ha producido el salto a un plano epistémico y epistemológico asimismo nuevo.

Pedro Purroy Chicot 